University of Louisville

ThinkIR: The University of Louisville's Institutional Repository

Electronic Theses and Dissertations

$5-2018$

\title{
The effects of habitat and connectivity on tropical ant ecology and behavior.
}

Benjamin Jacob Adams

University of Louisville

Follow this and additional works at: https://ir.library.louisville.edu/etd

Part of the Behavior and Ethology Commons, Entomology Commons, and the Zoology Commons

\section{Recommended Citation}

Adams, Benjamin Jacob, "The effects of habitat and connectivity on tropical ant ecology and behavior." (2018). Electronic Theses and Dissertations. Paper 2977.

https://doi.org/10.18297/etd/2977

This Doctoral Dissertation is brought to you for free and open access by ThinkIR: The University of Louisville's Institutional Repository. It has been accepted for inclusion in Electronic Theses and Dissertations by an authorized administrator of ThinkIR: The University of Louisville's Institutional Repository. This title appears here courtesy of the author, who has retained all other copyrights. For more information, please contact thinkir@louisville.edu. 
THE EFFECTS OF HABITAT AND CONNECTIVITY ON TROPICAL ANT ECOLOGY AND BEHAVIOR

\author{
By \\ Benjamin Jacob Adams \\ B.S., Louisiana State University 2010 \\ M.S., Louisiana State University 2012
}

\begin{abstract}
A Dissertation
Submitted to the Faculty of the

for the Degree of

Doctor of Philosophy

in Biology

Department of Biology

University of Louisville

Louisville, Kentucky
\end{abstract}

College of Arts and Sciences of the University of Louisville in Partial Fulfillment of the Requirements

May 2018 

THE EFFECTS OF HABITAT AND CONNECTIVITY ON TROPICAL ANT ECOLOGY AND BEHAVIOR

\author{
By \\ Benjamin Jacob Adams \\ B.S., Louisiana State University 2010 \\ M.S., Louisiana State University 2012 \\ A Dissertation Approved on
}

March 21, 2018

By the following Dissertation Committee:

Dissertation Director
Stephen P. Yanoviak

Stephen P. Yanoviak

Lee A. Dugatkin

Perri K. Eason

Sarah M. Emery

Stefan A. Schnitzer 


\section{DEDICATION}

This dissertation is dedicated to my parents Mr. Cedric Daniel Adams and Mrs. Bryanne McQueen Adams who have supported my love of nature and the outdoors from the beginning and who have encouraged me wholeheartedly to pursue my passions through education and exploration. They dealt with a fridge full of dead insects and a room full of collections, aquaria, and entirely too many living creatures. Thank you for everything!

This dissertation is also dedicated to three teachers who were beyond inspiring in their role as educators and laid the foundations for my love of academics. I can only hope to teach half as well.

Bill Lee, Ed.D. - who introduced me to the scientific method and made every second of it entirely captivating

Laurie Godshall, Ed.D - who made me fall in love with reading and writing and trained me to read frequently, broadly, and mindfully

Eddie Rising, LtCol USAF Ret. - who made even the most complex mathematic and scientific concepts both approachable and completely enjoyable 


\section{ACKNOWLEDGEMENT}

Marilyn Feil, Dana Frederick, Evan Gora, Noah Gripshover, Alyssa Stark, Rachel Wells, and Amanda Winters assisted in the field. John Longino, William Mackay, and Phillip Ward kindly confirmed and corrected ant species identifications. Greg Asner, Robin Martin, and S. Joseph Wright provided coordinates for Dipterx oleifera trees on Barro Colorado Island. Comments from Chloé Debyser, Evan Gora, Michael Kaspari, Riley Kneale, Daniella Prince, Ethan Staats, Alyssa Stark, and Rachel Wells improved final versions of each chapter profoundly. I thank Oris Acevedo, Melissa Cano, Belkys Jimenez, and the staff of the Smithsonian Tropical Research Institute for logistical support in Panama. Ropes were provided by the Little Rock Climbing Center, Arkansas and Rocksport Climbing, Kentucky. I thank Danielle Adams, Ethan Adams, Ellie Adams, and Greyson Adams for looking after Marley while I was in Panama. A special thanks to Chloé Debyser for the love and support throughout this degree. I also thank my major adviser, Stephen Yanoviak, and my advisory committee, Lee Dugatkin, Perri Eason, Sarah Emery, and Stefan Schnitzer for technical support, guidance, and plenty of patience over the last five years. This work was supported by the Carl C. Cornett Entomology Endowment; and NSF grants DEB-1252614 to Stephen Yanoviak; and DEBo845071 and DEB-1019436 to Stefan Schnitzer. 
ABSTRACT

\title{
THE EFFECTS OF HABITAT AND CONNECTIVITY ON TROPICAL ANT ECOLOGY AND BEHAVIOR
}

\author{
Benjamin J. Adams
}

March 21, 2018

This dissertation explores the role that physical connections among and within habitats play in determining the local diversity and behaviors of cursorial organisms. Understanding the processes that regulate local community assembly and that contribute to the maintenance of species diversity is a cornerstone of community ecology. Ants are a useful model for studies of local communities because they are abundant and fulfill a variety of ecological roles. Chapter one of the dissertation examines the how lianas (woody vines) function as connective structures among tree crowns and how these connections affect arboreal ant community structure within a tropical forest canopy. Trees without lianas act as islands and the number of ant species living in these isolated trees can be predicted by tree size alone. Chapter two describes an experimental approach to examining the relationship between arboreal ants and lianas. Cutting lianas out of trees and connecting trees with ropes revealed that connectivity is a key resource that lianas provide to arboreal ants. The removal of lianas decreased species richness and caused the development of a strong, positive species-area relationship between ant species richness and tree size. Connecting neighboring trees together with ropes completely mitigated the effects of liana removal. Chapter three 
explored how ants use physical pathways to move across the forest floor. Ants will readily use exposed roots or ropes as highways to move through the complex matrix of leaf litter on the forest floor. As a result, ants appeared in higher frequency on these structures compared to the nearby leaf litter. Increasing the number of paths in an area also increased the rate of discovery and recruitment to food resources by focal species. In combination, these observations and experimental manipulations highlight how connecting isolated habitats or providing bridges through complex environments can enhance local species diversity and promote a variety of interactions among organisms at small spatial scales. 
TABLE OF CONTENTS

Page

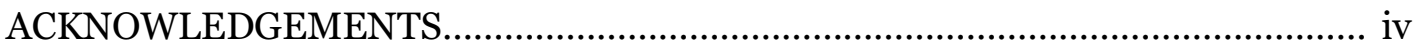

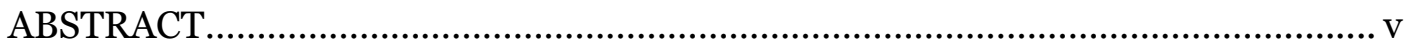

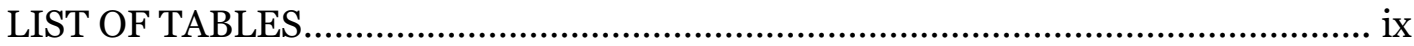

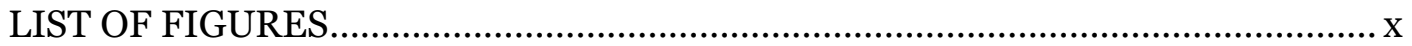

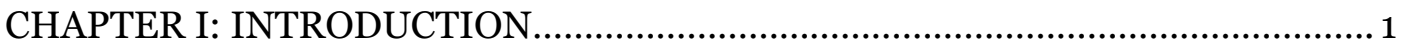

CHAPTER II: TREES AS ISLANDS: CANOPY ANT SPECIES RICHNESS INCREASES WITH THE SIZE OF LIANA-FREE TREES IN A NEOTROPICAL FOREST............

SUMMARY

CHAPTER III: LIANAS SHAPE ARBOREAL ANT COMMUNITIES BY PHYSICALLY CONNECTING ISOLATED TREE CROWNS........................................................... 29

SUMMARY

CHAPTER IV: SUBSTRATE USE BY LEAF LITTER ANTS IN A NEOTROPICAL

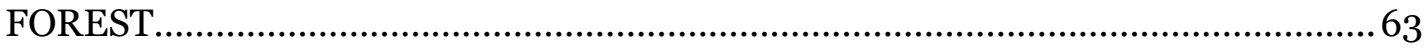

SUMMARY 


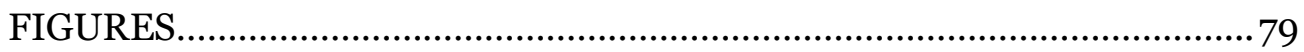

CHAPTER V: SUMMARY AND FUTURE DIRECTIONS.................................... 93

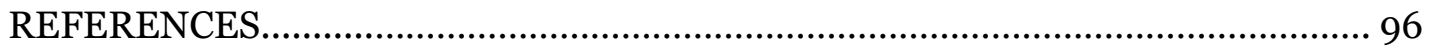

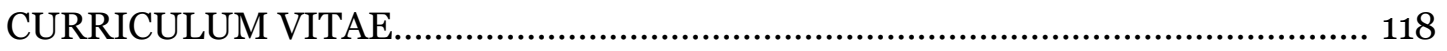




\section{LIST OF TABLES}

Table 1. Arboreal ants of Barro Colorado Island, Panama.......................................19

Table 2. Indicator ant species of trees with and without lianas..............................22

Table 3. Indicator ant species of Dipteryx oleifera and Apeiba membranacea...... 22

Table 4. List of segregated arboreal ant species pairs..........................................23

Table 5. List of aggregated arboreal ant species pairs...........................................24

Table 6. Ant species found on Dipteryx oleifera and within artificial nests ............43

Table 7. Comparisons of species composition in liana removal experiments.......... 46

Table 8. Global test results evaluating path use by epigeic ants............................76

Table 9. Comparisons of individual treatments of path use by epigeic ants............ 77 


\section{LIST OF FIGURES}

FIGURE

PAGE

Figure 1. A species accumulation curve of arboreal ants......................................26

Figure 2. Average ant species richness vs. liana stem density............................... 26

Figure 3. Ant species richness vs. air temperature ..............................................27

Figure 4. Ant species richness vs. tree size in trees with and without lianas........... 28

Figure 5. Map of Panama and Barro Colorado Island..........................................50

Figure 6. A Dipteryx oleifera tree with climbing rope and artificial nests...............51

Figure 7. Liana stems in the central fork of a Dipteryx oleifera ..............................52

Figure 8. Author secured in tree using single rope climbing techniques.................53

Figure 9. Two-by-two factorial design for connectivity experiment........................54

Figure 10. Ants cross a rope addition treatment................................................ 54

Figure 11. Two-by-two factorial design for artificial nest experiment..................... 55

Figure 12. A schematic of the artificial nest design............................................. 55

Figure 13. A photograph of artificial nests in a tree......................................... 56

Figure 14. A photograph of artificial nests showing connective wire......................56

Figure 15. Change in species richness in connectivity experiment.........................57

Figure 16. Ant species richness vs. tree size before and after liana removal.............58

Figure 17. Percent of nests occupied in trees with and without lianas....................59

Figure 18. Colony of ants living in hole at top of nest.......................................... 60

Figure 19. Entrance hole in nest sealed with carton.............................................60

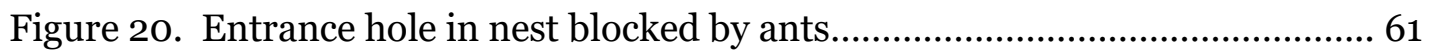

Figure 21. Entrance hole in nest occupied by stingless bees .................................61 
Figure 22. Change in species richness in nest experiment.................................62

Figure 23. Examples of a typical exposed root and leaf litter sites......................... 81

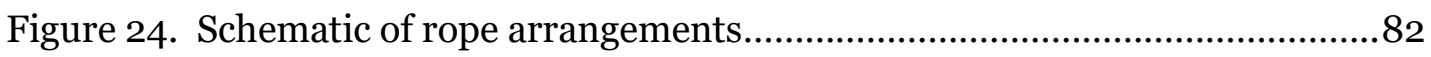

Figure 25. Difference in response variables between roots and leaf litter...............83

Figure 26. Difference in response variables to pathway density treatments............85

Figure 27. Difference in response variables to pathway connection treatments......87

Figure 28. Difference in response variables on litter control plots........................89

Figure 29. Difference in response variables on litter removal plots....................... 91 


\section{CHAPTER I}

\section{INTRODUCTION}

A central focus of community ecology is to determine the mechanisms shaping local species richness and species composition (Keddy 1992, Huston 1999, Agrawal et al. 2007). There are three major hierarchical filters governing occupancy and diversity of a habitat: species dispersal limitation, environmental/habitat filters, and species interactions (Preston 1962, MacArthur and Wilson 1967, Hanski and Gilpin 1991). Changes in the physical connections among habitats directly affect each of these filters by facilitating movement (Levins et al. 1973, Fahrig 2003); changing habitat size and resource availability (Tilman 1982, Gonzales et al. 1998, Tews et al. 2004); and disrupting or promoting encounters among species (Huffaker 1958). Tropical forests are some of the most diverse terrestrial habitats and provide a unique system for studying species richness and composition (Erwin 1982, Godfray et al. 1999, Basset et al. 2012). The role of connectivity in the structure and assembly of local communities in tropical rain forests remains largely unexplored.

Connections among habitats should be particularly important for organisms living in tropical forests. For example, trees in tropical forest are frequently isolated in space due to the phenomenon of crown shyness (i.e. the tendency for a gap to exist between neighboring tree crowns; Ng 1977, Putz et al. 1984). As a result, trees can function as ecological islands for small, non-volant arthropods (Wardle et al. 2003, Yanoviak 2015). Lianas (woody vines) commonly grow through the crowns of multiple trees creating physical bridges among normally isolated trees (Yanoviak and Schnitzer 2013, Adams et al. 2017). On the tropical forest floor, leaf litter creates a structurally 
complicated and spatially patchy environment for small cursorial organisms (Carroll and Janzen 1973, Kaspari 1996, Kaspari and Weiser 1999, Farji-Brener et al. 2004). Fallen branches and exposed roots facilitate movement through the leaf litter by providing smooth, clear pathways (Farji-Brener et al. 2007). Communities of small arthropods should be shaped by the presence or absence of connective paths in the forest canopy and forest floor.

Ants are an ideal focal taxon for studies of local community dynamics, as they are ecologically important (Hölldobler and Wilson 1990, Davidson 1997), taxonomically well resolved (Moreau et al. 2006, Longino 2010), easy to observe and collect (Ellison et al. 2011), and common in the forest canopy and on the forest floor (Yanoviak and Kaspari 2000, Ozanne et al. 2003). Moreover, species interactions and habitat filters regulate ant community structure (Majer 1972, Hölldobler and Lumsden 1980). Specifically, habitat characteristics such as connectivity can predict ant community structure and competitive interactions (Tschinkel and Hess 1999, Sanders et al. 2007, Ribas et al. 2003, Powell et al. 2011, Klimes et al. 2012, Cuissi et al. 2015). Ants are also centralplace foragers that rely heavily on short (Beckers et al. 1992), straight (Garnier et al. 2009, Clay et al. 2010) and unimpeded connective paths (Couzin and Franks 2003, Dussutour et al. 2004, Dussutour et al. 2006) while foraging. Local ant assemblages should depend largely on connectivity among habitats and resource patches.

This dissertation explores how physical connections shape the communities and behaviors of ants as a means of better understanding community assembly and the maintenance of species diversity. All field work was conducted from 2009 to 2017 in a lowland, seasonally moist tropical forest within the Barro Colorado Nature Monument in the Panama Canal Zone $\left(09.15^{\circ} \mathrm{N}, 79.85^{\circ} \mathrm{W}\right.$; Leigh et al. 1996). 


\section{CHAPTER II}

TREES AS ISLANDS: CANOPY ANT SPECIES RICHNESS INCREASES WITH THE SIZE OF LIANA-FREE TREES IN A NEOTROPICAL FOREST

\section{SUMMARY}

The physical characteristics of habitats shape local community structure; a classic example is the positive relationship between the size of insular habitats and species richness. Despite the high density and proximity of tree crowns in forests, trees are insular habitats for some taxa. Specifically, crown isolation (i.e., crown shyness) prevents the movement of small cursorial animals among trees. Here, I tested the hypothesis that the species richness of ants $\left(\mathrm{S}_{\mathrm{a}}\right)$ in individual, isolated trees embedded within tropical forest canopies increases with tree size. I predicted that this pattern disappears when trees are connected by lianas (woody vines) or when strong interactions among ant species determine tree occupancy. I surveyed the resident ants of 213 tree crowns in lowland tropical forest of Panama. On average, 9.2 (range $=2-20)$ ant species occupied a single tree crown. Average $\left( \pm\right.$ SE) $S_{a}$ was higher in trees with lianas (10.2 \pm o.26) than trees lacking lianas $(8.0 \pm 0.51) . \mathrm{S}_{\mathrm{a}}$ increased with tree size in liana-free trees $\left(S_{a}=10.99 A^{0.256}\right)$, but not in trees with lianas. Ant species composition also differed between trees with and without lianas. Specifically, ant species with solitary foragers occurred more frequently in trees with lianas. The mosaic-like pattern of species cooccurrence observed in other arboreal ant communities was not found in this forest. Collectively, the results of this study indicate that lianas play an important role in 
shaping the local community structure of arboreal ants by overcoming the insular nature of tree crowns.

\section{INTRODUCTION}

A key goal of ecology is to determine the factors that influence local community structure (Agrawal et al. 2007). Both regional and local processes shape local species richness and composition via dispersal filters, habitat limitation, and species interactions (Huston 1999), and effectively predict community structure across a variety of ecosystems (Cornell and Lawton 1992, Caley and Schluter 1997, Myers and Harms 2009). Likewise, habitat area is a fundamental determinant of species richness for insular communities (Preston 1962). In particular, species-area relationships and habitat isolation (MacArthur and Wilson 1963, 1967) are widespread and relatively scaleindependent predictors of species richness on islands (Simberloff and Wilson 1969, Ricklefs and Schluter 1993, Losos and Ricklefs 2009). Species richness also increases with habitat heterogeneity and resource availability, especially in combination with increasing total habitat area (Kohn and Walsh 1994, Tews et al. 2004, Kadmon and Allouche 2007, Hortal et al. 2009). However, identifying the most important determinants of local community structure in highly diverse systems such as tropical forests is challenging (Erwin 1982, Godfray et al. 1999, Basset et al. 2012).

The tropical forest canopy-the uppermost forest layer composed of the crowns of mature trees (Nadkarni et al. 2004) - provides a unique opportunity to examine the determinants of local species richness and community composition. Individual trees frequently are physically isolated within a forest canopy because of "crown shyness", or the tendency for a gap to exist between neighboring crowns (Ng 1977). Although narrow, such gaps can limit animal movement within the canopy (Emmons and Gentry 1983, Yanoviak 2015). Consequently, individual tree crowns function as habitat islands for 
some taxa (Southwood and Kennedy 1983, Harris 1984, Sverdrup-Thygeson and Midtgaard 1998), especially small, cursorial animals (Moeed and Meads 1983, Wardle et al. 2003, Yanoviak 2015). For example, species richness and total biomass of non-volant arthropods that are restricted by crown shyness (including Collembola, Araneae, and wingless Hymenoptera) increase with tree size (Hijii 1986, Ribas et al. 2003, Campos et al. 2006, Klimes et al. 2012), whereas this is not true for many winged taxa (Southwood et al. 1982).

Tree species differ in the resources they contribute to arboreal arthropod communities (Blüthgen et al. 2004, Poelman et al. 2008). As a result, some insect communities are more similar between conspecific trees compared to heterospecifics (Klimes et al. 2012). Tree species identity also affects the local distribution of specialized herbivores (Erwin 1982, Davidson and Epstein 1989, Basset 1992, Basset et al. 1996), many of which are tended by ants (Davidson et al. 2003). Moreover, some arboreal ant species are involved in obligate mutualisms with trees, often occupying specialized domatia (Ward 1999, Rico-Gray and Oliveira 2007). Consequently, at the scale of a forest stand, arboreal arthropod species richness tends to increase with increasing tree diversity (Ribas et al. 2003, Basset et al. 2012).

Arboreal ants are an ideal focal taxon for exploring the determinants of local community structure in forest canopies (Yanoviak et al. 2012, Yanoviak and Schnitzer 2013). Although forest canopies host a wide diversity of organisms (Lawton 1983, Ozanne et al. 2003), arboreal ants account for up to $50 \%$ of the total animal biomass and 90\% of total insect abundance (Davidson 1997, Davidson et al. 2003, Blüthgen and Stork 2007). Moreover, ants are relatively easy to collect, and the common arboreal taxa can be identified to species level.

Species interactions and habitat filters shape arboreal ant communities (Majer 1972, Yanoviak 2015). Specifically, competitive exclusion can result in mosaic-like 
patterns of ant species distributions among tree crowns (Hölldobler and Lumsden 1980, Blüthgen et al. 2004, Dejean et al. 2007, Sanders et al. 2007). Habitat characteristics such as tree size, tree species identity, and crown connectivity are good predictors of arboreal ant community structure in some systems (Tschinkel and Hess 1999, Ribas et al. 2003, Powell et al. 2011, Klimes et al. 2012, Cuissi et al. 2015). Because arboreal ants rarely descend from the canopy (Camargo and Oliveira 2012; but see Hahn and Wheeler 2002), and nearby tree crowns frequently do not touch ( $\mathrm{Ng}$ 1977), trees likely function as islands for arboreal ant communities (Yanoviak 2015). However, explicit tests of the hypothesis that local arboreal ant communities (i.e., within an individual tree) follow the classical insular species-area relationship (Preston 1962) are lacking.

Apart from trees, lianas (woody vines) are a conspicuous component of lowland tropical forests, where they commonly infest more than $70 \%$ of the canopy trees (PerezSalicrup et al. 2001, van der Heijden et al. 2008, Ingwell et al. 2010, Schnitzer et al. 2012). Lianas provide important resources for arboreal ant communities, including nest sites (Yanoviak and Schnitzer 2013), extrafloral nectaries (Blüthgen et al. 2000), and preferred feeding locations for trophobionts (Tanaka et al. 2010). Lianas also frequently occupy multiple tree crowns (on average, each liana inhabits 1.6 tree crowns, with some connecting up to 49 trees; Putz 1984). Arboreal ants use lianas as physical bridges to travel and forage among neighboring tree crowns (Yanoviak 2015), effectively overcoming isolation induced by crown shyness. Moreover, the number of liana stems in a single tree crown varies from zero to thousands of stems (Schnitzer and Bongers 2002), potentially producing natural gradients in resource availability and connectivity for arboreal ant communities. As such, lianas likely play an important role in determining local arboreal ant community structure. This is especially relevant to ant species that would be most affected by crown isolation-in particular, wide-ranging solitary foragers (Neoponera spp. and Paraponera clavata) or those that require a large 
resource base to support large colonies (e.g., Azteca spp., Cephalotes atratus; Hölldobler and Wilson 1990).

The principal objectives of this study were to determine if local arboreal ant species richness (i.e., the number of resident species in a single tree crown; hereafter, $\mathrm{S}_{\mathrm{a}}$ ) follows the classical species-area relationship $\mathrm{S}=\mathrm{CA}^{\mathrm{z}}$ (Preston 1962), and to explore the role of lianas in this pattern. Specifically, I predicted that $S_{a}$ in trees lacking lianas would increase with tree size. I expected such effects to disappear in trees occupied by lianas, and that $S_{a}$ would increase with liana density. Our secondary objective was to examine the effects of tree size, identity, and liana occupancy on ant species composition and cooccurrence. Specifically, our goals were to evaluate potential host-specificity between ants and trees, and to determine if ant species in this forest follow mosaic patterns of distribution (e.g., Leston 1978). Lianas are defensible, efficient foraging pathways for ants (Clay et al. 2012, Yanoviak et al. 2016), and can expand the foraging space of an ant colony well beyond its home tree. Thus, I expected that trees occupied by lianas would exhibit a higher frequency of behaviorally aggressive ant species with large colonies (e.g., Azteca spp.; Adams 1990) and ant species with wide-ranging solitary foragers (e.g., ponerines; Camargo and Oliveira 2012).

\section{METHODS}

Study site

Field work for this study was conducted from 2009 to 2015 within the Barro Colorado Nature Monument in the Panama Canal Zone $\left(09.15^{\circ} \mathrm{N}, 79.85^{\circ} \mathrm{W}\right.$; hereafter, BCNM). The BCNM is a lowland, seasonally moist tropical forest. More information about the site is available elsewhere (Leigh et al. 1996). Focal trees were scattered across Barro Colorado Island and the nearby Gigante Peninsula. Many of the Gigante trees were within sixteen $80 x 80 \mathrm{~m}$ plots that are part of a larger ongoing liana removal study 
(Martinez-Izquierdo et al. 2016); however, only non-manipulated trees were used for statistical analyses in this study. All data were collected between 09:00 and 16:00 in the early wet season (May to August) of each year.

\section{Canopy Sampling}

In total, 738 ant surveys were conducted in 213 trees representing 33 tree species across the BCNM. I accessed the crown of each tree using the single rope technique (Perry 1978) and censused the arboreal ant community using hand collections and baiting. Baits were placed near the main fork of each tree (10-35m above the ground) and on all accessible branches and liana stems. Baits consisted of a mixture of honey and meat (ham, tuna, or chicken) to provide a combination of carbohydrates, salts, fats, and proteins. Each bait was examined multiple times during each survey to ensure that species were not missed due to turnover. Baiting and hand collecting are commonly used in canopy ant research (Yanoviak and Kaspari 2000, Ribas et al. 2003, Yanoviak et al. 2007). Our collective decades of experience with canopy ant surveys, plus data from destructive sampling combined with baiting for other studies in the BCNM (e.g., Yanoviak et al. 2011), indicate that baiting is very effective at identifying resident species.

The collection effort was limited to one hour after baits were placed, and the survey area was limited to one tree crown and its associated lianas (Ellison et al. 2011). The total area sampled per survey varied with tree size such that the relative surveyed area per tree was approximately equal across trees. I collected representatives of all ant species and morphospecies observed in each tree crown throughout the one-hour survey period. If only one worker of a particular species or morphospecies was found in a tree, that ant was recorded as a stray (i.e., a non-resident forager). Collected workers were stored in 95\% ethanol for later species identification using online and published keys (e.g., Ward 1989, 1993, 1999; Longino 2010). Reference specimens were sent to 
taxonomists for confirmation. Voucher specimens were deposited at the University of Louisville; the United States National Museum, Washington DC; the Smithsonian Tropical Research Institute, Panama; and the Fairchild Museum at the University of Panama.

For every canopy ant survey, I recorded the date, time of day, air temperature, and relative humidity at the beginning of the collection period. I identified every focal tree to species, measured its diameter at breast height (DBH; used to compute basal area), and determined its liana score on a logarithmic scale from zero to three. The liana score was an estimate of liana abundance in a tree crown, where $0=$ no lianas, $1=$ 1-10 liana stems, $2=11-100$ liana stems, and $3=>100$ liana stems. Liana stems were counted as the number of stems that intercepted an imaginary horizontal plane extending from the main fork of the tree. A single individual liana may have hundreds of stems in a tree crown (Putz 1984); therefore, these counts do not represent individual liana abundance. For all trees with lianas, lianas within the focal tree crown extended into the crown of at least one neighboring tree.

Analysis

To determine if the whole arboreal ant community of the BCNM was well represented by the collection effort, I created a sample-based species accumulation curve (SAC) using all 738 surveys ( $\mathrm{S}_{\text {est }}$ function in EstimateS version 9.1.0; Colwell 2009). Since many collections represented annual resampling of the same trees, I also created a SAC using only data from the first survey conducted in each tree $(n=153)$. To maintain statistical independence, all subsequent analyses used only these initial survey data.

I used a linear model to determine which factors influence ant species richness in canopy trees. The complete model included liana score, tree species, tree size (using basal area as a proxy variable for crown area; O’Brien et al. 1995), temperature, and all 
possible interaction terms as fixed effects. I included temperature because it is a key abiotic variable affecting the activity of small ectotherms like ants (e.g., Kaspari et al. 2016). I eliminated non-significant terms using stepwise model reduction based on AIC values (Ribas et al. 2003, Johnson and Omland 2004), and used a post-hoc Tukey HSD test to compare groups within liana score and tree species. Finally, to test the predictions that individual trees function as islands and that lianas overcome the isolating effect of crown shyness, I conducted a parallel analysis in which liana score was replaced with liana presence or absence.

I used PERMANOVA (Anderson et al. 2008) to assess the effects of liana score or liana presence/absence in combination with tree species, tree size, and temperature on ant species composition. The complete model included all possible interaction terms. I converted the continuous variables basal area and temperature into ordered quartiles to meet the data structure requirements of this analysis. I calculated community similarity using the Jaccard index and used 9999 permutations for the analysis. I used post-hoc pairwise PERMANOVA tests to compare groups within liana score and tree species, and indicator species analysis to determine which ant species contributed the most to differences revealed by the PERMANOVA tests (Dufrêne and Legendre 1997, de Cáceres and Legendre 2009).

Tree size (basal area in $\mathrm{m}^{2}$ ) was log transformed to improve normality. Tree species represented by $<5$ individuals in the data set were excluded from pairwise PERMANOVA tests. I used a Bonferroni adjustment for multiplicity where necessary. Linear models and indicator species analyses were conducted using the $\mathrm{R}$ statistical package version 3.4.2 along with packages lsmeans, multcomp, MASS, and indicspecies (R Core Team 2016). I performed PERMANOVA analyses using PRIMER version 6.1.14 including the PERMANOVA+ package version 1.o.4 (PRIMER-E Ltd, 2012). 


\section{Species Co-occurrence}

Patterns of co-occurrence are commonly used to assess potential mosaic structures in canopy ant communities (Majer 1976, Blüthgen and Stork 2007, Sanders et al. 2007). The C-score is an index that compares patterns of co-occurrence in natural systems against a null model with a random distribution (Gotelli 2000). As described above, I limited the dataset to the first survey for each tree $(n=153)$, and then used EcoSimR 1.o (Gotelli and Ellison 2013) to generate a C-score for the whole community of canopy-dwelling ants of the BCNM. I used 9999 randomized matrices and applied a fixed-fixed algorithm to both ant species and individual tree survey. I assumed that ant species differ in their frequency of tree occupation, and that different individual trees harbor different potential habitats for ants (Tschinkel and Hess 1999, Gotelli 2000). I tested pairwise species associations using PAIRS software with the same parameters listed above (9999 randomizations and a fixed-fixed algorithm; Gotelli and Ulrich 2012). All species were accounted for in pairwise analyses but only results for species that occurred in at least 15 surveys ( $\geq 10 \%$ of the focal trees) are reported.

\section{RESULTS}

I found 128 species and morphospecies of ants representing 30 genera and 8 subfamilies in the BCNM forest canopy. The species accumulation curve predicted a maximum of 136 species in the canopy (Figure 1), thus, our collection effort captured $94 \%$ of the expected species richness at this site.

\section{Local Ant Species Richness $\left(S_{a}\right)$}

Using data from all tree surveys (including repeated surveys of the same trees; $\mathrm{n}$ $=738)$, canopy trees contained an average $( \pm$ SD) of $9.3 \pm 3.2$ ant species, with 20 ant species in the most diverse tree and two ant species in the least diverse tree. Limiting the 
data set only to the initial survey of each tree produced similar results $(9.8 \pm 3.1$ species; $\mathrm{n}=153$ surveys). $\mathrm{S}_{\mathrm{a}}$ was significantly influenced by liana score, tree size, and air temperature $\left(\mathrm{F}_{5,147}=4.55 ; \mathrm{P}=0.0007 ; \mathrm{R}^{2}=0.10\right)$. Specifically, $\mathrm{S}_{\mathrm{a}}$ increased with increasing liana score $\left(\mathrm{F}_{3,147}=2.97 ; \mathrm{P}=0.03\right.$; Figure 2$)$, tree size $\left(\mathrm{F}_{1,147}=9.12 ; \mathrm{P}=\right.$ 0.003), and air temperature $\left(\mathrm{F}_{1,147}=4.71 ; \mathrm{P}=0.03\right.$; Figure 3$)$. Although air temperature was a significant predictor of $S_{a}$, it spanned the normal range of thermal conditions at which canopy ants are active in this forest $\left(25^{-3} 4^{\circ} \mathrm{C}\right.$; Kaspari et al. 2016) and its effect was very small $\left(\mathrm{R}^{2}=0.03\right)$.

Replacing liana score with liana presence/absence in the model resulted in a significant interaction between liana presence and tree size $\left(\mathrm{F}_{4,148}=6.80 ; \mathrm{P}<0.0001 ; \mathrm{R}^{2}\right.$ = o.13), supporting the hypothesis that arboreal ant communities are functionally different in liana-free trees versus trees with lianas. Subsequent analysis of $S_{a}$ vs. tree size and temperature separately for trees with and without lianas revealed a positive linear relationship between $S_{a}$ and tree size (basal area in $\mathrm{m}^{2} ; A$ ) in trees without lianas $\left(F_{2,32}=19.27 ; \mathrm{P}=0.0001 ; \mathrm{R}^{2}=0.36\right)$. This relationship followed the power function $\mathrm{S}_{\mathrm{a}}=$ $10.99 \mathrm{~A}^{0.256}$. The observed value of $\mathrm{Z}(0.256)$ lies within the expected range predicted for other insular habitats (Rosenzweig 1995). In contrast, there was no species-area relationship in trees with lianas present $\left(\mathrm{F}_{2,115}=3.03 ; \mathrm{P}=0.08\right.$; Figure 4$)$. Temperature at the time of collection was not a significant predictor of species richness in either of these models.

\section{Species Composition}

Pseudomyrmex, a widespread arboreal specialist (Ward 1999), was the most common genus in our collections, and Pseudomyrmex gracilis was the most frequently encountered species, occurring in 69\% (106 trees) of initial tree surveys. Only two other species occurred in more than 50\% of initial surveys: Camponotus linnaei and 
Pseudomyrmex oculatus (56\% and 52\%, respectively). Nearly $40 \%$ of species (50 species) were relatively rare, appearing in less than $1 \%$ of the initial surveys (Table 1 ). Ant species composition differed among trees based on liana presence (Pseudo$\left.\mathrm{F}_{1,128}=1.50 ; \mathrm{P}=0.05\right)$. Cumulatively, 92 species occurred in trees with lianas and 58 species occurred in trees without lianas. Species with solitary foraging strategies (e.g. Neoponera villosa) occurred more frequently in trees with lianas; however, contrary to our prediction, species with large colony sizes (e.g., Azteca spp. and Cephalotes atratus) occurred with equal frequency in trees with and without lianas. Solenopsis picea, an open habitat specialist (Pacheco et al. 2013), occurred 10 times more frequently in trees lacking lianas. Indicator species analyses revealed four species that were associated with liana-free tree crowns (Crematogaster crinosa, Pseudomyrmex simplex, Pseudomyrmex tenuissimus, and Solenopsis picea) and three ant species from trees with lianas (Crematogaster carinata, Neoponera villosa, and Pheidole caltrop; Table 2).

Tree species identity also influenced the composition of local arboreal ant communities (Pseudo- $\mathrm{F}_{22,128}=1.17 ; \mathrm{P}=0.003$ ). However, post-hoc pairwise tests of tree species indicated that ant community composition differed between only two trees: Dipteryx oleifera $(\mathrm{n}=83)$ and Apeiba membranacea $(\mathrm{n}=13 ; \mathrm{t}=1.52 ; \mathrm{P}=0.008)$. Specifically, the ant species Neoponera striatinodis and Acromyrmex volcanus were positively associated with $A$. membranacea trees, whereas Camponotus cameroni was positively associated with D. oleifera trees (Table 3).

\section{Species Co-occurrence}

Unlike similar arboreal ant communities that exhibit mosaic patterns of distribution, the canopy ant community in the BCNM showed no general trends towards non-overlapping species occurrence (observed C-score $=112.1$; simulated mean C-score $=112.3$; variance of simulations $=0.15 ;$ observed $\leq$ simulated $\mathrm{P}=0.36$; observed $\geq$ 
simulated $\mathrm{P}=0.64)$. However, the pairwise tests revealed 16 species pairs that tended towards exclusion (Table 4), and 20 species pairs that tended to co-occur (Table 5). Using the biological characteristics established by Majer (1972, 1976; numerical abundance, polydomy, and exclusion of or aggression towards other ants at baits), and the tendency for dominant species to not co-occur (Gotelli and Ulrich 2012), I identified five "dominant" ant species from the 16 segregated species pairs: Azteca instabilis, Azteca trigona, Azteca forelii, Crematogaster curvispinosa, and Dolichoderus bispinosus. Azteca instabilis and A. trigona co-occurred with each other less frequently than predicted by the null model, and Azteca forelii never co-occured with $A$. instabilis. Finally, the occurrence of both C. curvispinosa and D. bispinosus was negatively associated with $A$. trigona.

\section{DISCUSSION}

Here I show that the species richness of resident ants in isolated tree crowns follow the classical species-area relationship (Preston 1962), and that the presence of lianas, a connective element of habitat structure, removes that pattern. The most parsimonious explanation for this effect is that the persistent physical contact among multiple tree crowns provided by lianas makes the area of a single tree crown a poor predictor of effective arboreal habitat area. The conclusion that individual tree crowns function as isolated islands for arboreal ants is further supported by the lower frequency of ant species that rely on wide-ranging solitary foragers in trees lacking lianas. Alternatively, lianas also provide nest sites and nutritional resources for arboreal ants (Blüthgen et al. 2000, Tanaka et al. 2010, Yanoviak and Schnitzer 2013). However, such resources by themselves should not eliminate species-area relationships in trees with lianas (see Nilsson et al. 1988, Ricklefs and Lovette 1999). 
The idea that individual trees and other forest structures function as islands is not new (Janzen 1968, 1973; Southwood and Kennedy 1983, Frank and Lounibos 1987), and evidence for increasing $S_{a}$ with increasing tree size exists for other arboreal ant communities (Majer and Delabie 1999, Tschinkel and Hess 1999, Powell et al. 2011, Klimes et al. 2012). However, such examples come from forests with relatively isolated tree crowns (e.g., pine plantations, Brazilian cerrado, and dipterocarp forests), or were conducted at smaller temporal and spatial scales than this study.

The close correspondence between species-area relationships predicted by theory (Preston 1962) and the results of this study have interesting ecological implications. Specifically, the value of $\mathrm{C}$ in the equation $\mathrm{S}_{\mathrm{a}}=\mathrm{CA}^{\mathrm{z}}$ predicts that very small trees (i.e., saplings ranging from ca. 1-4 cm DBH) will support one ant species. Indeed, our observations in the BCNM suggest that this prediction is realistic, especially in myrmecophytic trees, which are often occupied by ants as seedlings (Janzen 1966). Given the density of trees in the BCNM forest (2000-2700 stems $>2.5 \mathrm{~cm} \mathrm{DBH} \mathrm{ha}^{-1}$; Leigh et al. 1996), and the frequency of liana occupancy in BCNM trees (75\%; Schnitzer et al. 2012), I expect at least 500 tree crowns per hectare to function as small islands for ants in this forest.

Crown isolation also should contribute to the clearly delimited territories that characterize ant mosaic distributions (Majer 1976, Leston 1978) in other arboreal systems (e.g., tropical agroecosystems, the dipterocarp forests of Borneo, the coastal forests of Australia, and the Brazilian cerrado; Majer et al. 1994, Ribas and Schoereder 2004, Blüthgen and Stork 2007, Sanders et al. 2007, Klimes et al. 2012). For territorial animals, the cost of maintaining exclusive territories decreases when shared boundaries between neighbors are minimized (Eason 1992, Adams 2001, Adams 2016). For arboreal ants, high liana frequency should increase the cost of maintaining territories by forcing dominant ant colonies to defend multiple pathways among tree crowns, effectively 
increasing shared boundary length. Thus, forests in which lianas are common should be less likely to exhibit well defined ant mosaics, and forests with low liana frequency should be more likely to exhibit ant mosaics. Indeed, apart from this study, there is some evidence for this pattern. Specifically, the forests with strong evidence of ant mosaics mentioned above either have lower frequencies of lianas compared to other tropical forests, are agricultural systems managed to reduce liana frequency, or are tropical savannas with widely dispersed trees (Emmons and Gentry 1983, Ratter et al. 1997, Schnitzer and Bongers 2002). Furthermore, in primary forests in the Neotropics and Africa - where liana frequencies are high - ant mosaics are either absent or less well defined (Ribas and Schoereder 2002, Schulz and Wagner 2002; but see Dejean et al. 1999, 2000).

This study is the largest (in terms of spatial scale) structured survey of arboreal ants in a natural ecosystem. Other regional estimates of arboreal ant richness conducted fewer total surveys (Montgomery 1985, Wilson 1987, Longino et al. 2002, Schulz and Wagner 2002, Ribas et al. 2003, Blüthgen and Stork 2007, Powell et al. 2011), covered smaller forest plots (Klimes et al. 2012), or focused on tropical agroecosystems (Majer et al. 1994, Sanders et al. 2007). The regional ant species richness recorded here (128 species) and average species per tree (9.3) are within the range of other large scale surveys in natural ecosystems (73-169 total species and averages between 3-20 ant species per tree). Compared to a study with a similar total number of surveys (Klimes et al. 2012), the regional ant species richness in the BCNM is higher (99 vs. 128 species, respectively). I attribute the higher species richness recorded here in part to the difference in sampling area (ca. $5 \mathrm{~km}^{2}$ in this study vs. $<0.01 \mathrm{~km}^{2}$ in the Bornean forest), but also to biogeographical differences in ant diversity between the Neotropics and Southeast Asia. Specifically, the regional ant species richness reported by Klimes et al. (2012) is comparable to that observed in other studies of Asian and Australian forests 
(Blüthgen and Stork 2007), whereas the total ant species richness I observed in the BCNM is similar to that found in Peru and Brazil (Wilson 1987, Ribas et al. 2003). Although increased tree species richness was positively associated with ant species richness in other plot-level surveys (Ribas et al. 2003), I found little evidence of tree species effects on the structure of local arboreal ant communities. The patchy distribution of relatively uncommon ant species (especially Acromyrmex volcanus and Neoponera striatinodis, which appeared in 5\% and 6\% of samples, respectively) likely inflated the compositional differences found between Dipteryx oleifera and Apeiba membranacea trees. Furthermore, ant species predicted to be most influenced by tree species richness, specifically those involved in obligate ant-plant mutualisms (Ward 1993, Rico-Gray and Oliveira 2007), were poorly represented in this study (I collected only one such species, Cephalotes setulifer; de Andrade and Baroni Urbani 1999).

Ant body size differences provide a potential explanation for some of the patterns of co-occurrence among the "dominant" ants of the BCNM. All three Azteca species overlap in head width (Longino 2007), a morphological trait associated with diet and resource use (Weiser and Kaspari 2006). As such, these ants likely compete for similar resources resulting in less frequent co-occurrence than expected. Similarly, A. trigona and Crematogaster curvispinosa (Longino 2003), also greatly overlap in head width and tend not to co-occur. Although our community-wide analyses do not support the predictions of an ant mosaic, these pairwise findings suggest that further study of the effects of interspecific interactions on local species richness in arboreal ant communities is needed.

The results of this study raise additional questions that are potentially useful avenues for future investigation. First, does tree size predict arboreal ant species richness in smaller, non-canopy trees? The results of this study suggest that even very small trees will harbor arboreal ants; however, the range of tree sizes sampled in this 
study did not include that lower limit. Second, how do tree traits (e.g., deciduousness, dioecy, crown architecture, and canopy status), plot characteristics (e.g., forest stand age), or species identity of lianas or epiphytes (Yanoviak et al. 2011) affect ant community structure in individual tree crowns? Finally, why do certain ant species tend to co-occur more or less frequently than expected? Body size appears to explain some of the patterns of exclusion between species; however, territory mapping and aggression assays are still needed to fully evaluate the potential presence of ant mosaics (Majer 1976, Dejean et al. 2007, Adams 2016) in this forest. Ultimately, understanding patterns of local species richness in forest canopies is important because tropical tree crowns harbor ca. $40 \%$ of extant species (Ozanne et al. 2003), but factors affecting local variation in diversity remain poorly studied. I show that for one of the most abundant members of the tropical forest canopy - arboreal ants - tree crowns function as islands in the absence of lianas. 


\section{Tables}

Table 1. The complete list of 128 ant species collected from tree crowns in the Barro

Colorado Nature Monument, Panama. Values are collection frequencies (percent occurrence in independent collections) from trees with lianas $(n=118)$ and trees without lianas ( $\mathrm{n}=35)$. Morphospecies which could not be identified are listed as "sp\#”.

\begin{tabular}{|c|c|c|c|}
\hline Subfamily & Species & $\begin{array}{c}\text { Lianas } \\
\text { Present }\end{array}$ & $\begin{array}{l}\text { Lianas } \\
\text { Absent }\end{array}$ \\
\hline \multirow[t]{16}{*}{ Dolichoderinae } & Azteca brevis & 0 & 2.86 \\
\hline & Azteca flavigaster & 3.39 & 0 \\
\hline & Azteca forelii & 11.02 & 8.57 \\
\hline & Azteca instabilis & 30.51 & $25 \cdot 71$ \\
\hline & Azteca nigricans & 5.93 & 2.86 \\
\hline & Azteca pilosula & 1.69 & o \\
\hline & Azteca trigona & 31.36 & 22.86 \\
\hline & Dolichoderus bispinosus & 19.49 & $25 \cdot 71$ \\
\hline & Dolichoderus debilis & 7.63 & o \\
\hline & Dolichoderus lamellosus & 0 & $\mathrm{O}$ \\
\hline & Dolichoderus laminatus & 8.47 & 14.29 \\
\hline & Dolichoderus lutosus & 0 & o \\
\hline & Tapinoma litorale & 0 & o \\
\hline & Tapinoma melanocephalum & 6.78 & o \\
\hline & Tapinoma sp1 & 0 & o \\
\hline & Technomyrmex fulvus & 0.85 & o \\
\hline \multirow[t]{2}{*}{ Ecitoninae } & Eciton hamatum & 0.85 & o \\
\hline & Neivamyrmex pilosus & o & $\mathrm{O}$ \\
\hline \multirow[t]{4}{*}{ Ectatomminae } & Ectatomma ruidum & $3 \cdot 39$ & 0 \\
\hline & Ectatomma tuberculatum & 5.93 & 2.86 \\
\hline & Gnamptogenys concinna & 1.69 & o \\
\hline & Gnamptogenys regularis & 0 & o \\
\hline \multirow[t]{10}{*}{ Formicinae } & Brachymyrmex coactus & 4.24 & o \\
\hline & Brachymyrmex longicornis & 0 & 0 \\
\hline & Brachymyrmex pictus & 10.17 & 11.43 \\
\hline & Camponotus atriceps & $3 \cdot 39$ & 2.86 \\
\hline & Camponotus brevis & 5.08 & $5 \cdot 71$ \\
\hline & Camponotus cameroni & 21.19 & 37.14 \\
\hline & Camponotus canescens & 11.02 & 2.86 \\
\hline & Camponotus claviscapus & 6.78 & $\mathrm{O}$ \\
\hline & Camponotus curviscapus & 0 & o \\
\hline & Camponotus linnaei & 57.63 & 48.57 \\
\hline
\end{tabular}




\begin{tabular}{|c|c|c|}
\hline Camponotus mucronatus & 12.71 & 11.43 \\
\hline Camponotus novogranadensis & 27.97 & 34.29 \\
\hline Camponotus pittieri & 2.54 & O \\
\hline Camponotus planatus & 0 & o \\
\hline Camponotus sanctaefidei & $5 \cdot 93$ & O \\
\hline Camponotus senex & 24.58 & 31.43 \\
\hline Camponotus sericeiventris & 10.17 & 8.57 \\
\hline Camponotus sp1 & 1.69 & 2.86 \\
\hline Camponotus sp2 & 0 & 0 \\
\hline Camponotus sp3 & o & 2.86 \\
\hline Camponotus sp4 & o & o \\
\hline Camponotus textor & $\mathrm{O}$ & o \\
\hline Nylandaria caeciliae & 0.85 & o \\
\hline Nylandaria guatemalensis & o & o \\
\hline Nylandaria sp1 & $\mathrm{O}$ & $\mathrm{O}$ \\
\hline Nylandaria steinheili & 4.24 & 2.86 \\
\hline Paratrechina longicornis & $\mathrm{O}$ & o \\
\hline Acromyrmex octospinosus & 0.85 & 2.86 \\
\hline Acromyrmex volcanus & 6.78 & 0 \\
\hline Cephalotes atratus & 34.75 & 14.29 \\
\hline Cephalotes basalis & 39.83 & 34.29 \\
\hline Cephalotes christopherseni & 31.36 & 11.43 \\
\hline Cephalotes cordiventris & O & 2.86 \\
\hline Cephalotes foliaceus & 4.24 & 2.86 \\
\hline Cephalotes grandinosus & O & $\mathrm{o}$ \\
\hline Cephalotes maculatus & $13 \cdot 56$ & 17.14 \\
\hline Cephalotes minutus & 2.54 & O \\
\hline Cephalotes porrasi & 1.69 & o \\
\hline Cephalotes setulifer & 0.85 & $\mathrm{O}$ \\
\hline Cephalotes umbraculatus & 21.19 & 20 \\
\hline Crematogaster acuta & $3 \cdot 39$ & 0 \\
\hline Crematogaster brasiliensis & 6.78 & 2.86 \\
\hline Crematogaster carinata & 16.1 & o \\
\hline Crematogaster crinosa & 5.08 & 17.14 \\
\hline Crematogaster crucis & $3 \cdot 39$ & 0 \\
\hline Crematogaster curvispinosa & 27.97 & 22.86 \\
\hline Crematogaster limata & $3 \cdot 39$ & o \\
\hline Crematogaster longispina & 0 & 2.86 \\
\hline Crematogaster raptor & 0.85 & o \\
\hline Crematogaster rochai & $\mathrm{O}$ & 2.86 \\
\hline Crematogaster stollii & 4.24 & 0 \\
\hline Cyphomyrmex salvini & $\mathrm{O}$ & o \\
\hline Monomorium pharaonis & o & o \\
\hline Nesomyrmex anduzei & 2.54 & o \\
\hline Nesomyrmex pleuriticus & $\mathrm{O}$ & $\mathrm{O}$ \\
\hline
\end{tabular}




\begin{tabular}{|c|c|c|c|}
\hline & Pheidole bilimeki & 0.85 & $\mathrm{O}$ \\
\hline & Pheidole boliviana & $3 \cdot 39$ & o \\
\hline & Pheidole caltrop & 12.71 & o \\
\hline & Pheidole nr excubitor & o & o \\
\hline & Pheidole flavens & 4.24 & o \\
\hline & Pheidole perpusilla & 0.85 & o \\
\hline & Pheidole sp1 & 0.85 & o \\
\hline & Pheidole sp2 & o & o \\
\hline & Pheidole susannae & $\mathrm{O}$ & o \\
\hline & Procryptocerus belti & 22.03 & 8.57 \\
\hline & Solenopsis picea & 1.69 & 20 \\
\hline & Solenopsis $\mathrm{sp} 1$ & 0.85 & $\mathrm{O}$ \\
\hline & Solenopsis sp2 & 0.85 & o \\
\hline & Solenopsis sp3 & 4.24 & 2.86 \\
\hline & Solenopsis zeteki & 2.54 & o \\
\hline & Tetramorium bicarinatum & o & o \\
\hline & Wasmannia auropunctata & 1.69 & o \\
\hline & Wasmannia rochai & 11.86 & 8.57 \\
\hline & Xenomyrmex panamanus & 4.24 & 8.57 \\
\hline Paraponerinae & Paraponera clavata & 5.08 & 8.57 \\
\hline Ponerinae & Anochetus bispinosus & 0 & o \\
\hline & Neoponera antecurvata & 0.85 & $\mathrm{O}$ \\
\hline & Neoponera carinulata & 15.25 & $5 \cdot 71$ \\
\hline & Neoponera crenata & 1.69 & o \\
\hline & Neoponera curvinodis & 0 & 0 \\
\hline & Neoponera foetida & 25.42 & 11.43 \\
\hline & Neoponera striatinodis & 8.47 & o \\
\hline & Neoponera villosa & 35.59 & 11.43 \\
\hline & Odontomachus bauri & o & o \\
\hline & Odontomachus ruginodis & 1.69 & 2.86 \\
\hline & Platythyrea pilosula & 3.39 & 2.86 \\
\hline Pseudomyrmecinae & Pseudomyrmex beccarii & 9.32 & 8.57 \\
\hline & Pseudomyrmex browni & 2.54 & 2.86 \\
\hline & Pseudomyrmex cretus & 0 & 0 \\
\hline & Pseudomyrmex duckei & 1.69 & $\mathrm{O}$ \\
\hline & Pseudomyrmex ejectus & o & 2.86 \\
\hline & Pseudomyrmex elongatus & 39.83 & 51.43 \\
\hline & Pseudomyrmex euryblemma & 0.85 & o \\
\hline & Pseudomyrmex gracilis & 71.19 & 62.86 \\
\hline & Pseudomyrmex ita & 16.95 & 14.29 \\
\hline & Pseudomyrmex kuenckeli & o & 2.86 \\
\hline & Pseudomyrmex laevivertex & $\mathrm{O}$ & 0 \\
\hline & Pseudomyrmex oculatus & 55.08 & 40 \\
\hline & Pseudomyrmex rochai & 2.54 & 5.71 \\
\hline & Pseudomyrmex simplex & 6.78 & 22.86 \\
\hline
\end{tabular}


Pseudomyrmex sp1

Pseudomyrmex sp2

Pseudomyrmex spiculus

Pseudomyrmex tenuis

Pseudomyrmex tenuissimus

Pseudomyrmex viduus
0.85

2.54

11.86

0

42.37

O
2.86

0

2.86

2.86

71.43

o

Table 2. The list of indicator species of arboreal ants in trees with and without lianas. Values include are the indicator value (IndVal) and adjusted p-value (P). A separate analysis was conducted for both trees with and trees without lianas. See the text and de Cáceres and Legendre (2009) for more details about indicator species analysis.

\begin{tabular}{llcc}
\hline Liana Presence & Ant Species & IndVal & $\boldsymbol{P}$ \\
\hline Present & Crematogaster carinata & 0.401 & 0.0436 \\
Present & Neoponera villosa & 0.519 & 0.0252 \\
Present & Pheidole caltrop & 0.357 & 0.0474 \\
Absent & Crematogaster crinosa & 0.364 & 0.0311 \\
Absent & Pseudomyrmex simplex & 0.420 & 0.0114 \\
Absent & Pseudomyrmex tenuissimus & 0.670 & 0.0021 \\
Absent & Solenopsis picea & 0.429 & 0.0009 \\
\hline
\end{tabular}

Table 3. The list of indicator species of arboreal ants for Apeiba membranacea and Dipteryx oleifera trees with their indicator value (IndVal) and adjusted p-value (P). A separate analysis was conducted for each tree species. See the text and de Cáceres and Legendre (2009) for more details about indicator species analysis.

\begin{tabular}{llcc}
\hline Tree Species & Ant Species & IndVal & $\boldsymbol{P}$ \\
\hline A. membranacea & Acromyrmex volcanus & 0.447 & 0.0279 \\
A. membranacea & Neoponera striatinodis & 0.457 & 0.0169 \\
D. oleifera & Camponotus cameroni & 0.601 & 0.0196 \\
\hline
\end{tabular}


Table 4. The list 16 segregated species pairs of arboreal ants. The table includes both of the species within the pair, the observed C-score, the expected average C-score with standard deviation, and the p-value.

\begin{tabular}{llccc}
\hline Species 1 & Species 2 & C-score & Expected & $\boldsymbol{P}$ \\
\hline A. forelii & A. instabilis & 1.00 & $0.63 \pm 0.11$ & 0.0013 \\
A. forelii & C. umbraculatus & 1.00 & $0.70 \pm 0.13$ & 0.0216 \\
A. instabilis & B. pictus & 1.00 & $0.65 \pm 0.12$ & 0.0019 \\
A. trigona & A. instabilis & 0.87 & $0.50 \pm 0.07$ & $<0.0001$ \\
A. trigona & C. curvispinosa & 0.74 & $0.51 \pm 0.08$ & 0.0055 \\
A. trigona & D. bispinosus & 0.80 & $0.54 \pm 0.09$ & 0.0026 \\
B. pictus & N. foetida & 1.00 & $0.71 \pm 0.13$ & 0.0279 \\
C. cameroni & C. carinata & 1.00 & $0.65 \pm 0.10$ & 0.0004 \\
C. cameroni & C. senex & 0.85 & $0.57 \pm 0.09$ & 0.0014 \\
C. cameroni & N. carinulata & 0.93 & $0.67 \pm 0.12$ & 0.0388 \\
C. christopherseni & C. cameroni & 0.81 & $0.57 \pm 0.10$ & 0.0147 \\
C. curvispinosa & N. foetida & 0.80 & $0.58 \pm 0.10$ & 0.0229 \\
C. linnaei & C. mucronatus & 0.64 & $0.39 \pm 0.10$ & 0.0165 \\
C. mucronatus & D. bispinosus & 0.93 & $0.66 \pm 0.12$ & 0.0222 \\
C. mucronatus & N. villosa & 0.86 & $0.61 \pm 0.11$ & 0.0186 \\
C. novogranadensis & C. senex & 0.95 & $0.53 \pm 0.08$ & $<0.0001$ \\
\hline
\end{tabular}


Table 5. The list of 20 aggregated species pairs of arboreal ants. The table includes the two species in the pair, the observed C-score, the expected average C-score with standard deviation, and the p-value.

\begin{tabular}{llccc}
\hline Species 1 & Species 2 & C-score & Expected & $\boldsymbol{P}$ \\
\hline A. forelii & B. pictus & 0.32 & $0.78 \pm 0.14$ & 0.0005 \\
A. instabilis & C. basalis & 0.24 & $0.40 \pm 0.07$ & 0.0116 \\
A. instabilis & C. mucronatus & 0.27 & $0.59 \pm 0.11$ & 0.0037 \\
A. instabilis & C. umbraculatus & 0.32 & $0.56 \pm 0.09$ & 0.0115 \\
A. instabilis & P. belti & 0.32 & $0.56 \pm 0.09$ & 0.0093 \\
A. trigona & C. atratus & 0.31 & $0.50 \pm 0.08$ & 0.0135 \\
A. trigona & C. maculatus & 0.21 & $0.59 \pm 0.11$ & 0.0003 \\
A. trigona & C. umbraculatus & 0.35 & $0.55 \pm 0.08$ & 0.0209 \\
A. trigona & P. tenuissimus & 0.24 & $0.36 \pm 0.05$ & 0.0177 \\
B. pictus & C. curvispinosa & 0.40 & $0.63 \pm 0.11$ & 0.0424 \\
C. curvispinosa & P. elongatus & 0.22 & $0.41 \pm 0.07$ & 0.0046 \\
C. linnaei & D. bispinosus & 0.18 & $0.35 \pm 0.07$ & 0.0121 \\
C. mucronatus & C. basalis & 0.32 & $0.51 \pm 0.10$ & 0.0475 \\
C. mucronatus & C. umbraculatus & 0.28 & $0.67 \pm 0.12$ & 0.0012 \\
C. mucronatus & P. tenuissimus & 0.18 & $0.42 \pm 0.11$ & 0.0266 \\
C. novogranadensis & W. rochai & 0.38 & $0.63 \pm 0.11$ & 0.0244 \\
C. umbraculatus & P. belti & 0.37 & $0.61 \pm 0.11$ & 0.0283 \\
C. umbraculatus & P. ita & 0.33 & $0.65 \pm 0.11$ & 0.0038 \\
N. carinulata & N. foetida & 0.40 & $0.67 \pm 0.11$ & 0.0115 \\
P. elongatus & P. simplex & 0.32 & $0.53 \pm 0.11$ & 0.0495 \\
\hline & & & &
\end{tabular}




\section{Figure Captions}

Figure 1. A species accumulation curve (SAC) based on the total collection data set $(\mathrm{n}=$ 738). Dotted lines indicate $95 \%$ confidence intervals. The total number of species collected was 128 with a maximum of 136 predicted.

Figure 2. Average ( \pm SE) ant species richness vs. approximate liana stem density in focal tree crowns. Means were calculated from 153 independent tree samples $(\mathrm{n}=35,18,43$, and 57 trees in liana density categories $0,<10,10-100$, and $>100$, respectively). Similar letters indicate means that do not differ based on Tukey HSD tests.

Figure 3. Species richness (Sa) of arboreal ants vs. air temperature (T) at the time of collection for the liana score model. The equation for the regression is $\mathrm{Sa}=0.399 \mathrm{~T}$ $1.86\left(\mathrm{R}^{2}=0.03 ; \mathrm{P}=0.03\right)$

Figure 4. Arboreal ant species richness vs. tree size (as basal area) in trees lacking lianas (top panel) and trees with lianas (bottom panel). Ant species richness (Sa) increases with tree size (A) in trees lacking lianas as described by the equation $\mathrm{Sa}=10.99 \mathrm{Ao} .256$ $\left(\mathrm{R}^{2}=0.36 ; \mathrm{P}=0.0001\right)$. Tree size does not correlate with ant species richness in trees with lianas. 


\section{Figures}

Figure 1.

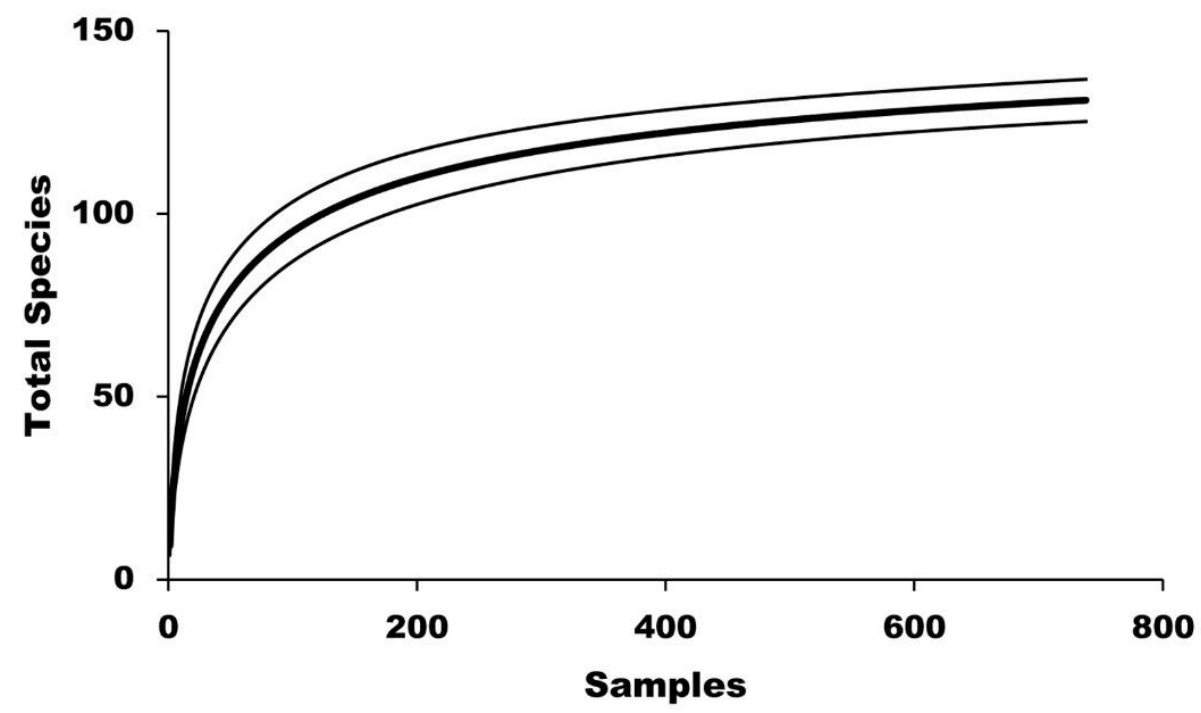

Figure 2.

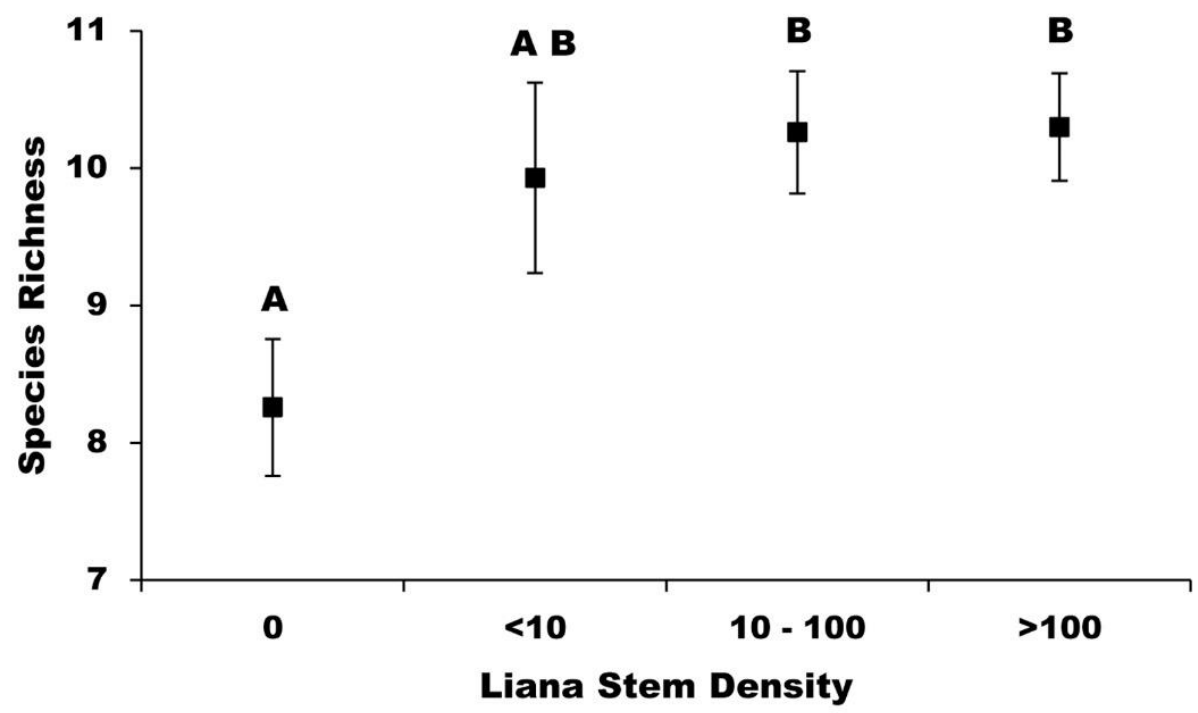


Figure 3 .

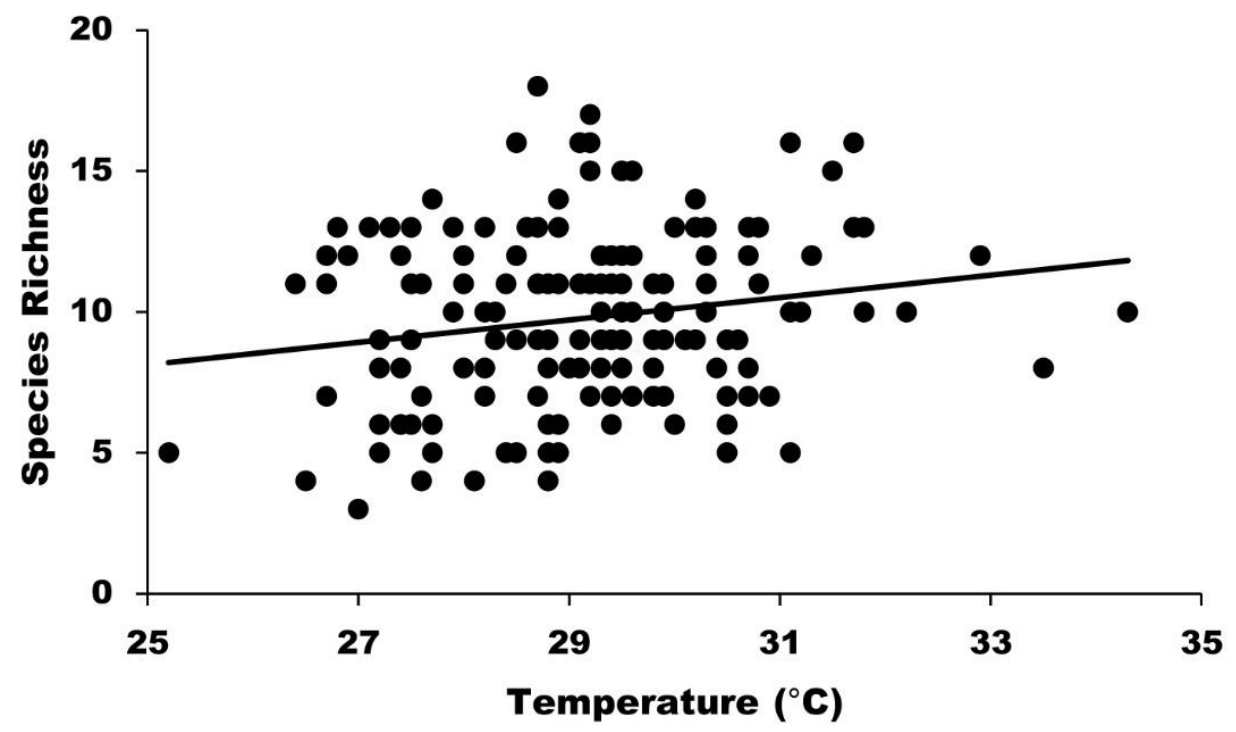


Figure 4.
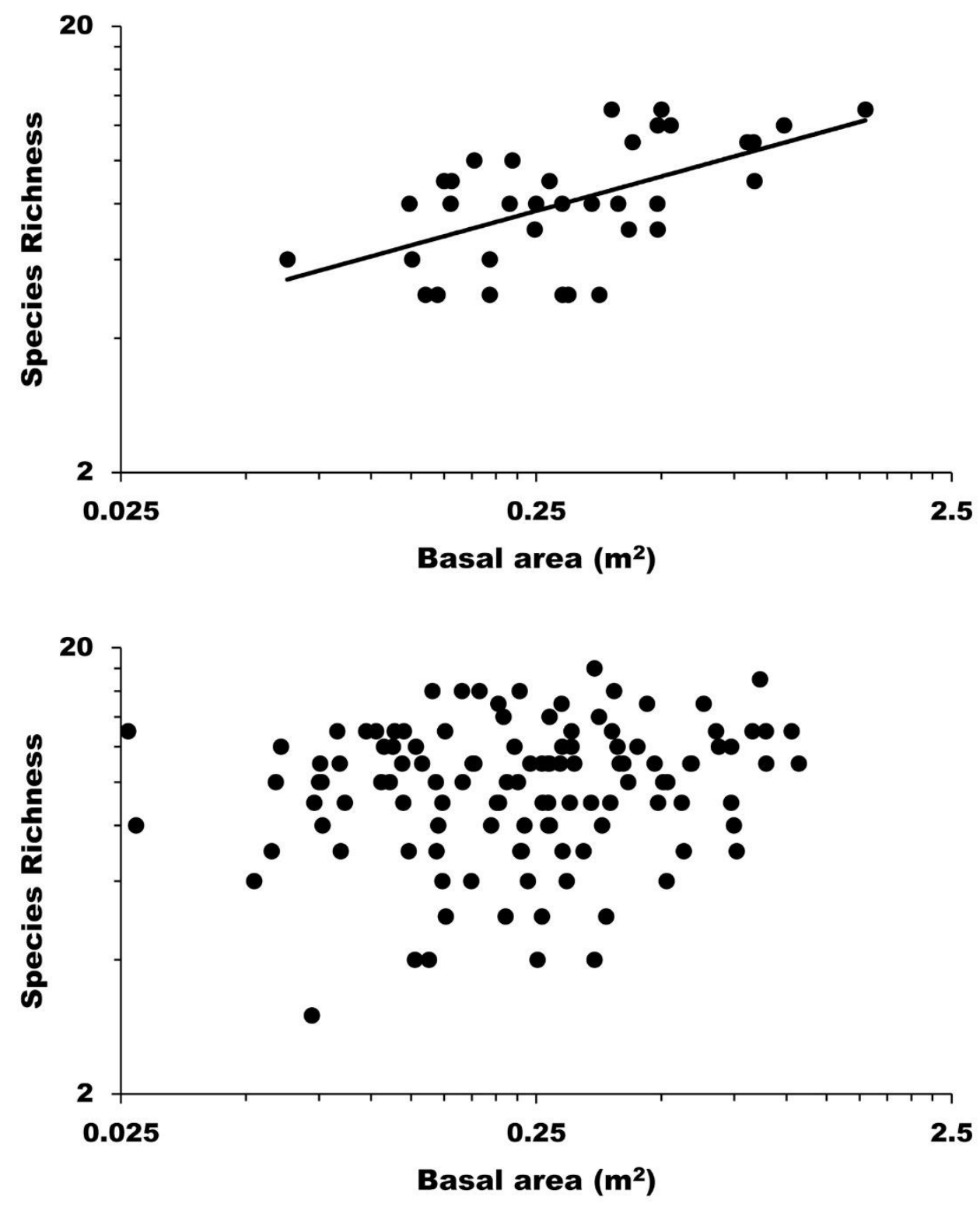
CHAPTER III

LIANAS SHAPE ARBOREAL ANT COMMUNITIES BY PHYSICALLY CONNECTING ISOLATED TREE CROWNS

\begin{abstract}
SUMMARY
Physical connections among neighboring patches in a habitat mosaic shape local community structure. For non-volant arthropods like ants, gaps between neighboring trees are a significant barrier to movement within the forest canopy. Lianas (woody vines) connect neighboring tree crowns and are often used by ants to traverse the canopy. I experimentally tested how lianas affect arboreal ant species richness, species composition, and $\beta$-diversity by removing lianas from individual tree crowns in a lowland tropical forest in Panama. I focus on two resources lianas provide for arboreal ants: connectivity and nest sites. Removing lianas from a tree crown caused a $25 \%$ reduction of species richness and a change in species composition within two years of the experimental manipulation. Adding ropes (i.e., artificial connectivity) to removal trees prevented this effect. Artificial nests added to trees without lianas were occupied $>60 \%$ of the time, and nests added to trees with lianas were occupied only $25 \%$ of the time. Artificial nests were often occupied by polydomous, resident ant species. As a result, the presence of nests did not affect total species richness, composition, or $\beta$-diversity in trees with or without lianas. Collectively, these results indicate that lianas are important to the maintenance of arboreal ant diversity specifically by providing connectivity among neighboring tree crowns. Anticipated increases in liana abundance in this forest should
\end{abstract}


increase the local species richness of arboreal ants and could alter local species composition.

\section{INTRODUCTION}

Explaining the mechanisms underlying local species richness and composition is a fundamental goal of community ecology (Keddy 1992, Huston 1999, Agrawal et al. 2007). Because of their discrete boundaries, insular habitats have been particularly important in the development of community assembly theory (e.g., species-area curves, the theory of island biogeography, and metapopulation theory; (Preston 1962, MacArthur and Wilson 1963, MacArthur and Wilson 1967, Hanski 1982). In general, species dispersal limitation, environmental filters, and species interactions determine the occupancy and community diversity of local, insular habitats (Preston 1962, MacArthur and Wilson 1967, Hanski and Gilpin 1991). Both natural and anthropogenic changes to habitat boundaries can directly influence all three of these community assembly processes (Brown 1971, Fahrig 2003, Wu et al. 2003, Rahel 2007). However, experimental manipulations of habitat boundaries are few and often focus on simplified communities (Huffaker 1958, Gonzalez et al. 1998; but see Tewksbury et al. 2002).

Structural heterogeneity and resource availability also contribute to the diversity of local species assemblages (Gause 1934, MacArthur and MacArthur 1961). Specifically, shared resources among species impose limits on population and individual growth rates (Tilman 1982, Shulman 1984, Bloom et al. 1985). As a result, resource limitation can directly influence local species richness and composition on an ecological time scale via competition (Levins et al. 1973, Tilman and Pacala 1993, Ribas et al. 2003). Nest site or shelter availability are especially important resources for communities in some isolated habitats such as small coral reefs (Smith 1978, Shulman 1984), tidal pools (Metaxas and Scheibling 1993), or tree crowns (Ribas et al. 2003). 
Trees can function as ecological islands for some arboreal communities (Southwood and Kennedy 1983, Adams et al. 2017). Although forests often are viewed as continuous landscapes, the forest canopy is a series of individual tree crowns that typically are isolated in space due to the phenomenon of crown shyness (i.e., the propensity for a space to exist between neighboring tree crowns; Ng 1977, Putz et al. 1984). Such inter-crown gaps function as a deterrent to movement for some organisms, thus producing a series of neighboring species assemblages that are spatially very close but nonetheless isolated (Emmons and Gentry 1983, Southwood and Kennedy 1983, Frank and Lounibos 1987, Wardle et al. 2003, Yanoviak 2015). Consequently, local community structure (e.g., species richness and composition) is in part limited by local, within-tree resource availability (Ribas et al. 2003).

Lianas (woody vines) are a common and conspicuous component of forest canopies (Pérez-Salicrup et al. 2001, Van Der Heijden and Phillips 2008, Ingwell et al. 2010, Schnitzer et al. 2012). Although lianas are structural parasites that damage their host trees (Schnitzer and Bongers 2002), they can enhance the local species richness of arboreal animals (Ødegaard 2000, Yanoviak and Schnitzer 2013, Yanoviak 2015, Adams et al. 2017). The increase in species richness is potentially due to the physical connections lianas create among neighboring tree crowns and the additional resources lianas provide including food and nest locations (Blüthgen and Fiedler 2002, Tanaka et al. 2010, Yanoviak and Schnitzer 2013, Yanoviak 2015). But not every tree has lianas, and many trees shed lianas during their lifetimes (Putz 1984a); therefore, inter-tree connectivity and other resources provided by lianas are naturally variable within an ecological time frame and across space. Liana abundance also is increasing in some tropical forests (Schnitzer and Bongers 2011, Schnitzer et al. 2012) and it is not known how this change will influence arboreal insect communities (Yanoviak 2015). 
Lianas influence the presence of arboreal insects, including arboreal ants (Yanoviak 2015, Adams et al. 2017). Ants are an ecologically important arthropod taxon in tropical forest canopies (Ozanne et al. 2003, Rico-Gray and Oliveira 2007). Ants also are an ideal study organism as they are taxonomically well resolved (Moreau et al. 2006, Longino 2010) and are easy to observe and collect (Ellison et al. 2011). Many arboreal ant species use the physical network provided by lianas as pathways for movement through the forest canopy (Davidson et al. 1988, Powell et al. 2011, Yanoviak and Schnitzer 2013, Yanoviak 2015). Arboreal ant assemblages in trees without lianas tend to have lower species richness and are compositionally different than ant assemblages in trees without lianas (Adams et al. 2017). Ant species richness also increases predictably with tree size in trees without lianas (Adams et al. 2017). Together these observations indicate that lianas influence the structure of ant communities by connecting otherwise isolated tree crowns. Where connectivity was explicitly tested in other studies, the role of lianas was not included (Davidson et al. 1988, Powell et al. 2011).

Ants also take advantage of resources provided by lianas. Specifically, nest sites are a limiting resource in some arboreal systems (Tschinkel 2002, Philpott and Foster 2005, Frederickson 2006, Hosang et al. 2010, Powell et al. 2011) and the hollow stems that are characteristic of many lianas are commonly used by arboreal ants as nest sites (Rico-Gray and Oliveira 2007, Philpott 2010, Yanoviak 2015). There are no explicit tests of how liana presence influences nest site availability and occupancy in arboreal ecosystems.

I experimentally investigated how lianas affect local ant community structure (i.e., species richness, species composition, and $\beta$-diversity in and among individual tree crowns). Given that ant assemblages in liana-free trees follow patterns of insular communities (Adams et al. 2017), and that nest sites are likely a limiting resource for arboreal ant communities (Philpott and Foster 2005, Powell et al. 2011), I focused on 
four specific mechanistic questions. First, does removing lianas from tree crowns decrease ant species richness and impact ant species composition and $\beta$-diversity? Second, does the removal of lianas cause a change in ant species richness such that richness follows a species-area relationship similar to those observed in liana-free trees (Adams et al. 2017)? Third, are arboreal ants in trees without lianas more nest site limited compared to ants living in trees with lianas? Finally, does increasing nest site availability increase species richness and change patterns of $\beta$-diversity and species composition in trees without lianas compared to trees with lianas? I employed a largescale experimental approach to answer these questions in a well-studied lowland forest of Panama.

\section{METHODS}

\section{Study Site}

All field work occurred in the Barro Colorado Nature Moment (BCNM) in the Panama Canal Zone $\left(09.15^{\circ} \mathrm{N}, 79.85^{\circ} \mathrm{W}\right)$ from 2013 to 2017 with each individual field project lasting $\leq 4$ years. I surveyed arboreal ants during the early wet season (MayAugust) of each year between 09:00 and 16:00. Both the plants and the ants are communities in the BCNM are relatively well documented (Condit 1995, Levings and Windsor 1996, Hahn and Wheeler 2002, Schnitzer et al. 2012). Additional details about this site can be found in (Leigh et al. 1996).

\section{Ant Surveys}

I conducted 275 surveys in 80 Dipteryx oleifera trees in the BCNM (Figure 5). I focused on a single tree species, D. oleifera (Figure 6), to avoid potential tree species effects on arboreal ant community structure (Ribas et al. 2003, Adams et al. 2017). Moreover, the dense wood and growth form of $D$. oleifera provide a wide range of 
climbable tree sizes (15-115 $\mathrm{cm}$ diameter at breast height [DBH]) and a wide range of liana infestation (from zero to thousands of liana stems per crown; Figure 7). I accessed the trees using the single rope climbing technique (Figure 8; Perry 1978) and surveyed the arboreal ant communities by baiting and hand collecting.

I recorded date, time of day, and air temperature at the beginning of each survey. I used DBH for each tree to calculate individual tree basal area $\left(\mathrm{BA}=\pi(\mathrm{DBH} / 2)^{2}\right)$, which served as a proxy for arboreal habitat size (i.e., crown area; O'Brien et al. 1995). I collected ants using a combination of chicken or tuna with honey as bait. I placed baits on surfaces of branches and liana stems that were accessible from the central fork of the focal tree and collected samples of all the ants in the tree following the methods described elsewhere (Adams et al. 2017). I stored collected ants in 95\% ethanol and later identified them in the lab using online and published keys (Ward 1989, Ward 1993, Ward 1999, Longino 2010). Taxonomists confirmed the species identity of reference specimens, and vouchers were deposited at the University of Louisville; the United States National Museum, Washington DC; the Smithsonian Tropical Research Institute, Panama; and the Fairchild Museum at the University of Panama.

\section{Liana Removal and Rope Additions}

I used a two-by-two factorial experiment to determine how species richness, composition, and $\beta$-diversity of arboreal ants are affected by inter-tree connectivity (Figure 9). At the beginning of this experiment, each focal tree contained at least one liana in its crown that connected it to at least one nearby canopy tree. The experimental design included a liana removal treatment and a rope addition treatment. For liana removal treatments, liana stems were cut at ground level and allowed to die and fall out of the tree over the course of a year (Reid et al. 2015, Martínez-Izquierdo et al. 2016). The rope addition treatment consisted of a single 10-14 $\mathrm{mm}$ diameter climbing rope tied 
to the central axis of the focal tree and to the nearest canopy tree, thereby connecting the two tree crowns. These connections typically were between $20-40 \mathrm{~m}$ in total length. Arboreal ants readily used the climbing ropes to move between trees (Figure 10). Each of the four experimental treatments included ten D. oleifera trees for a total of 40 trees. I surveyed the arboreal ants in each tree prior to experimental manipulations to provide pre-treatment controls.

I used repeated measures linear model to determine if the proportional change in species richness in individual tree crowns $(\Delta S)$ was affected by the connectivity treatments across the four years of this study. $\Delta \mathrm{S}$ for each tree was calculated as the difference in ant species richness in each year of the experiment from the species richness recorded in the pre-treatment survey all divided by the pre-treatment species richness value (e.g., $\left.\left(\Delta \mathrm{S}_{\text {year }}-\Delta \mathrm{S}_{\text {pre }}\right) / \Delta \mathrm{S}_{\text {pre }}\right)$. Individual trees served as the repeated measure grouping factor across years for these analyses. I used a post-hoc Tukey's HSD to compare groups within treatment and year when significant differences were detected. I also used t-tests to determine if raw species richness values $\left(\mathrm{S}_{\mathrm{a}}\right)$ differed between the pre-treatment controls and final collection (Year 4). I used regression analyses to test for a linear relationship between tree basal area and arboreal ant species richness in the initial and final surveys of the liana removal experiment to determine if a species-area curve developed as a result of liana removal.

I used PERMANOVA (Anderson et al. 2008) to determine if ant species composition changed within and between treatments over the course of the study. Time (the initial and final years of the study) and treatment served as fixed effects for these analyses. I used a Jaccard index to calculate the similarity matrix because the data were incidence-based. P-values were computed using 9999 permutations. When the experimental treatment had a significant effect on species composition, I used a post-hoc pairwise PERMANOVA to determine how composition differed among treatments. 
I tested for differences in $\beta$-diversity in the connectivity experiment using a modern multivariate statistical analysis (distance-based test for the homogeneity of multivariate dispersion, or PERMDISP; Anderson et al. 2008). PERMDISP uses fixed factors from a statistical model to define sample groups in a data set. It then compares the average distance of individual samples within a sample group to a group-defined centroid in multivariate space created from a similarity matrix (Anderson 2006, Anderson et al. 2006). A sample group with higher $\beta$-diversity (i.e., higher variability in species composition among individual samples) will have a larger average distance from the group centroid (Anderson et al. 2011). P-values for this test are computed using permutations of the least-squared residuals. I used the same Jaccard similarity matrix and models used in the PERMANOVA analyses and 9999 permutations of the leastsquared residuals.

\section{Artificial Nest Additions}

I established a second factorial experiment on the BCNM in 40 additional $D$. oleifera trees to determine: 1) how colonization of artificial nests differ between trees with and without lianas; and 2) how arboreal ant species richness, species composition, and $\beta$-diversity are affected by the addition of artificial nests to trees with and without lianas. In contrast with the previous factorial experiment, half of the trees selected for this experiment naturally did not have lianas in their crowns at the start of the experiment; the other half contained at least one liana that connected the focal tree crown to at least one other canopy tree. I added 15 artificial nests to each tree in the nest addition treatments (e.g., trees with and without lianas, Figure 11). An artificial nest consisted of one $5 \mathrm{~cm}$ x $5 \mathrm{~cm}$ x $20 \mathrm{~cm}$ block of a native hardwood (Bombacopsis quinata) containing a $2 \mathrm{~cm} \times 10 \mathrm{~cm}$ hollow cylindrical chamber with a $0.67 \mathrm{~cm}$ diameter entrance hole (Figure 12). I secured the artificial nests to branches or lianas near the central axis 
of the focal tree. Individual nests were separated from each other by $\geq 1 \mathrm{~m}$ (Figure 13). Nests were secured to the trees using a metal wire or nylon cord that was strung through a small hole ( $0.67 \mathrm{~cm}$ diameter) drilled through the wooden block on the sides opposite from the nest cavity entrance hole (Figure 14).

I used a t-test to determine if the proportion (\%) of nests occupied differed between trees with and without lianas in the final survey year. Additionally, I used the same methods described in the liana removal experiment (above) to analyze differences in species richness, species composition, and $\beta$-diversity across the nest site treatments and time.

I originally included ten trees in each treatment of both liana removal and nest addition factorial experiments; however due to tree falls or wasps establishing nests in a tree, each tree was not surveyed every year. Ultimately, I included at least 9 trees per treatment per year. Both basal area and air temperature were initially included as covariates in the linear models but subsequently were removed via backwards stepwise reduction based on AIC values (Johnson and Omland 2004). Raw species richness and basal area were log transformed to improve normality which was confirmed using the Shapiro-Wilk test. Percentages of nests occupied were arcsine-square root transformed. Bonferroni-adjusted alphas were used to correct for multiplicity. All statistical methods were performed in the R statistical package version 3.4.2 (R Core Team 2016) along with package nlme. PERMANOVA and PERMDISP analyses were performed using PRIMER version 6.1.18 (Clarke and Gorley 2006) including the PERMANOVA+ package 1.o.8 (Anderson et al. 2008).

\section{RESULTS}

All ant surveys were conducted under sunny to partly cloudy conditions. Air temperature averaged 29.3 \pm 1.6 C (mean $\pm \mathrm{SD}$ ) and ranged between 25.2-34.2 C during 
collections. The average size (as DBH) of focal trees was $66.7 \pm 21.4 \mathrm{~cm}$ and ranged between $18.2-114.5 \mathrm{~cm}$. AIC values showed that neither of these covariates significantly contributed to the linear models. In total, 105 species of ants were collected during this project (Table 6).

\section{Liana Removal and Rope Additions}

The removal of lianas resulted in a $25 \%$ reduction in ant species richness. Specifically, the change in arboreal ant species richness $(\Delta \mathrm{S})$ differed between the four experimental treatments in the connectivity experiment by year $\left(\mathrm{F}_{3,113}=6.85, \mathrm{P}=\right.$ 0.0003; $\alpha=0.025$ ) and post-hoc tests of treatment within year revealed that average $\Delta \mathrm{S}$ in the liana removal group was smaller than the other three treatments after three years $\left(F_{3,35}=6.17, P=0.002 ; \alpha=0.025 ;\right.$ Figure 15$)$. In the liana removal treatment, mean $( \pm$ $\mathrm{SE})$ arboreal ant species richness per tree $\left(\mathrm{S}_{\mathrm{a}}\right)$ decreased from $12.4 \pm 0.6$ to $9.3 \pm 0.7$ three years after liana removal $(t=3.13, P=0.006 ; \alpha=0.025) . S_{a}$ in the other three treatments did not differ from their pre-treatment values three years following treatment $(\mathrm{t}<5.19, \mathrm{P}>0.04 ; \alpha=0.025$ for each test).

Liana removal also resulted in a positive relationship between species richness and tree size three years after treatment in removal trees $\left(F_{1,7}=6.54, P=0.038, \mathrm{R}^{2}=\right.$ 0.41; Figure 16). The relationship follows the power function $S_{a}=10.87 \mathrm{~A}^{0.16}$ which is similar to the function previously described for liana free trees in this forest $\left(\mathrm{S}_{\mathrm{a}}=\right.$ 10.99 $\mathrm{A}^{0.25}$; Adams et al. 2017). This relationship was not present prior to liana removal $\left(\mathrm{F}_{1,8}=1.35, \mathrm{P}=0.28\right)$.

Liana removal did not change ant species composition or $\beta$-diversity. Overall, ant species composition differed among the four connectivity treatments in both the pretreatment and final surveys (Pseudo- $\left.\mathrm{F}_{3,71}=1.86, \mathrm{P}=0.0002\right)$. However, post-hoc pairwise tests of the different treatments in each year revealed that differences between 
treatments were the same in both pre-treatment and final surveys (Table 7). This means there was no significant change in the species composition due to the experimental treatments. $\beta$-diversity did not differ among connectivity treatments $(\mathrm{F}<2.21, \mathrm{P}>0.13)$.

\section{Artificial Nest Additions}

Arboreal ants occupied artificial nests at a higher frequency in trees without lianas $(72.9 \pm 6.8 \%)$ compared to trees with lianas $(27.5 \pm 5.2 \% ; t=4.69, P=0.0003$; Figure 17). The majority of the nest occupations in any given tree (and 94\% of nest occupations overall) were the result of colony expansion by resident polydomous ants. Only eight of the 300 artificial nests used in this experiment were colonized by ants not already detected in the focal trees during the pre-treatment surveys. One tree had two non-resident ants occupying its artificial nests. On five occasions, more than one species of ant occupied a single nest. When this occurred, one species always occupied the main cavity in the nest. The other, generally smaller and less aggressive species (e.g., Brachymyrmex pictus balboae, Nylandaria steinheili, Pseudomyrmex tenuissimus, Solenopsis picea, or Tapinoma melanocephalum; Table 5), occupied the small hole drilled in the top of the artificial nest (Figure 18). In many cases, Azteca spp. or Crematogaster spp. covered the nest entrances with carton (Figure 19). Cephalotes spp. relied on major workers to defend nests entrances by blocking the opening with their enlarged, phragmotic heads (Figure 20). Stingless bees and termites also frequently occupied the artificial nests (Figure 21).

Nest additions had no effect on the arboreal ant community parameters that were measured. Specifically, species richness $(\mathrm{F}<1.88, \mathrm{P}>0.14$ for treatment and the year by treatment interaction; Figure 22), species composition (Pseudo-F $<1.06, \mathrm{P}>0.33$ for treatment in both the initial and final surveys), and $\beta$-diversity $(\mathrm{F}<2.15, \mathrm{P}>0.13$ in both 
initial and final surveys) were all unaffected by the addition of artificial nests in trees with and without lianas.

\section{DISCUSSION}

Here I show that lianas maintain arboreal ant species richness by providing connectivity among tree crowns. The decrease in ant species richness associated with liana removal can be mitigated by the addition of a climbing rope which functioned solely as a connective structure between tree crowns. These results in combination with other work in Peru (Davidson et al. 1988) and the Brazilian cerrado (Powell et al. 2011) highlight how connective corridors shape arboreal ant community assembly by expanding the available habitat of an ant colony to multiple tree crowns. Variability in the importance of connectivity to arboreal ant communities among the three studies is likely explained in part by differences in canopy height. For example, Powell and colleagues detected only a weak trend towards less diverse arboreal ant communities in less connected trees. Trees in the cerrado often range between 3-8 $\mathrm{m}$ tall (de Castro and Kauffman 1998) compared to an average of $30 \mathrm{~m}$ in the BCNM (Putz 1984b). Many species of arboreal ants in the high forest canopy rarely descend to the forest floor (Camargo and Oliveira 2012) and thus should be more reliant on lianas to connect neighboring tree crowns (Yanoviak 2015). This is potentially not the case in the cerrado where the short tree stature presumably would not impose a major impediment to movement among trees.

The removal of lianas created a positive species-area relationship between ant species richness and tree size (basal area) similar to the trend previously recorded in trees lacking lianas (Adams et al. 2017). This result is notable for multiple reasons. First, competitive interactions among ants are generally viewed as the major driver of ant diversity in arboreal systems (Dejean et al. 2007, Sanders et al. 2007). The current 
study does not preclude competition as an important mechanism structuring communities, but indicates that physical features of the environment also can predict local species richness. Habitat size and connectivity are historically strong predictors of species richness in other insular systems both experimental (Huffaker 1958, Gonzalez et al. 1998) and natural (Rahel 2007). Additionally, because ant colonies can persist for decades-much longer than the duration of this study (Henderson et al. 1989, Ingram et al. 2013)-the response of species richness to liana removal within just three years further highlights the importance of the structural contributions lianas make to ant community dynamics.

The results of the nest addition experiment show that nest site availability differs between trees with and without lianas but still has little effect on the structure of arboreal ant communities in this system. Nest sites are more frequently occupied in trees without lianas indicating that trees without lianas provide fewer nesting resources. However, colonization of artificial nests generally was due nest expansion by polydomous, resident ants likely precluded the establishment of new, non-resident ant species. Consequently, the presence of additional nest sites did not increase ant species richness or change ant species composition in a tree crown. This outcome corroborates the findings of other studies that focused on nest site limitation (Philpott and Foster 2005, Powell et al. 2011). Other factors, such as tree crown connectivity or antagonistic species interactions, are more important to the dynamics of arboreal ant communities (Blüthgen and Stork 2007, Yanoviak 2015, Adams et al. 2017, Camarota et al. 2016).

Liana abundance is increasing in BCNM (Schnitzer and Bongers 2011, Schnitzer et al. 2012) and will likely affect the structure of arboreal ant communities (Yanoviak 2015). Specifically, arboreal ant species richness per tree crown should increase with increased liana abundance. However, there is no evidence in this study to support a predicted decrease in overall $\beta$ or $\gamma$ diversity, as would be expected by connecting a 
normally discontinuous environment like coral reefs or lakes (Tockner et al. 1999, Cowen et al. 2000, Rahel 2007). In the future, experimental additions of ropes in naturally liana-free trees would further address the importance of connectivity for the maintenance of arboreal ant community structure. Additionally, other types of artificial nest designs should also be tested as occupations rates have varied among distinct types of nests (Philpott and Foster 2005, Yanoviak 2015). 


\section{Tables}

Table 6. The 105 ant species collected during this study. Species found occupying artificial nests are marked with an "X". Morphospecies are marked as "sp\#" and match those from Adams et al. (2017).

\begin{tabular}{|c|c|c|}
\hline Subfamily & Species & Nests \\
\hline \multirow[t]{14}{*}{ Dolichoderinae } & Azteca brevis & \\
\hline & Azteca flavigaster & $\mathrm{X}$ \\
\hline & Azteca forelii & $\mathrm{X}$ \\
\hline & Azteca instabilis & $\mathrm{X}$ \\
\hline & Azteca nigricans & $\mathrm{X}$ \\
\hline & Azteca pilosula & $\mathrm{X}$ \\
\hline & Azteca trigona & $\mathrm{X}$ \\
\hline & Dolichoderus bispinosus & $\mathrm{X}$ \\
\hline & Dolichoderus debilis & $\mathrm{X}$ \\
\hline & Dolichoderus lamellosus & \\
\hline & Dolichoderus laminatus & $\mathrm{X}$ \\
\hline & Dolichoderus lutosus & \\
\hline & Tapinoma litorale & \\
\hline & $\begin{array}{l}\text { Tapinoma melanocephalum } \\
\text { Technomyrmex fulvus }\end{array}$ & $\mathrm{X}$ \\
\hline Ecitoninae & Eciton hamatum & \\
\hline \multirow[t]{3}{*}{ Ectatomminae } & Ectatomma ruidum & \\
\hline & Ectatomma tuberculatum & \\
\hline & Gnamptogenys concinna & \\
\hline \multirow[t]{16}{*}{ Formicinae } & Brachymyrmex coactus & \\
\hline & Brachymyrmex pictus & $\mathrm{X}$ \\
\hline & Camponotus atriceps & $\mathrm{X}$ \\
\hline & Camponotus brevis & \\
\hline & Camponotus cameroni & $\mathrm{X}$ \\
\hline & Camponotus canescens & $\mathrm{X}$ \\
\hline & Camponotus claviscapus & $\mathrm{X}$ \\
\hline & Camponotus curviscapus & \\
\hline & Camponotus linnaei & $\mathrm{X}$ \\
\hline & Camponotus mucronatus & \\
\hline & Camponotus novogranadensis & $\mathrm{X}$ \\
\hline & Camponotus pittieri & \\
\hline & Camponotus sanctaefidei & \\
\hline & Camponotus senex & $\mathrm{X}$ \\
\hline & Camponotus sericeiventris & $\mathrm{X}$ \\
\hline & Camponotus sp1 & \\
\hline
\end{tabular}


Camponotus textor

Nylandaria caeciliae

Nylandaria guatemalensis

Nylandaria steinheili

$\mathrm{X}$

Paratrechina longicornis

Myrmicinae

Acromyrmex vulcanus

Cephalotes atratus

Cephalotes basalis

Cephalotes christopherseni

$\mathrm{X}$

Cephalotes cordiventris

Cephalotes foliaceus

$\mathrm{X}$

$\mathrm{X}$

Cephalotes grandinosus

Cephalotes maculatus

Cephalotes minutus

Cephalotes porrasi

Cephalotes setulifer

Cephalotes umbraculatus

Crematogaster acuta

$\mathrm{X}$

Crematogaster brasileinsis

$\mathrm{X}$

Crematogaster carinata

Crematogaster crinosa

Crematogaster crucis

Crematogaster curvispinosa

Crematogaster limata

Crematogaster rochai

Crematogaster stollii

Monomorium pharaonis

Nesomyrmex pleuriticus

Pheidole bilimeki

Pheidole boliviana

Pheidole caltrop

Pheidole flavens

Pheidole perpusilla

Pheidole sp1

Pheidole sp2

Pheidole susannae

Procryptocerus belti

Procryptocerus hylaeus

Solenopsis picea

X

Solenopsis sp2

Solenopsis sp3

Solenopsis zeteki

Wasmannia auropunctata

Wasmannia rochai

Xenomyrmex panamanus 


\begin{tabular}{|c|c|c|}
\hline \multirow{9}{*}{$\begin{array}{l}\text { Paraponerinae } \\
\text { Ponerinae }\end{array}$} & \multicolumn{2}{|l|}{ Paraponera clavate } \\
\hline & \multicolumn{2}{|l|}{ Neoponera antecurvata } \\
\hline & \multicolumn{2}{|l|}{ Neoponera carinulata } \\
\hline & \multicolumn{2}{|l|}{ Neoponera crenata } \\
\hline & \multicolumn{2}{|l|}{ Neoponera foetida } \\
\hline & \multicolumn{2}{|l|}{ Neoponera striatinodus } \\
\hline & \multicolumn{2}{|l|}{ Neoponera villosa } \\
\hline & \multicolumn{2}{|l|}{ Odontomachus ruginodis } \\
\hline & \multicolumn{2}{|l|}{ Platythyrea pilosula } \\
\hline \multirow[t]{16}{*}{ Pseudomyrmecinae } & \multicolumn{2}{|l|}{ Pseudomyrmex beccarii } \\
\hline & \multicolumn{2}{|l|}{ Pseudomyrmex browni } \\
\hline & \multicolumn{2}{|l|}{ Pseudomyrmex duckei } \\
\hline & \multicolumn{2}{|l|}{ Pseudomyrmex ejectus } \\
\hline & Pseudomyrmex elongatus & $\mathrm{X}$ \\
\hline & \multicolumn{2}{|l|}{ Pseudomyrmex euryblemma } \\
\hline & Pseudomyrmex gracilis & $\mathrm{X}$ \\
\hline & \multirow{2}{*}{\multicolumn{2}{|c|}{ Pseudomyrmex ita }} \\
\hline & Pseudomyrmex kuenckeli & \\
\hline & Pseudomyrmex oculatus & $\mathrm{X}$ \\
\hline & Pseudomyrmex rochai & \\
\hline & Pseudomyrmex simplex & \\
\hline & Pseudomyrmex sp2 & \\
\hline & Pseudomyrmex spicules & \\
\hline & Pseudomyrmex tenuis & \\
\hline & Pseudomyrmex tenuissimus & $\mathrm{X}$ \\
\hline
\end{tabular}


Table 7. Pairwise comparisons of species composition between different experimental treatment levels in the pre-treatment and final surveys of the liana removal experiment. Differences between individual treatment pairs were the same in both the pre-treatment and final surveys of the arboreal ant communities.

\begin{tabular}{llrr}
\hline Survey & Pairwise Comparisons & \multicolumn{1}{c}{$\boldsymbol{t}$} & \multicolumn{1}{c}{$\boldsymbol{P}$} \\
\hline Pre-treatment & Control - Removal & 1.1207 & 0.181 \\
Pre-treatment & Control - Ropes & 1.3548 & 0.0088 \\
Pre-treatment & Control - Ropes + Removal & 1.4285 & 0.0017 \\
Pre-treatment & Removal - Ropes & 1.03 & 0.3678 \\
Pre-treatment & Removal - Ropes + Removal & 1.2842 & 0.173 \\
Pre-treatment & Ropes - Ropes + Removal & 1.1253 & 0.1538 \\
Final & Control - Removal & 1.0698 & 0.2547 \\
Final & Control - Ropes & 1.3119 & 0.0158 \\
Final & Control - Ropes + Removal & 1.336 & 0.0103 \\
Final & Removal - Ropes & 1.0304 & 0.3709 \\
Final & Removal - Ropes + Removal & 1.0642 & 0.295 \\
Final & Ropes - Ropes + Removal & 1.1144 & 0.1921 \\
\hline
\end{tabular}




\section{Figure Captions}

Figure 5. Location of the study site. Images respectively show Panama, the Panama Canal Zone, and the Barro Colorado Nature Monument. Each subsequent photograph is a magnification of the area outlined in red in the previous photograph.

Figure 6. A Dipteryx oleifera tree with a climbing rope installed and artificial nests spread throughout the crown.

Figure 7. Liana stems in the central fork of a Dipteryx oleifera tree.

Figure 8. The author secured in a tree crown using the single rope technique and canopy slings.

Figure 9. The two-by-two factorial design used for the connectivity experiment. Lianas are represented by the brown lines. Ropes are represented by the yellow line. Each section of the factorial contains 10 replicate trees.

Figure 10. Ants walking across one of the experimental ropes.

Figure 11. The two-by-two factorial design used for the artificial nest experiment. Lianas are represented by the brown lines. Artificial nests are represented by the brown boxes. Each section of the factorial contains 10 replicate trees.

Figure 12. A schematic of the artificial nest design. 
Figure 13. A photograph of the artificial nests in a liana-free tree two years after the nest addition treatment.

Figure 14. A photograph of an artificial nest showing the metal wire used to connect the nest to a tree branch.

Figure 15. The mean $( \pm \mathrm{SE})$ change in species richness $(\Delta \mathrm{S})$ each year for three years following the application of the four connectivity treatments. Annual means are calculated from $n \geq 9$ trees per treatment per year. Treatments sharing a letter indicate means that do not differ.

Figure 16. Arboreal ant species richness compared to tree size (as basal area) in removal trees prior to experimental treatment (top panel) and three years after liana removal (bottom panel). Ant species richness (Sa) did not correlate with tree size (A) in trees prior to liana removal. Three years following liana removal, species richness increased with tree size as described by the equation $\mathrm{Sa}=10.87 \mathrm{~A}^{0.156}\left(\mathrm{R}^{2}=0.41, \mathrm{P}=0.038\right)$.

Figure 17. The mean percent occupation $( \pm \mathrm{SE})$ of 15 artificial nests placed in trees with and without lianas ( $\mathrm{n} \geq 9$ for both liana statuses) after two years. A higher percentage of nests was occupied in trees that did not have lianas compared to trees that had lianas in their crowns.

Figure 18. A colony of Solenopsis picea occupying the hole used to hang an artificial nest from a tree branch. 
Figure 19. The entrance hole of an artificial nest sealed with carton by a colony of Crematogaster crinosa.

Figure 20. Major workers of Cephalotes foliaceus blocking the entrance of an artificial nest.

Figure 21. The waxy entrance to a stingless bee nest coming out of one of the artificial nests.

Figure 22. The mean $( \pm \mathrm{SE})$ change in species richness $(\Delta \mathrm{S})$ of the four nest addition treatments for each year for two years following treatment application. Annual means are calculated from $n \geq 9$ trees per treatment per year. Means within and between Years 1 and 2 do not differ. 
Figures

Figure 5 .
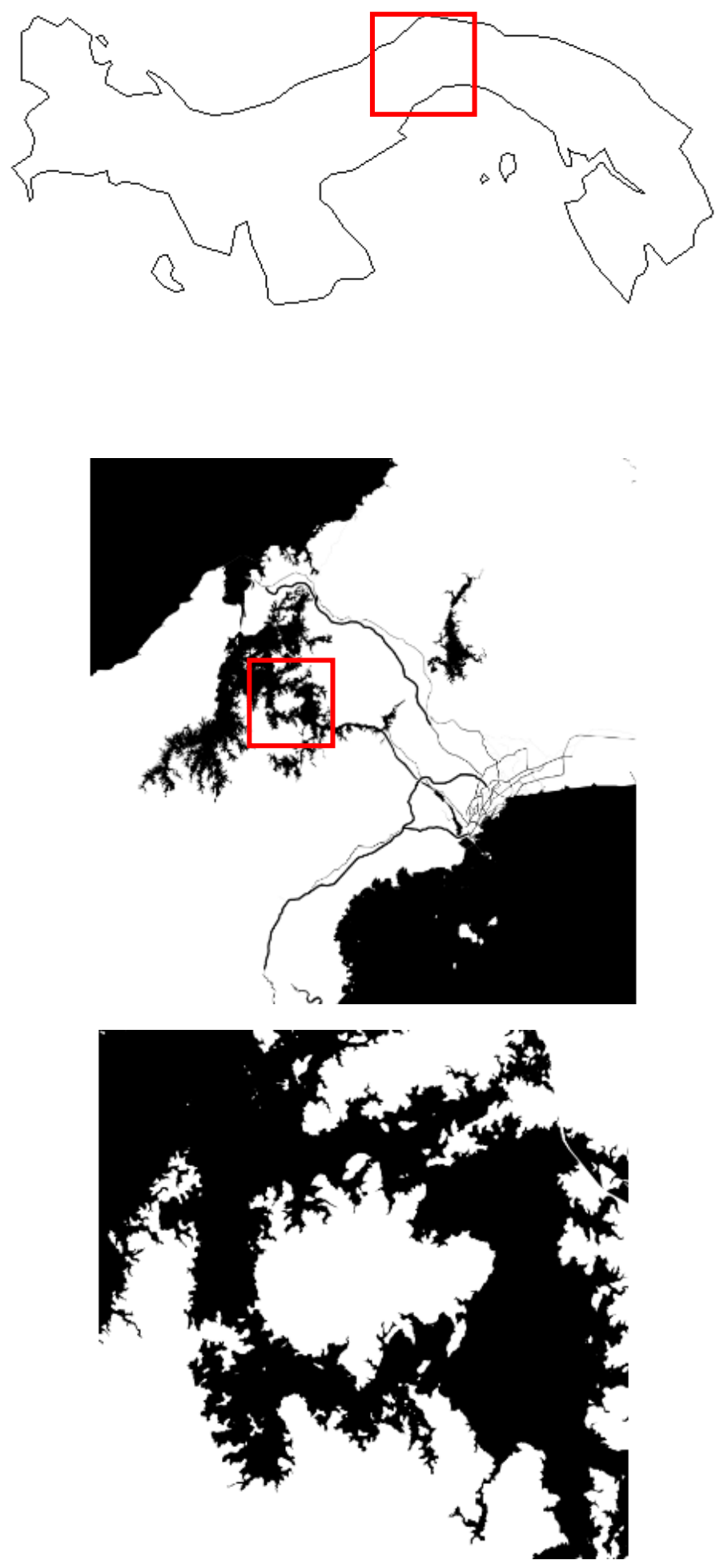
Figure 6.

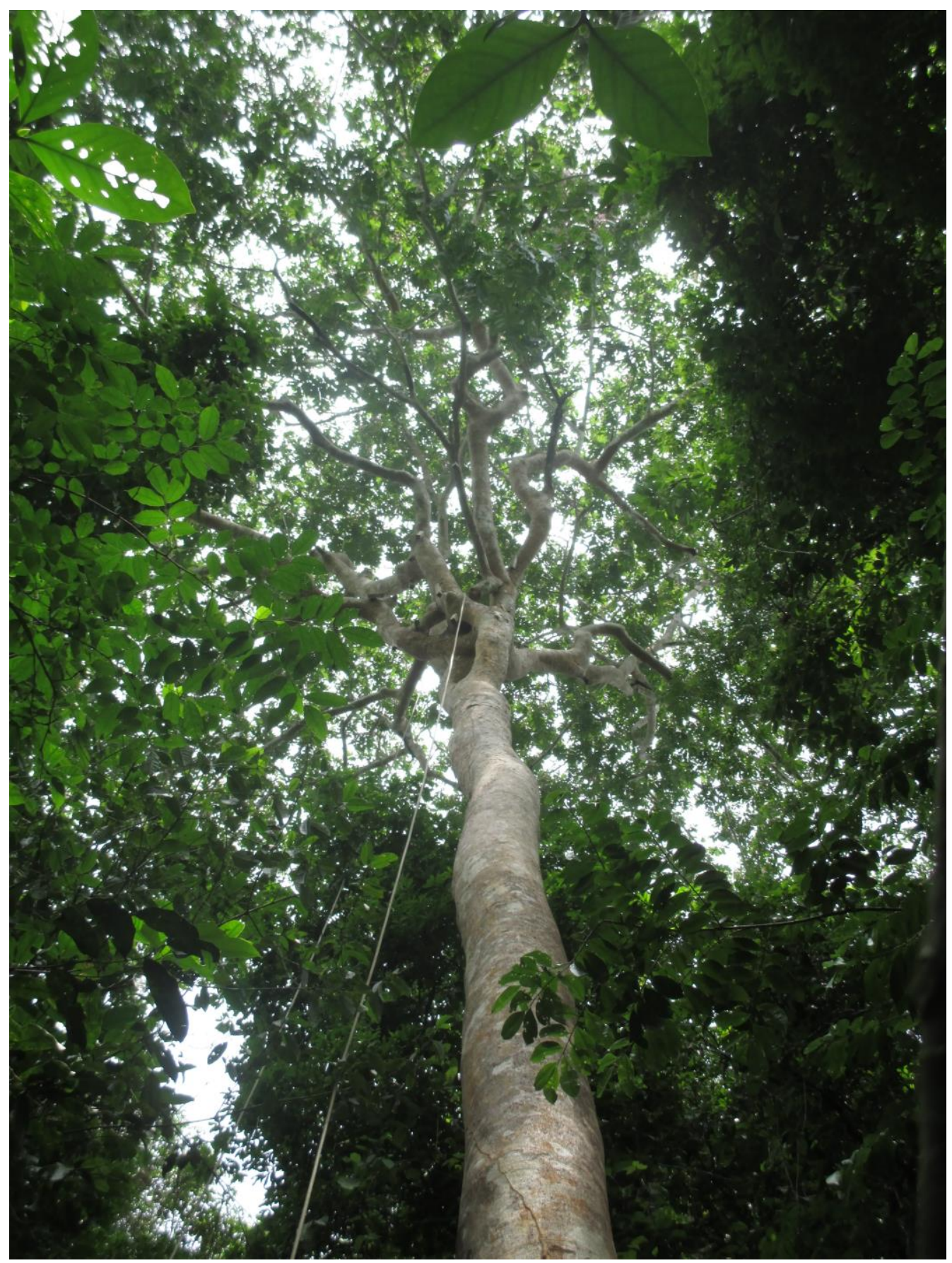


Figure 7.

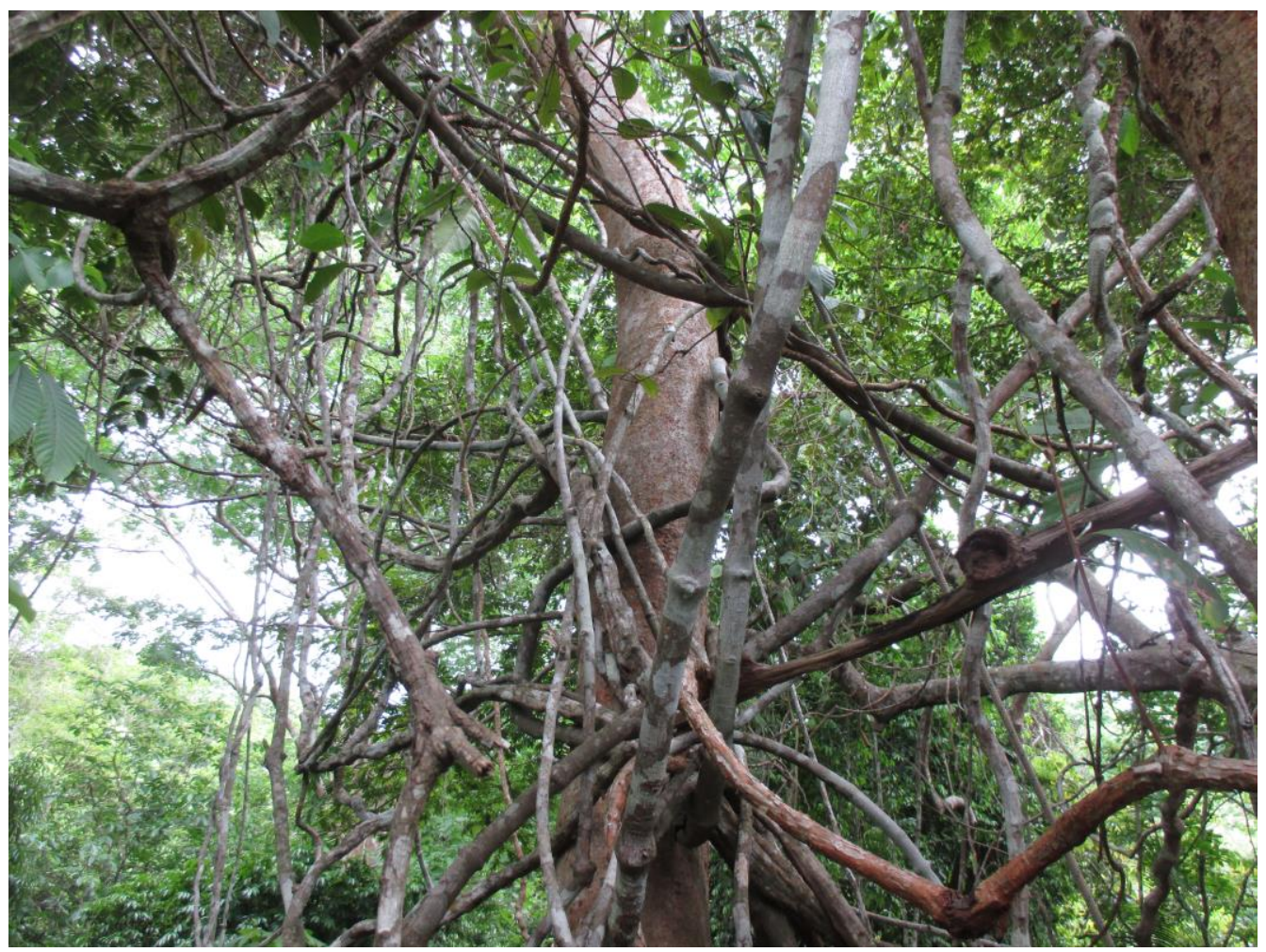


Figure 8.

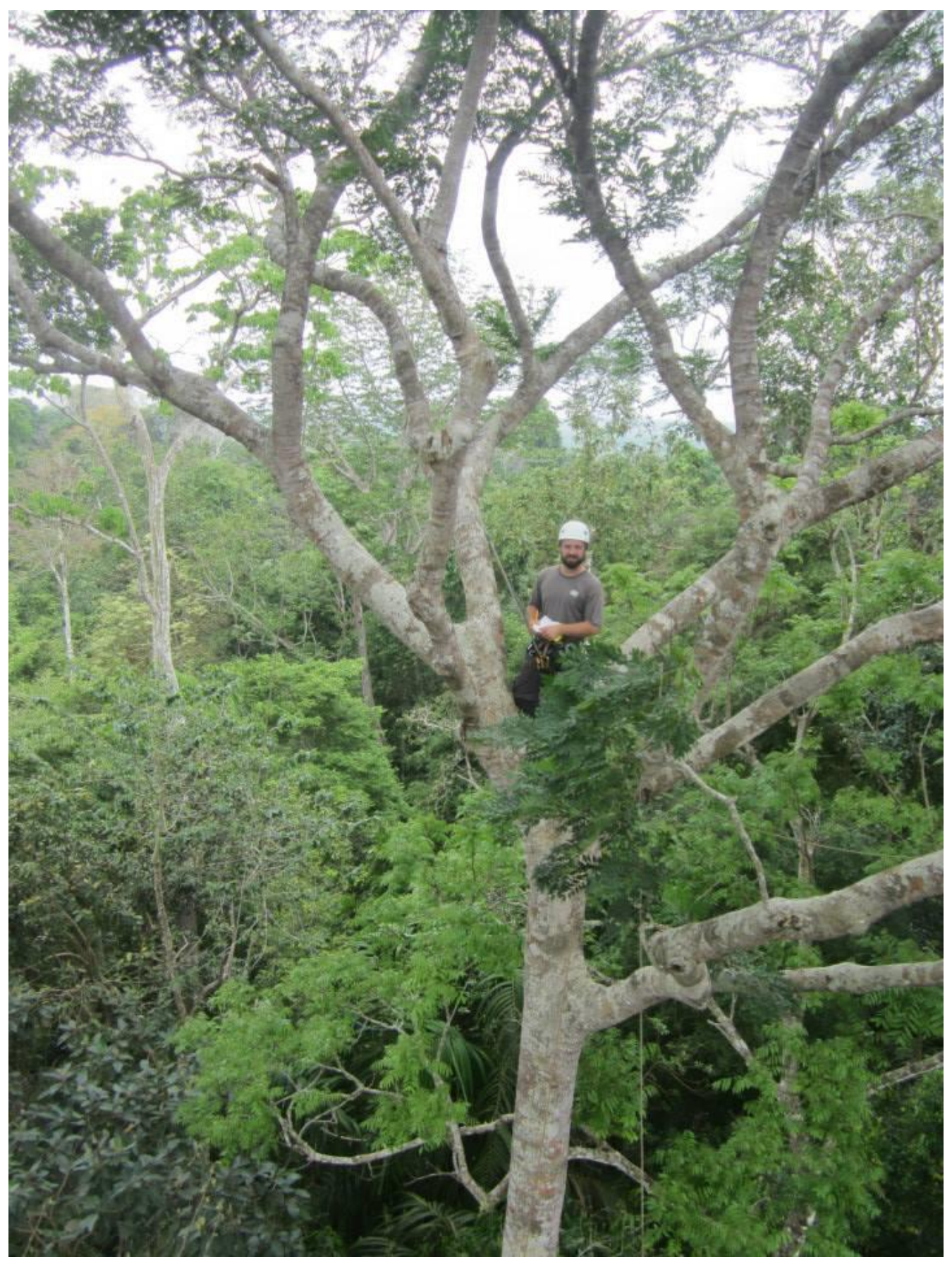


Figure 9.

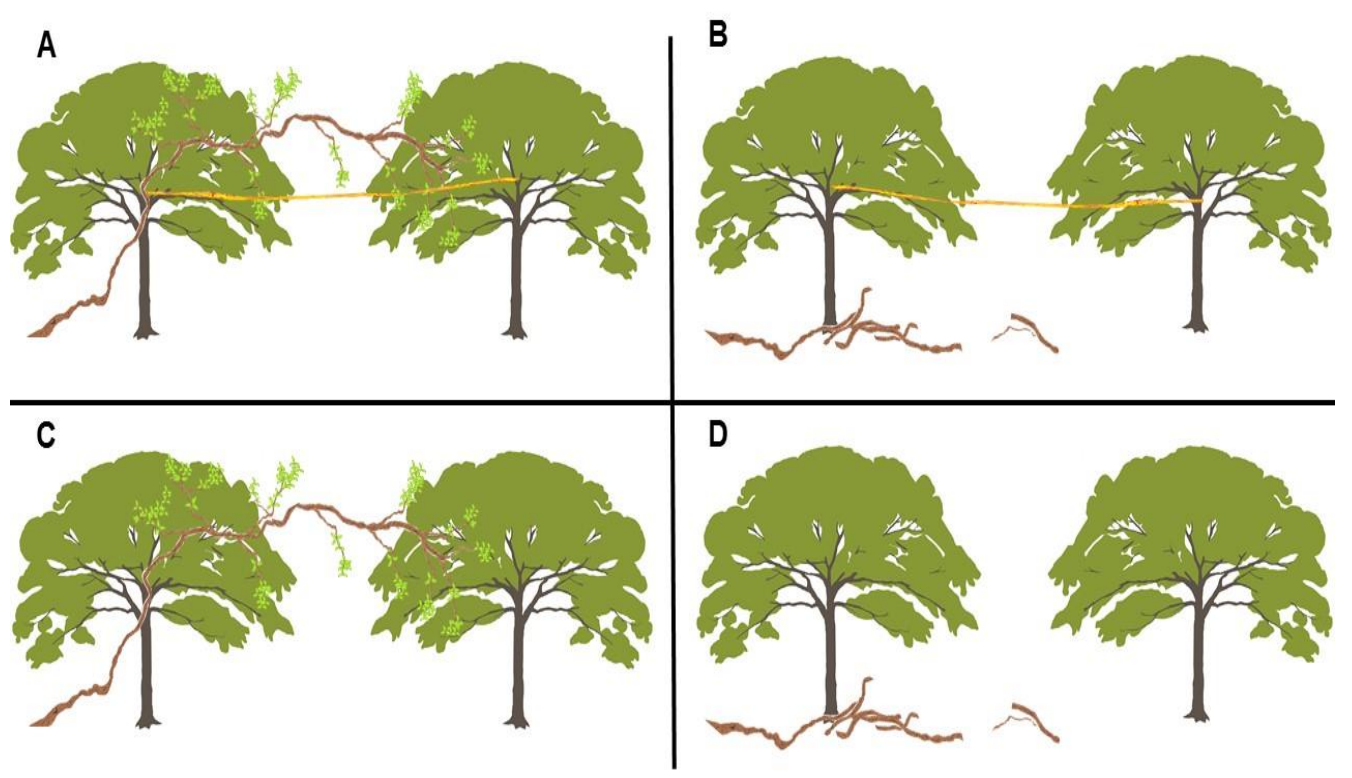

Figure 10.

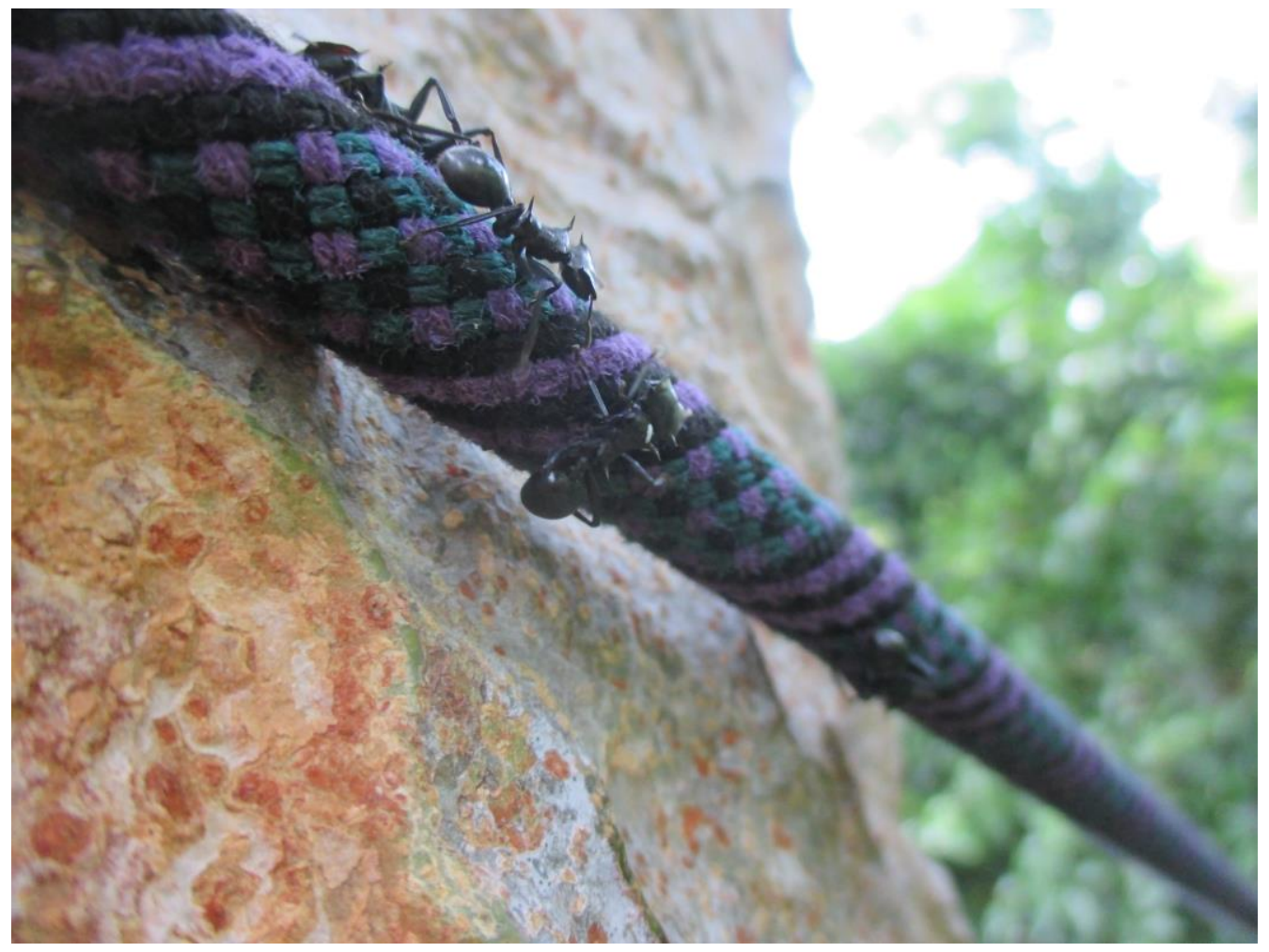


Figure 11.

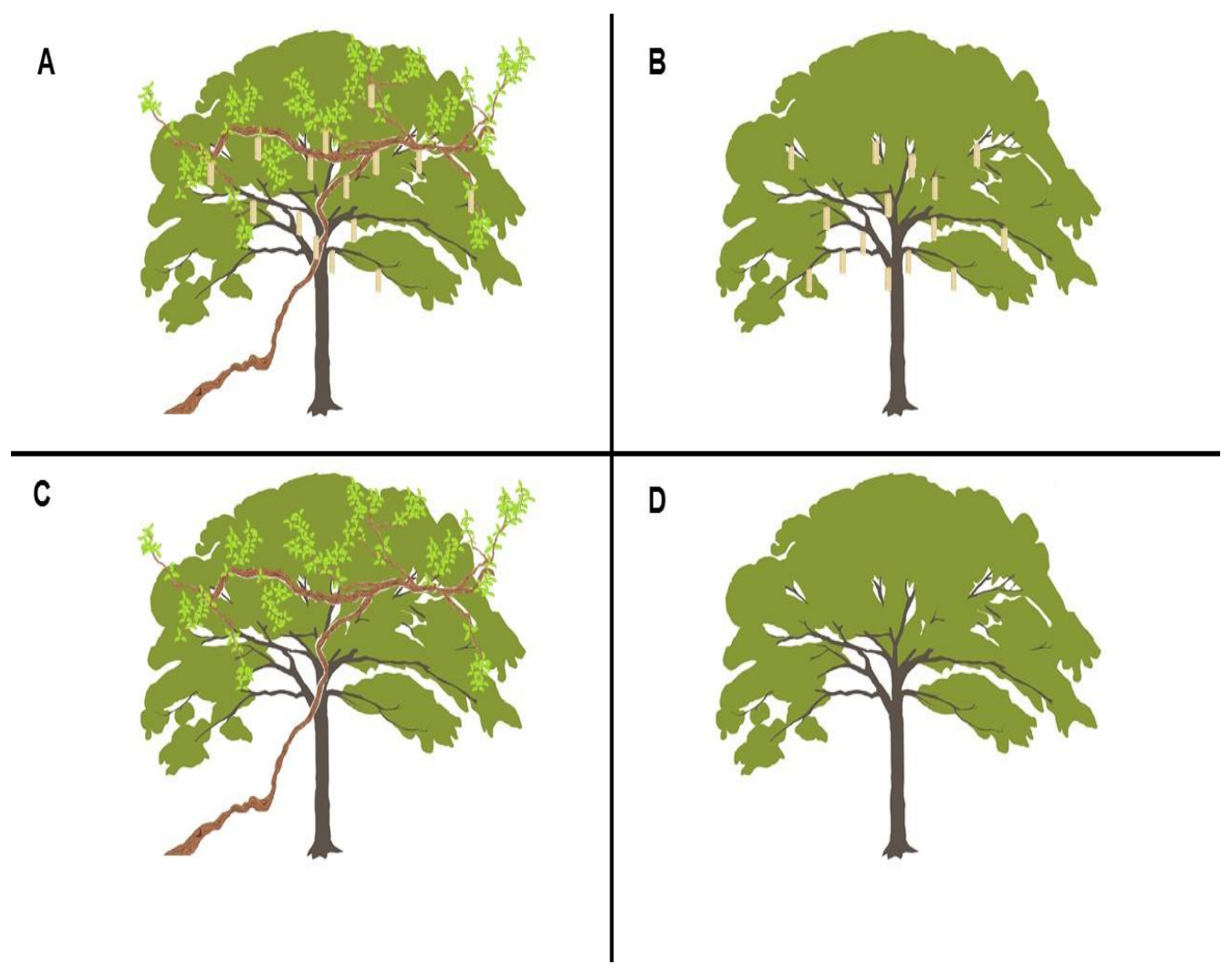

Figure 12.

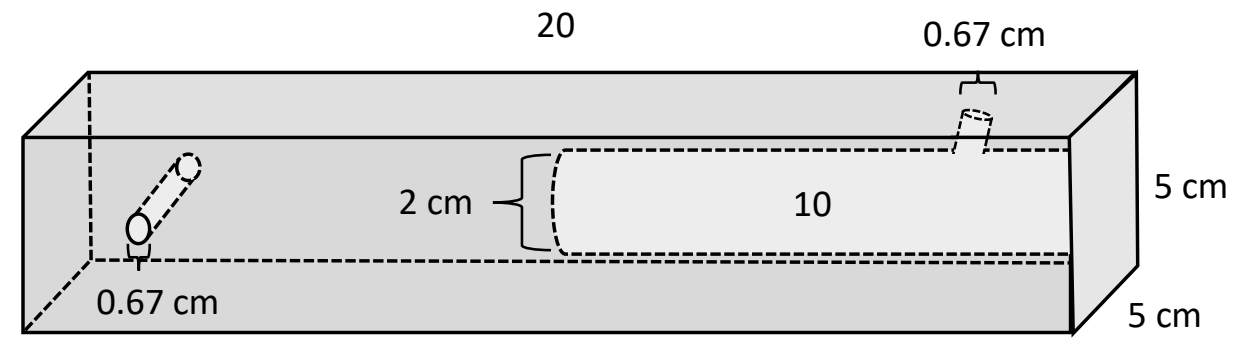


Figure 13.

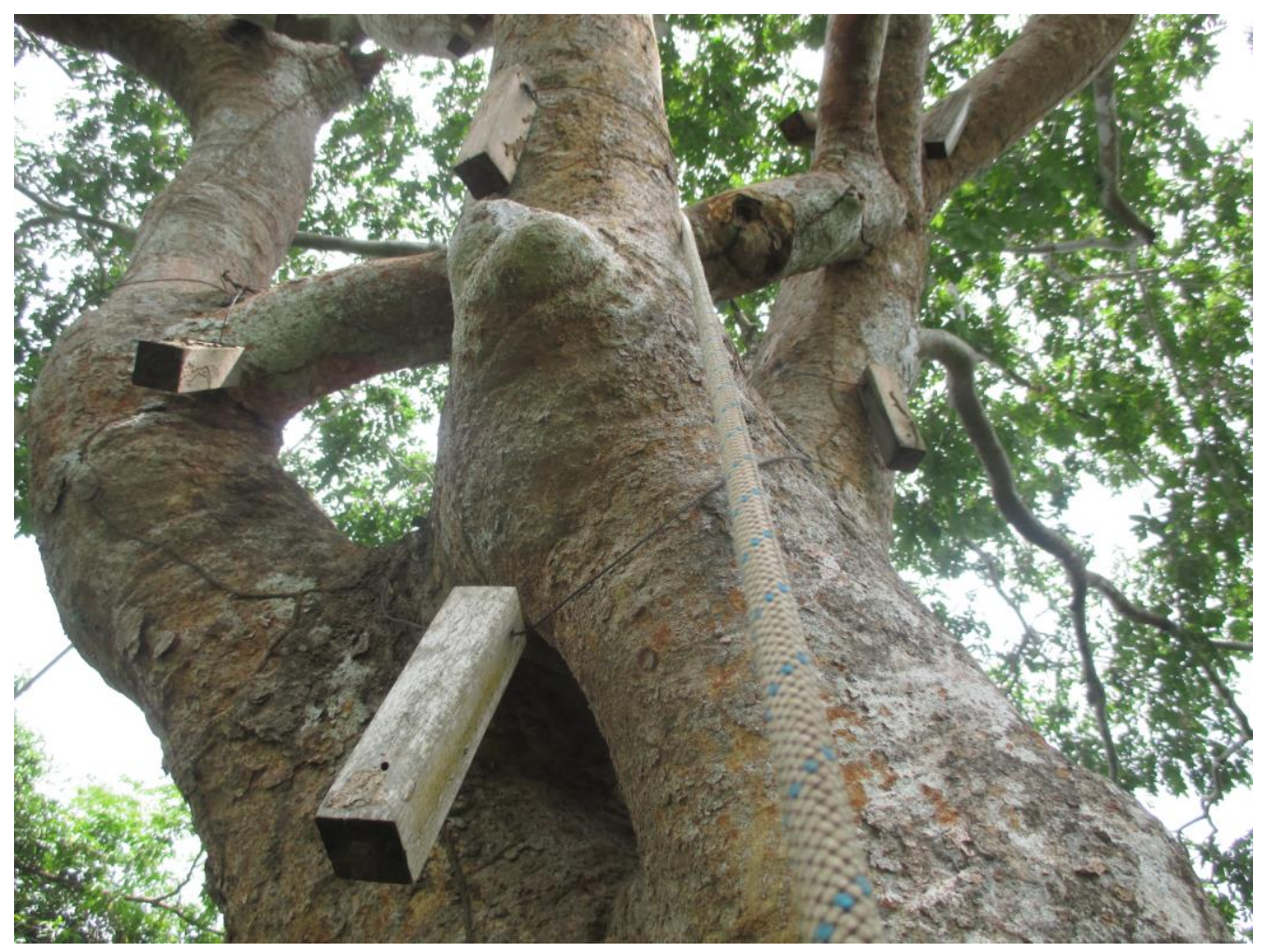

Figure 14.

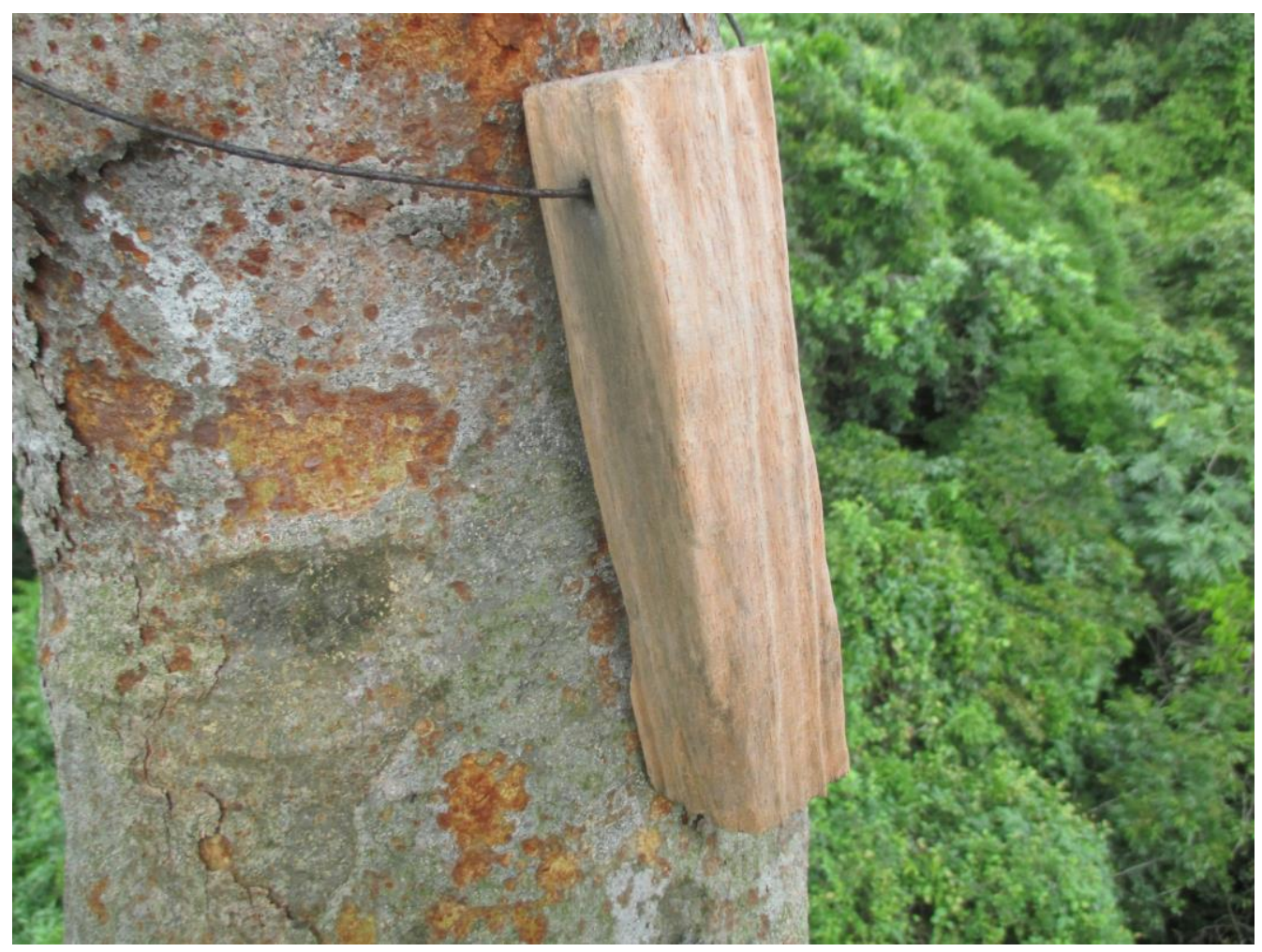


Figure 15.

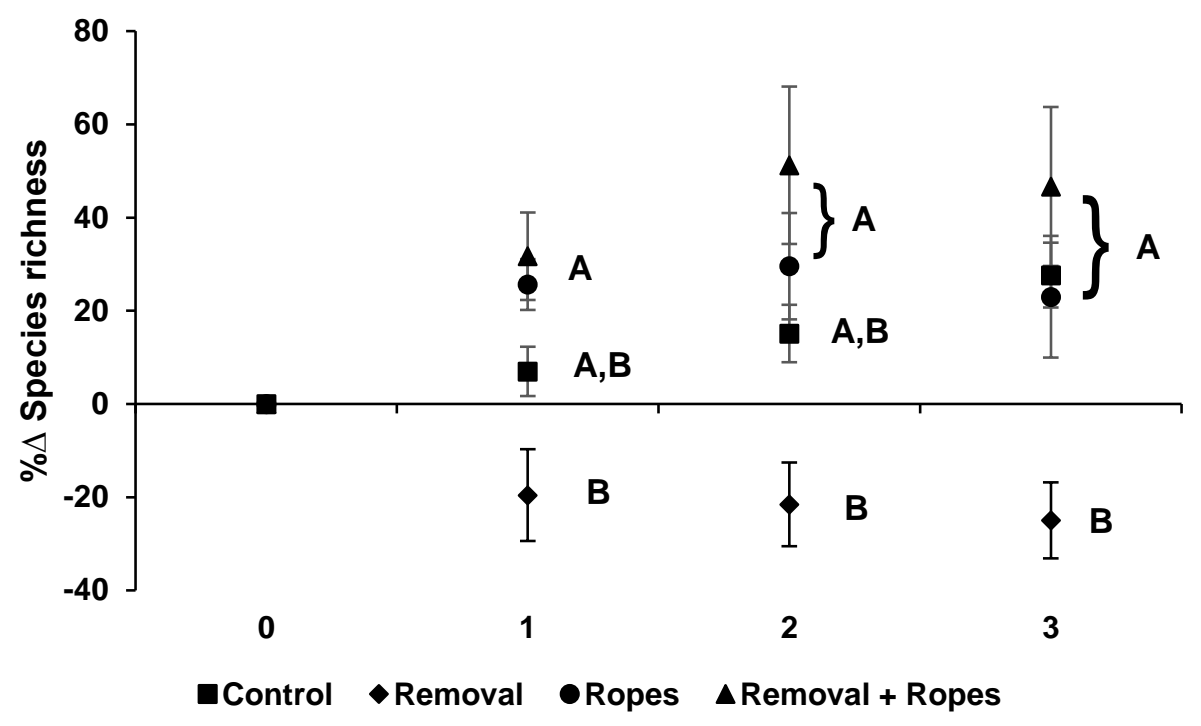


Figure 16.
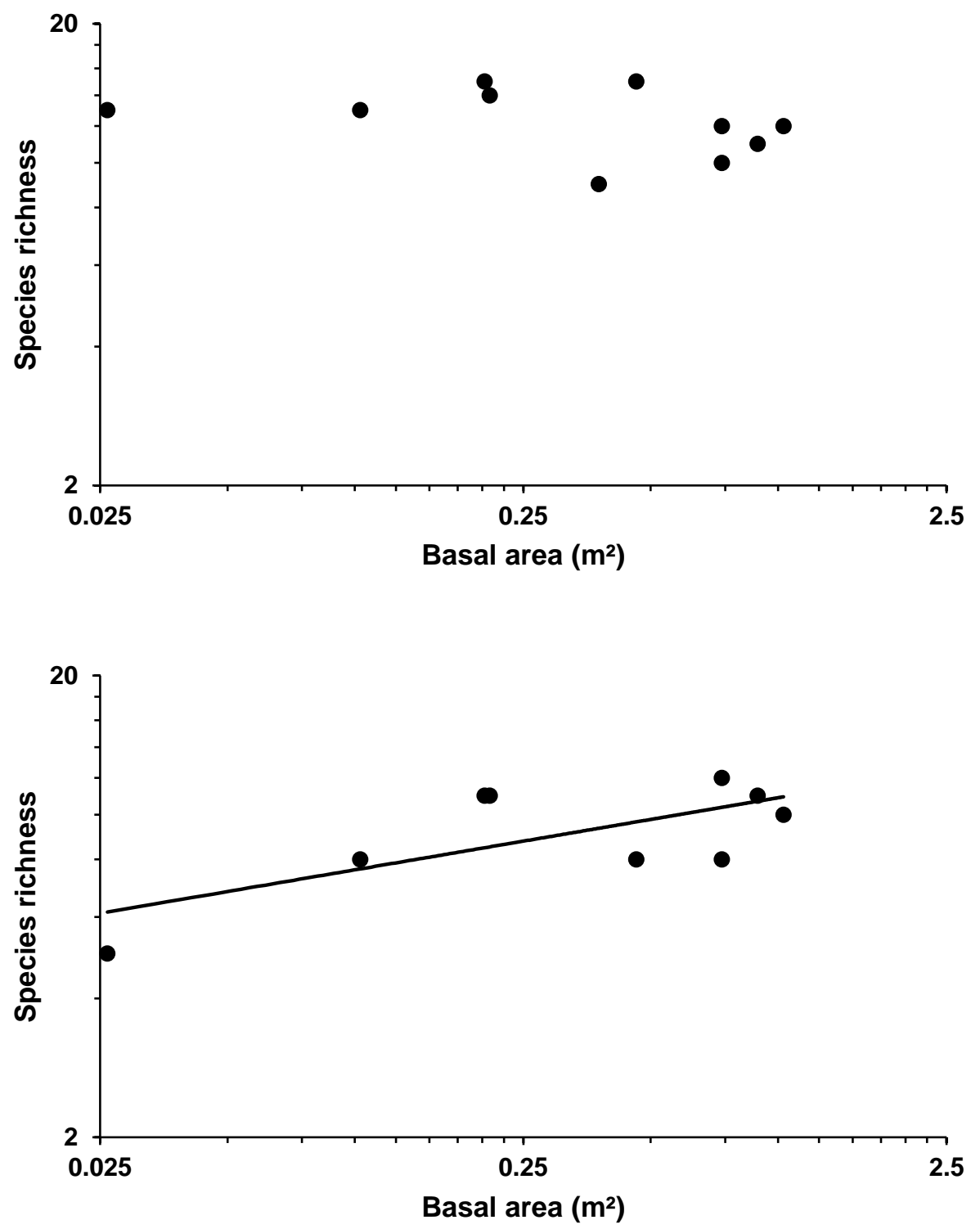
Figure 17.

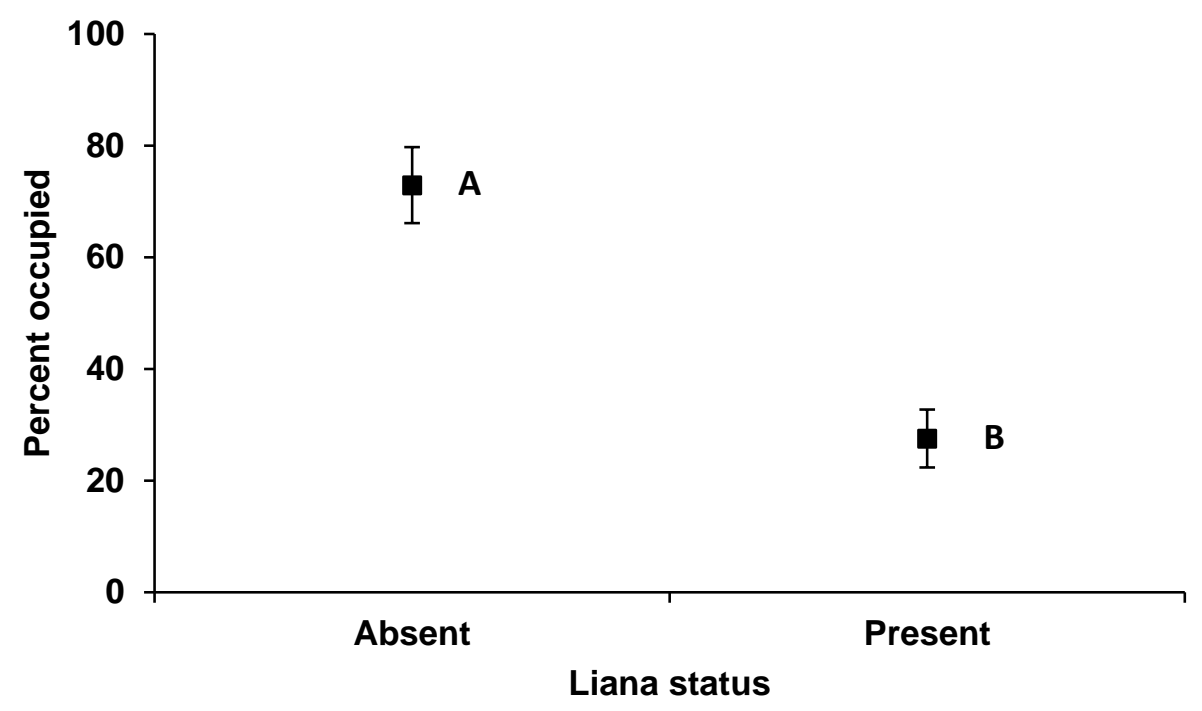


Figure 18.

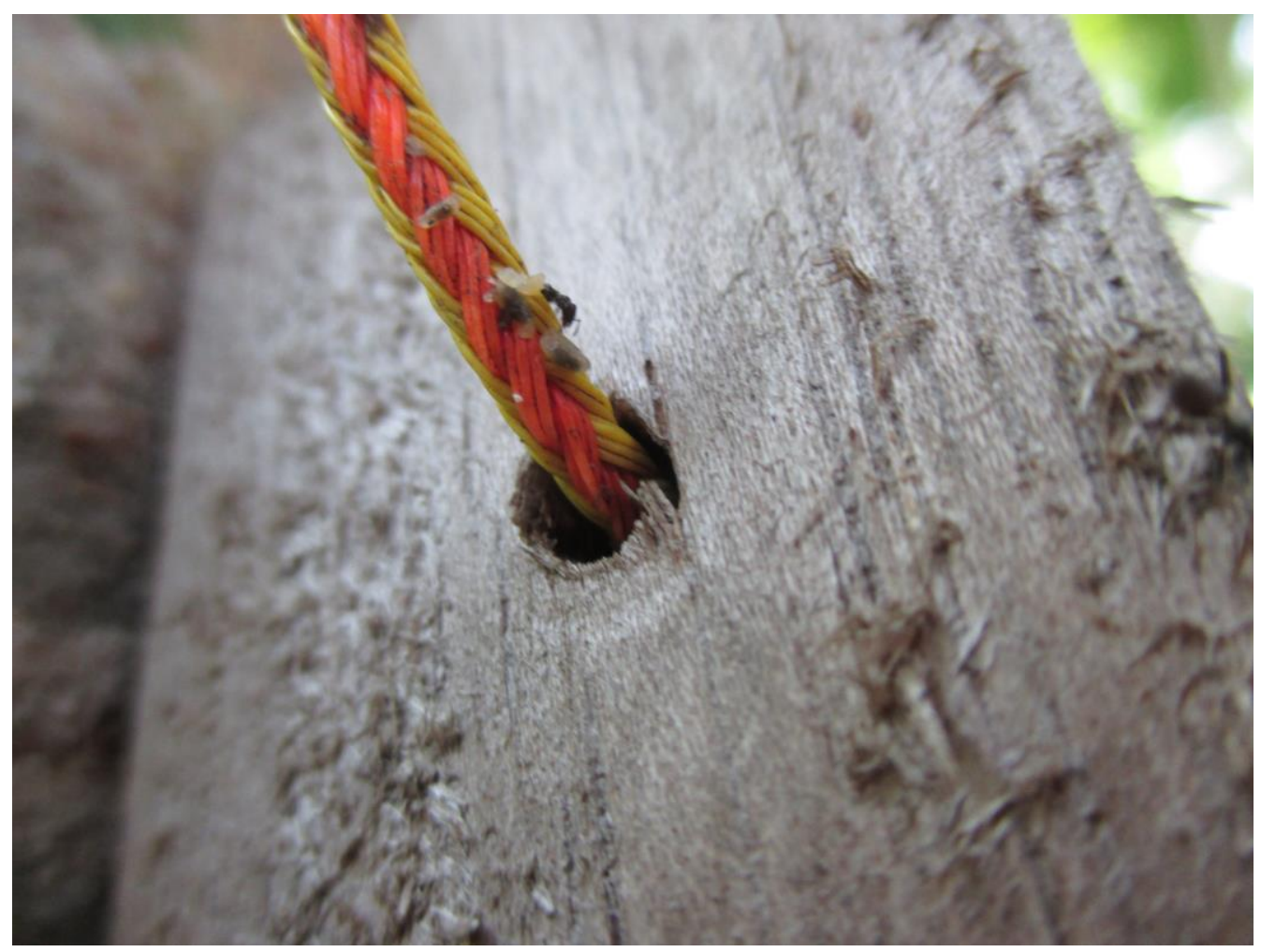

Figure 19.

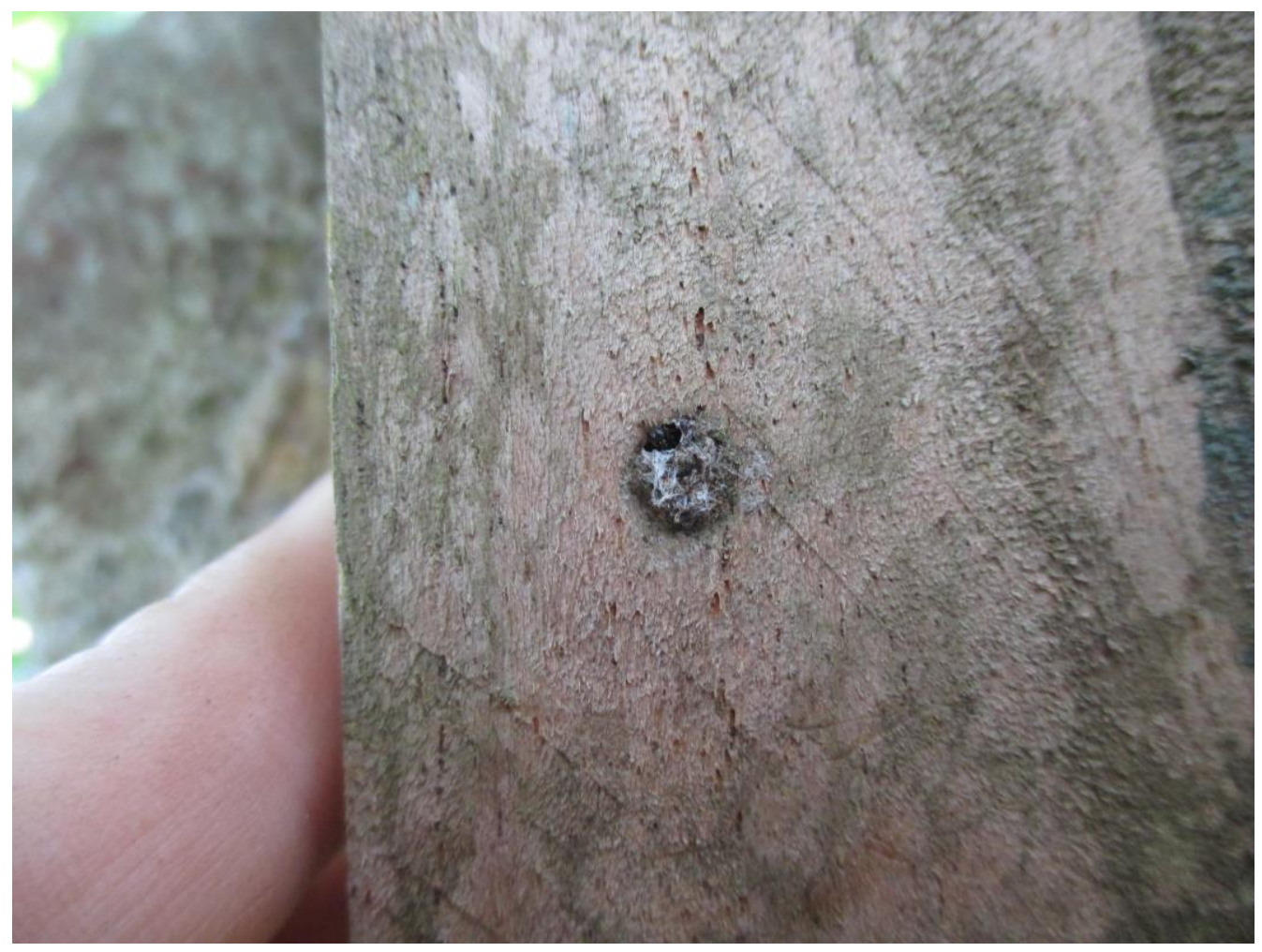


Figure 20.

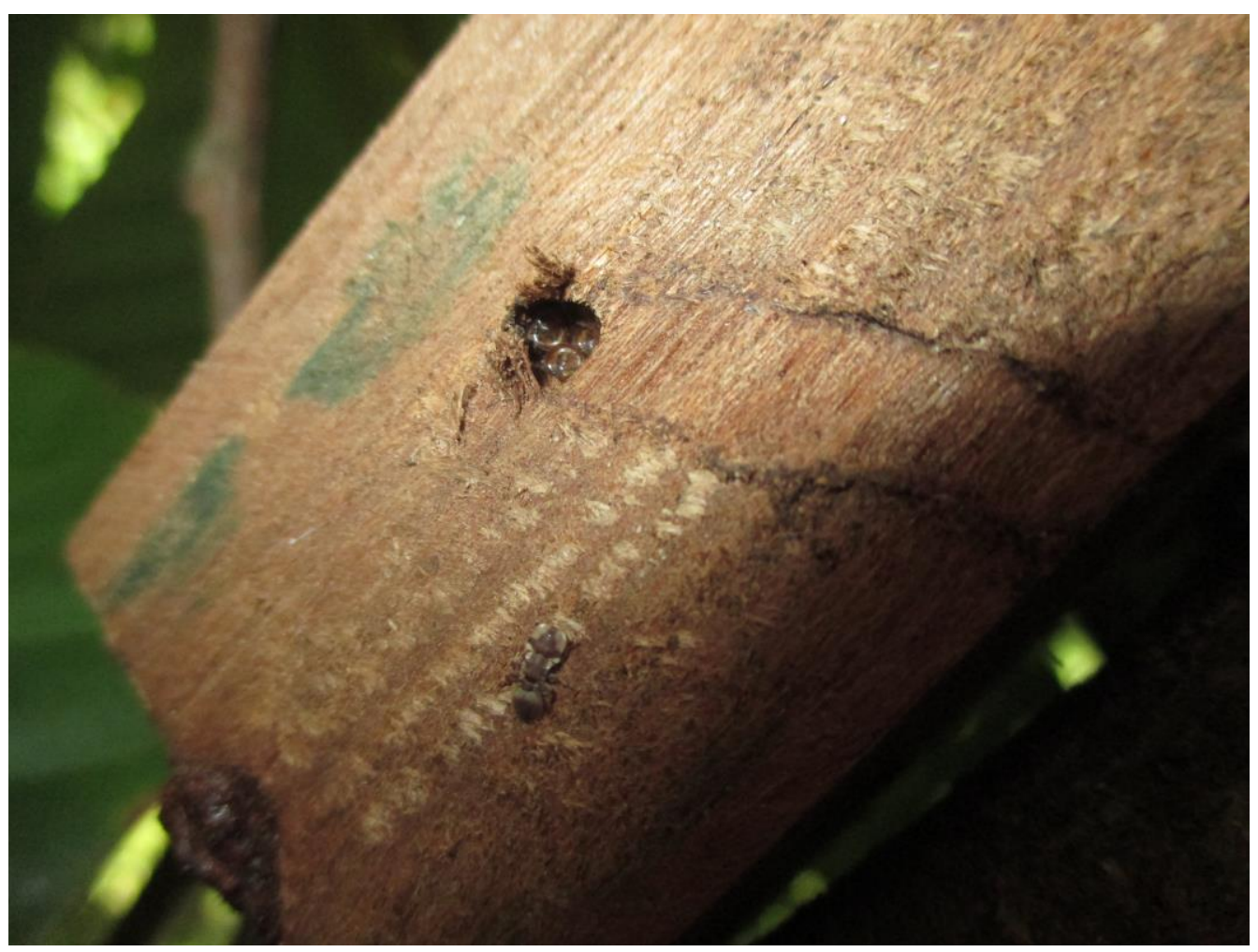

Figure 21.

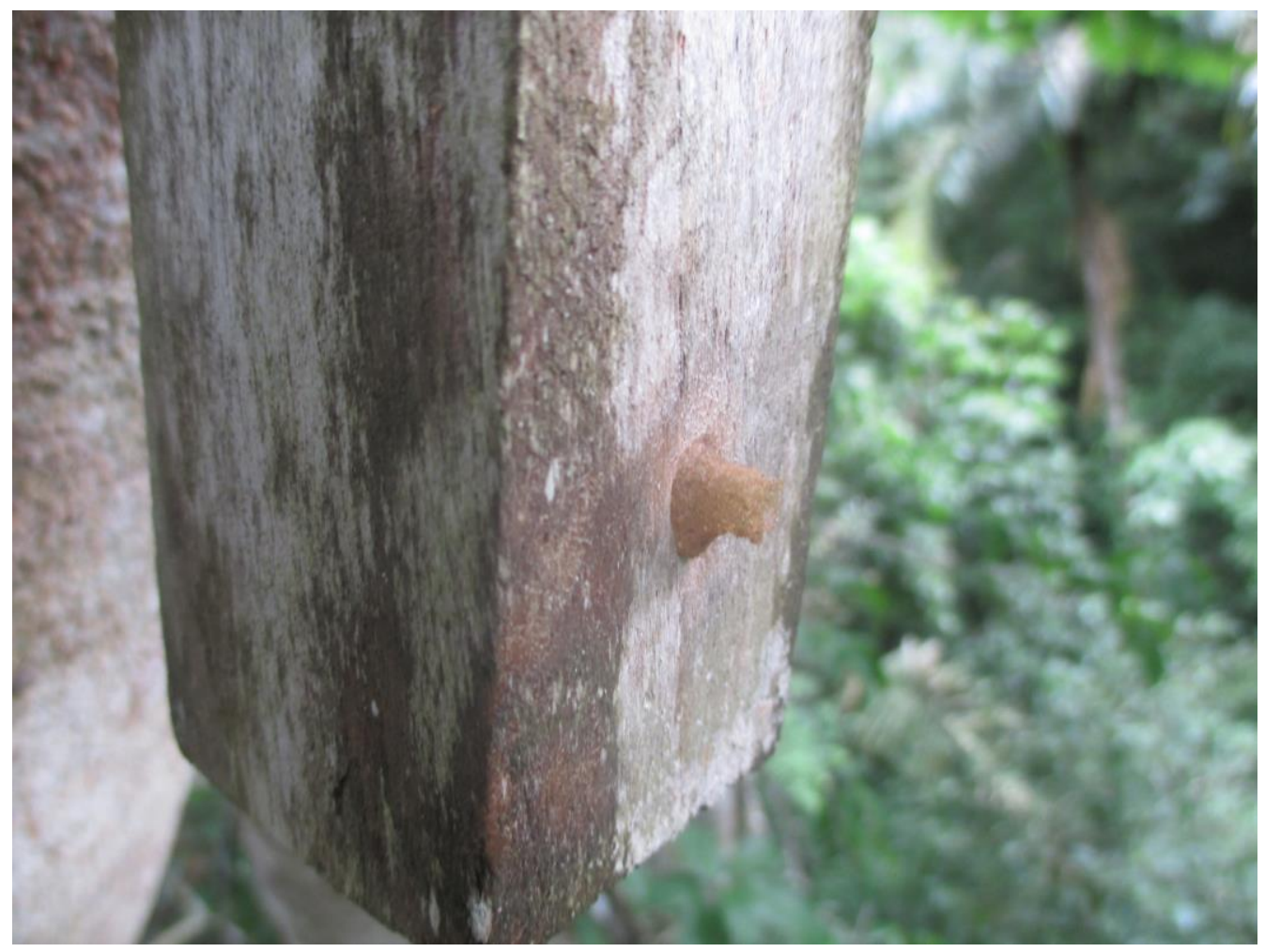


Figure 22.

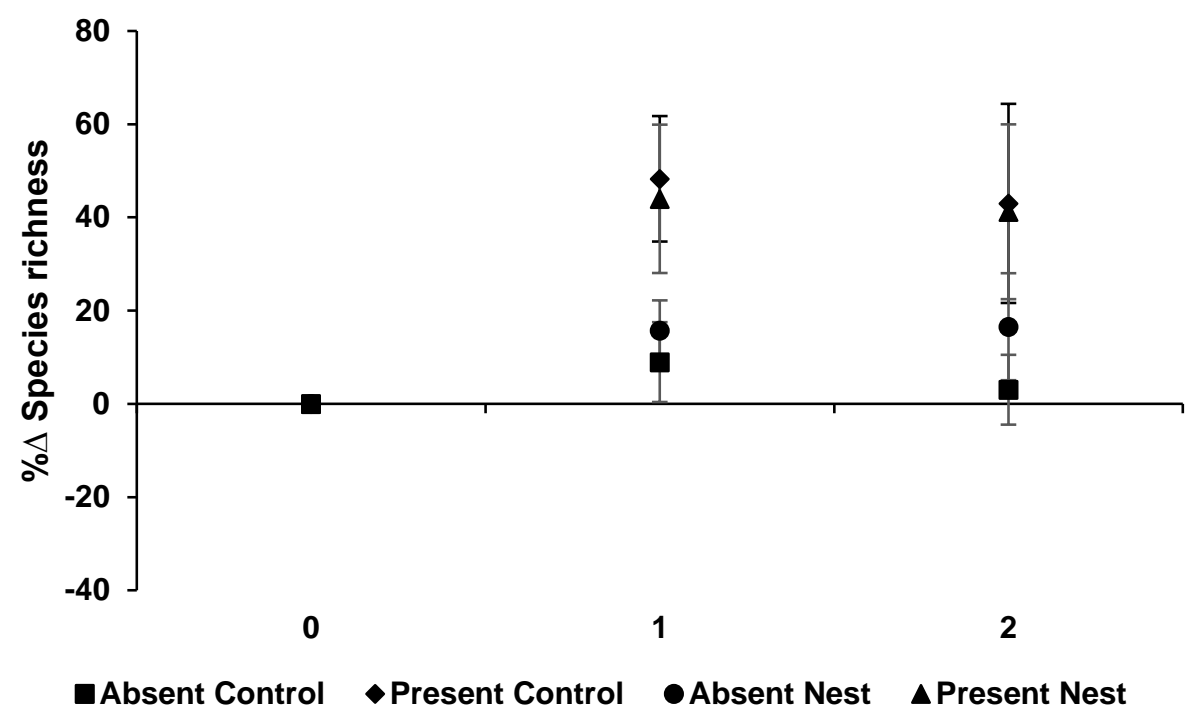




\section{CHAPTER IV}

\section{SUBSTRATE USE BY LEAF LITTER ANTS IN A NEOTROPICAL FOREST}

\section{SUMMARY}

Optimizing foraging efficiency is a key characteristic shared by successful organisms. Central-place foragers specifically increase foraging efficiency by selecting paths that minimize the costs of travel associated with resource acquisition. Ants are a model example of central-place foragers that general decrease travel costs by selecting paths that decrease time spent outside of the nest.

Some ant species will create cleared paths to move through complex substrates such as leaf litter on the forest floor. However, most ant species do not greatly modify the leaf litter environment and should rely on pre-existing pathways to optimize movement and maximize foraging efficiency. To test if ants preferentially used preexisting pathways in the leaf litter, I compared the abundance and species richness of ants walking on natural (exposed roots) and artificial (ropes) pathways compared to nearby locations in the leaf litter. To determine if using pre-existing pathways increases ant foraging efficiency, I also recorded the time it took for ants to discover and recruit to baits placed on pathways versus a haphazardly chosen location in the leaf litter. I also examined how increasing the number of pathways, increasing pathway connections, and decreasing leaf litter influenced how ants used pre-existing paths.

Ants appeared more frequently on exposed roots and artificial rope paths than on the surrounding leaf litter. However, using roots as paths did not facilitate faster 
resource discovery or decrease the time to recruitment. Increasing the number of paths in a given area increased species richness of ants at baits and decreased discovery and recruitment times to baits. Increasing the number of connections or removing leaf litter from the environment had no effect on ant presence or the discovery and recruitment to baits. In combination, this series of observations and experiments suggests that epigeic ants rely on pre-existing pathways to move through the leaf litter but that using these paths does not necessarily increase foraging efficiency.

\section{INTRODUCTION}

Organisms should optimize their expenditure of both time and energy to maximize acquisition of necessary resources (MacArthur and Pianka 1966, Werner and Hall 1974, Charnov 1976). Consequently, a foraging organisms should, on average, select paths that decrease the time and energy costs required to forage for resources (Pyke et al. 1977, Fewell 1988). Central-place foragers employ a strategy wherein an organism leaves a nest or roost, obtains food, and subsequently returns to the same nest or roost (Hamilton III and Watt 1970). For central-place foragers, both time and energy expenditures are reduced by foraging nearer to the nest (Hamilton et al. 1967), by developing specialized knowledge of local foraging areas (Kugler 1984, Fresneau 1985), and by selecting or creating short, simplified paths between resources patches and the nest (Soltz 1986, Bovet and Benhamou 1991, Beckers et al. 1992). Ants and other social Hymenoptera provide model examples of central-place foragers that select or create paths that optimize foraging efficiency (Kasuya 1982, Harkness and Maroudas 1985, Soltz 1986, Holder and Polis 1987, Hölldobler and Wilson 1990).

For ants, optimal foraging frequently is marked by decreasing foraging time (Fewell 1988, Burd 1996; but see Denny et al. 2001). As such, ants will select shorter (Beckers et al. 1992), straighter (Clay et al. 2010), less bifurcated (Garnier et al. 2009), or 
unimpeded paths (Couzin and Franks 2003, Dussutour et al. 2004, Dussutour et al. 2006) specifically to minimize congestion and increase individual ant running speed. For example, leaf-cutting ants and harvester ants will increase forager running speed by incorporating smooth, fallen branches into long-lasting, cleared paths called trunk trails (Fewell 1988, Farji-Brener and Sierra 1998, Howard 2001, Farji-Brener et al. 2007). Smoother paths are particularly important to ants, as minor increases in surface rugosity of a path decrease ant running speed, and ants will selectively choose smoother paths when given the option (Bernadou et al. 2011, Yanoviak et al. 2017). As such, all epigeic ants (ants living on the surface of soil or in associated leaf litter) should incorporate exposed roots and branches into their foraging paths where possible; however, this phenomenon has only been documented for ants that create trunk trails.

Ants rely on randomized search behaviors (Wehner and Srinivasan 1981) and mass foraging events to procure or defend large resource patches (Carroll and Janzen 1973). If cleared paths are preferred routes during foraging, path density (paths/unit area) should increase path use as a simple product of chance encounters during foraging. Connections among cleared paths should also facilitate path use, as recruitment trails develop along the most efficient routes to a resource in laboratory experiments and computational models (Beckers et al. 1992, Stickland et al. 1992, Garnier et al. 2009). Indeed, the structural connectivity of an environment plays a significant role in shaping wood ant foraging trails (Buhl et al. 2009). Whether path structure (density and connectivity) affects path use by a larger variety of epigeic ants has not been explored.

Ants that forage in leaf litter must contend with patchy resources dispersed across a structurally complicated environment (Carroll and Janzen 1973, Kaspari 1996, Hansen 2000, Farji-Brener et al. 2004). Leaf litter depth is highly variable within small spatial scales (1 m²; Kaspari 1996), but also patchy over much larger spatial and temporal scales due to differences in decomposition rates (Kaspari and Yanoviak 2008), 
annual cycles in leaf fall (Haines and Foster 1977), and drought (Wright and Cornejo 1990). The presence of leaf litter increases the abundance of arthropods that are preyed upon by ants (Bultman and Uetz 1984, Wardle 2002, Richardson et al. 2010, Ashford et al. 2013). However, leaf litter also slows individual ant movement and reduces overall foraging success despite increased resource availability (Shepherd 1982, Farji-Brener et al. 2004, Sarty et al. 2006, Gibb and Parr 2010). There should be intense evolutionary pressure on epigeic ants to use paths, such as exposed roots, to optimize foraging efficiency in areas with more leaf litter. Conversely, there should be less pressure for ants to use cleared paths in areas without leaf litter, and ants should prioritize using the shortest paths available (Beckers et al. 1992, Denny et al. 2001).

As central-place foragers, ants should use pathways that offer the least resistance to linear movement and reduce overall foraging time. The goal of this project was to determine if roots function as cleared paths for epigeic ants and to examine how changes in path structure or the surrounding leaf litter affect overall path usage. I made four predictions related to how ants use pathways in the leaf litter. First, more individual ants and more species of ants will be found on cleared paths compared to a nearby location in the leaf litter. Second, ants should also more quickly discover and recruit to baits placed on paths compared to baits in the leaf litter. Third, increasing the density of paths or the connections among paths in a given area should decrease the time to resource discovery and recruitment given that ants selectively move to the shortest paths during the recruitment process. Finally, pathways should be more frequently used by ants in areas with leaf litter compared to areas without leaf litter. 


\section{METHODS}

Study site

Field work for this study was conducted along the trail system in the Barro Colorado Nature Monument in the Panama Canal Zone $\left(09.15^{\circ} \mathrm{N}, 79.85^{\circ} \mathrm{W}\right.$; hereafter, $\mathrm{BCNM}$ ). The BCNM is characterized as a lowland, seasonally moist tropical forest (Leigh et al. 1996). Data were collected from 09:00 to 16:00 during the early wet season (July and August) in 2015, 2016, and 2017.

\section{Natural Observations}

I haphazardly selected 30 trees (locations) having exposed roots (i.e., upper surfaces of roots clear and visible in the surrounding litter) along walking trails in the BCNM to explore if ants appeared with more frequency on cleared surfaces compared to the leaf litter. Each tree was $\geq 5 \mathrm{~m}$ from a trail and focal trees were $>50 \mathrm{~m}$ apart. Under each tree, I selected two $1 \mathrm{~m}^{2}$ sites. One site was centered on a root that was continuously exposed above the soil and leaf litter for $\geq 1 \mathrm{~m}$. The other site was located in a section of leaf litter with no visible roots $\geq 1 \mathrm{~m}$ (Figure 23). The sites were $\geq 1 \mathrm{~m}$ from each other and from the base of any tree. I observed ant activity at a focal area of ca. $9 \mathrm{~cm}^{2}$ on the middle of the exposed root at the center of the site and at the center of the rootless site during two 15 min periods. The first $15 \mathrm{~min}$ period was a non-manipulated observation (pre-bait period). I then placed a small amount of bait (ca. $1 \mathrm{~cm}^{3}$; composed of chicken and honey) at the center of each focal area and conducted a second 15 min observation period (bait period).

I recorded the total number of individual ants (abundance), the number of different ant species (richness), and the time at which the first ant of each species entered the focal area (arrival time) during the pre-bait period. During the bait period, I recorded ant species richness, arrival time, and the lag time between the arrival time and 
the arrival of a second ant of the same species (recruitment time). The difference in time between the arrival of the first ant of a species and the arrival of a second ant of the same species was almost always associated with several ants all arriving at once. After the two observation periods, I measured temperature, relative humidity, and litter depth for each site. I calculated average litter depth by taking measurements from the center and four corners of each site ( $n=5$ measurements). I collected voucher ant specimens from the bait following the end of the last trial period. I stored vouchers in 95\% ethanol and later identified individual ants to species using published and online keys. Reference specimens were examined by taxonomists to confirm species identities when needed. Voucher specimens were deposited at the University of Louisville; the United States National Museum, Washington DC; the Smithsonian Tropical Research Institute, Panama; and the Fairchild Museum at the University of Panama.

\section{Experimental Manipulations}

To determine if any differences in the number of ants observed on roots compared to the nearby leaf litter was due to the presence of a clear and well-connected pathway, I created artificial pathways in the leaf litter using $1 \mathrm{~m}$ lengths of rope $(1 \mathrm{~cm}$ in diameter) in four different arrangements: star, cross, pound, and lines (Figure 24). These arrangements variously differ in total density of available pathways (number of paths per site) and the number of connections among pathways in a given area. Specifically, the star and cross have only one connection point in the center of the arrangement but differ in the total density of rope used (four $1 \mathrm{~m}$ ropes vs. two $1 \mathrm{~m}$ ropes, respectively). By contrast, the pound and lines arrangements have the same number of ropes, but pound has ropes intersecting at four points.

To test the effects of pathway density and number of connections, I used the method described above to select 60 new observation locations along walking trails in 
the BCNM. At these locations, I selected three $1 \mathrm{~m}^{2}$ sites $\geq 1 \mathrm{~m}$ apart. At 30 locations, I placed the star and cross rope arrangements in two of the sites to manipulate pathway density. At the other 30 locations I placed the pound and line arrangements in two sites to determine how the number of pathway connections affected how ants used the paths. I left the rope arrangements in the forest 24-48 hours before observations to allow for acclimation and conditioning. To test the effect of pathway density, I observed a focal area $\left(\right.$ ca. $9 \mathrm{~cm}^{2}$ ) at the central connection point on both the star and cross arrangements (Figure 24) and compared it to a focal area placed in the middle of the third site. To determine the role of the number of connections in an arrangement, I observed a focal area at the midpoint of one of the four ropes in both lines and pound (Figure 24) and compared that to a focal area in the middle of the third site. As described above, I recorded ant abundance, species richness, arrival times, and recruitment times during two 15 min observation periods (i.e., with and without bait). I also measured air temperature, relative humidity, and litter depth (at the four corners and the middle of the site).

Finally, to determine how ants use pathways when litter is completely absent, I placed ropes in the star and pound arrangements within litter-free and control plots (45 m x 45 m) of a large-scale, long-term litter removal experiment (Sayer and Tanner 2010). I placed the ropes ca. $10 \mathrm{~m}$ from the four corners and in the middle of three of the leaf litter removal plots ( $\mathrm{n}=15$ replications). I repeated this process in three of the leaf litter control plots in which the leaf litter was unmanipulated. Ant activity and abiotic parameters were recorded as described above.

Analysis

I used mixed effects linear models to determine how the different observational and experimental substrates affected ant abundance, arrival times, and recruitment 
times (Bates et al. 2014). Specifically, models compared differences between roots and leaf litter, among the different rope arrangements, and between rope arrangements in plots with and without leaf litter. I ran separate tests on the pre-bait and bait observation periods. I included location as the random grouping factor in all models following model selection using AIC values comparing models that treated temperature, relative humidity, and location as random factors. I tested for normality using a Shapiro-Wilks tests and response variables were log or square-root transformed where necessary to meet the assumptions of normality. Degrees of freedom were calculated using a Satterthwaite approximation.

Species richness never exceeded five species in any given trial and did not meet the assumptions of normality using standard transformations in any test. Consequently, the parametric mixed effects models described above were not applicable. Instead, I used a cumulative link mixed model (Guisan and Harrell 2000, Christensen 2010) to assess the effects of the different substrates on ant species richness. Cumulative link mixed models can be used if the response variables are integers and are treated as ordinal data. These models do not assume a normal distribution but otherwise function similarly to a linear mixed model (Christensen 2010). I compared differences in species richness between the roots and leaf litter in the natural experiments and among the rope designs and leaf litter in the experimental manipulations. I included location as a random grouping factor. To determine if treatment significantly affected species richness, I compared the final model in each test to a null model comparing AIC values and a likelihood ratio test.

Each treatment in this project had either 15 or 30 replicates. For experimental tests with more than two treatments per trial, I used a Tukey's HSD for pairwise comparisons of treatments. I performed all statistical methods in the R version 3.4.2 ( $\mathrm{R}$ Core Team 2016) including the packages lme4 and ordinal. 


\section{RESULTS}

I found 36 different ant species (in six subfamilies) using the roots and ropes as pathways during this study. Ectatomma ruidum was the most commonly observed species; it occurred in $56.1 \%$ of trials $(\mathrm{n}=370)$. Pheidole dasypyx, Odontomachus bauri, and Wasmannia auropunctata also occurred in > 10\% of trials (19.1\% 12.9\%, and 11.7\%, respectively). All other ant species occurred with lower frequency.

Excluding the litter removal experiments, litter depth averaged $1.9 \pm 0.1 \mathrm{~cm}$ $($ mean $\pm \mathrm{SE}$; range $=0-10.0 \mathrm{~cm} ; \mathrm{n}=285)$. Temperature averaged $27.4 \pm 0.1^{\circ} \mathrm{C}$ across all trials and was within normal ranges for the area $\left(24.8-30.8^{\circ} \mathrm{C} ; \mathrm{n}=330\right.$; Leigh et al. 1996).

\section{Natural Observations}

Ants were observed more frequently on roots versus on the nearby leaf litter (Table 1). In the natural observations, ant abundance (Figure 25A) and species richness (Figure 25B) were higher (141\% and 45\%, respectively) on roots compared to the leaf litter during the pre-bait period. The arrival time of the first ant of each species also occurred 12\% sooner on roots compared to leaf litter (Figure $25 \mathrm{C}$ ). Following the placement of the baits, ant species richness (Figure 25B) and arrival times (Figure 25C) were similar between the root and leaf litter focal sites. Recruitment time to baits also did not differ between roots and leaf litter (Figure 25D).

\section{Experimental Manipulations}

Ant abundance and species richness increased, whereas recruitment times decreased, with increasing pathway density (Table 8). Specifically, ant abundances in the pre-bait periods were higher on the star and cross arrangements compared to the leaf litter (Figure 26A; Table 9; >250\% more ants). Species richness was only higher on 
the star arrangement compared to the litter (Figure 26B; Table 9, >190\% more species). In contrast to the natural observations, I did not detect differences in ant arrival time among the experimental rope arrangements and the leaf litter (Figure 26C) before baiting. Following baiting, the star arrangement consistently had a higher species richness compared to the leaf litter (Figure 26B; Table 9; >37\% more species). The arrival time (Figure 26C) and the recruitment times (Figure 26D) also were shorter on the star treatment compared to the leaf litter ( $>37 \%$ faster on star). The cross arrangement was similar to both leaf litter and star in the baited observation period (Table 9).

Variation in the number of connections among the pathways had limited effects on ant usage of pathways (Table 8). Ant abundance (Figure 27A) and species richness (Figure 27B) were higher on both the pound and lines arrangements compared to the leaf litter during the pre-bait period (Table 9). However, neither ant abundance nor species richness differed between pound and lines. There was no difference detected in arrival time among all three arrangements (Figure 27C; Table 9). After the addition of bait, neither ant species richness nor arrival times differed among any treatments. In contrast, ants recruited to baits more quickly on the both rope treatments compared to the leaf litter but again there was no difference between the pound and lines treatments (Figure 27D; Table 9).

Regardless of litter presence or absence, ants used rope pathways with higher frequency than the surrounding substrate (Table 8). In the presence of normal litter without baits, the pound and star rope arrangements had higher ant abundance (Figure 28A; >700\% more ants) and species richness (Figure 28B; >140\% more ant species), and faster average arrival time (Figure 28C; 60\% faster) compared to the focal site in the surrounding leaf litter (Table 9). Similarly, in the litter removal plots, abundance (Figure 29A; >250\% more ants) and species richness (Figure 29B; >60\% more species) 
were both higher for the star arrangement compared to the leaf litter (Table 9). Ant abundance was also higher on the pound arrangement compared to the leaf litter. Arrival times did not differ across the three treatments in the litter removal plots (Figure 29C). The application of bait under normal litter conditions resulted in faster recruitment times to the star and pound treatment compared to the nearby leaf litter control (Figure 28D; Table 9; >45\% faster recruitment). Arrival times and species richness were comparable across the three treatments. The same patterns occurred in the leaf litter removal plots; i.e., faster recruitment to bait on the star and pound treatments (Figure 29D; Table 9) and no differences in arrival time or species richness among the three treatments.

\section{DISCUSSION}

Collectively, the results of this study support the hypothesis that epigeic ants use paths that offer the least resistance to linear movement. Specifically, roots and ropes provide relatively clear and straight paths that ants readily use to move through the leaf litter on the forest floor. However, using these paths does not necessarily facilitate more efficient foraging. Path use is also predicated on path density rather than connectivity or the overall presence of leaf litter. As ants prioritize running speed while moving outside of the nest (Couzin and Franks 2003, Dussutour et al. 2006, Yanoviak et al. 2017), it is likely that using roots and artificial paths increased individual ant running speed.

The expectation that ants on roots would discover and recruit more quickly to baits compared to baits in the leaf litter was not supported. Differences between the results of this study and similar work with leaf-cutting ants (Farji-Brener et al. 2007) are likely due to differences in the foraging syndromes of the focal ants. Leaf-cutting ants uses trunk-trail foraging patterns that include distinct travel and searching stages (Crist and MacMahon 1991); whereas, the ants observed in this study likely rely only on 
correlated random-walk search behavior (Wehner and Srinivasan 1981, Crist and MacMahon 1991, Tan et al. 2002). Baits in the leaf-cutting ant study were incorporated into the frequently traveled trunk trail where ants exhibit behaviors marked by rapid and directed movement (Fewell 1988, Farji-Brener et al. 2007). Discovery and recruitment in the current study were likely more dependent on random chance encounters. The lack of faster discovery and recruitment to baits also implies that ants potentially use pathways due to other ecological pressures. Predation and parasitism are often overlooked in studies of ant behaviors and communities but could explain why epigeic ants prioritize moving quickly through the leaf litter (Feener 2000, LeBrun 2005).

Foraging ants often rely on variations of a correlated random-walk behavior when searching for resources (Wehner and Srinivasan 1981, Crist and MacMahon 1991, Tan et al. 2002). Thus, increasing the density of paths in a site increases the likelihood that an ant will randomly discover and use a path. Indeed, the cross arrangement had half the density of paths compared to the star arrangement and was intermediate to the litter and star arrangement in terms of ant species richness, arrival times, and recruitment times.

Path fidelity as a means of decreasing average foraging costs is likely the best explanation for why increasing connectivity among paths did not decrease the time to bait discovery or recruitment. Specifically, when given asymmetrical path choices in laboratory settings, ants generally select the path that most closely matches their current direction (Garnier et al. 2009) and infrequently change directions once they have selected a path (Beckers et al. 1992). Additionally, using straighter routes while foraging increases foraging area without increasing average energy costs for ants (Fewell 1988). Ants walking on a rope path in the current study tended to stay on that rope and did not deviate or turn onto other rope pathways at connection points. 
The removal of leaf litter did not reduce how frequently ants use cleared paths to move across the forest floor. The lack of adaptability in path use by ants was unexpected considering the variability in leaf litter depth across the forest floor (Kaspari 1996, FarjiBrener et al. 2004, Kaspari and Yanoviak 2008) and seasonally (Haines and Foster 1977, Wright and Cornejo 1990). However, since using a cleared path can increase total foraging area (Fewell 1988, Denny et al. 2001), the evolutionary pressure to use paths could outweigh the temporary benefits of ignoring paths in litter-free areas. Additionally, both ropes and roots in the leaf litter removal plots emerged above the surface of the forest floor, creating a distinct raised edge. Ants tend to selectively follow along the edges of walls or other raised structures when available as the edges provide distinct visual markers that aid navigation (Pratt et al. 2001, Dussutour et al. 2005). When encountering the rope designs in the litter removal trials, ants frequently walked on the ground along the edge of the rope pathway.

In conclusion, epigeic ants use natural and artificial paths to move through the leaf litter. However, many questions about ant foraging behavior remain unanswered, and potentially informative extensions of this project could include measuring difference in running speed and average trajectory of ants using paths or moving through the leaf litter. Increased running speeds on cleared paths could be the explanation for why the paths are used by ants and would match other studies of ant foraging behaviors (Fewell 1988, Farji-Brener et al. 2007, Clay et al. 2010, Yanoviak et al. 2017). Due to spatial and seasonal variability of ant parasitoids (De Almeida et al. 2008), the effects of predator/parasite pressure on path use could also be explored by repeating the experiment during the dry season or at forest edges. Ultimately, understanding which factors influence path selection in ants provides insight into the foraging decision of all central-place foragers (Kasuya 1982, Harkness and Maroudas 1985, Soltz 1986, Holder and Polis 1987, Hölldobler and Wilson 1990). 


\section{Tables}

Table 8. Statistical results from the all global models evaluating whether ants used paths more frequently than leaf litter (Roots) and how changing the structure of the paths (Density, Connections) and the leaf litter (Litter Control, Litter Removal) influenced path usage. Values are provided for each response variable (Abundance, Species Richness, Arrival time, and Recruitment time) under pre-bait and baited conditions. Values include the F-statistic (Abundance, Arrival, and Recruitment) or X² (Species Richness), the degrees of freedom for each test (DF), and the P-value for each test (P). Significant differences marked with “*”.

\begin{tabular}{lllllr}
\hline Experiment & Trial & Response & F or $\boldsymbol{X}^{\mathbf{2}}$ & DF & \multicolumn{1}{c}{$\boldsymbol{P}$} \\
\hline Roots & Pre & Abundance & 11.5 & 1,58 & $0.001^{*}$ \\
Roots & Pre & Richness & 5.3 & 1 & $0.02^{*}$ \\
Roots & Pre & Arrival & 9.9 & 1,51 & $0.003^{*}$ \\
Roots & Bait & Richness & 0.5 & 1 & 0.49 \\
Roots & Bait & Arrival & 0.7 & 1,29 & 0.41 \\
Roots & Bait & Recruitment & 0.8 & 1,101 & 0.37 \\
Density & Pre & Abundance & 11.5 & 2,58 & $<0.0001^{*}$ \\
Density & Pre & Richness & 16.7 & 2 & $0.0002^{*}$ \\
Density & Pre & Arrival & 1.0 & 2,51 & 0.38 \\
Density & Bait & Richness & 8.9 & 2 & $0.01^{*}$ \\
Density & Bait & Arrival & 3.4 & 2,58 & $0.04^{*}$ \\
Density & Bait & Recruitment & 7.0 & 2,128 & $0.001^{*}$ \\
Connections & Pre & Abundance & 12.7 & 2,58 & $<0.0001^{*}$ \\
Connections & Pre & Richness & 16.2 & 2 & $0.0003^{*}$ \\
Connections & Pre & Arrival & 1.8 & 2,55 & 0.18 \\
Connections & Bait & Richness & 5.7 & 2 & 0.06 \\
Connections & Bait & Arrival & 3.0 & 2,83 & 0.06 \\
Connections & Bait & Recruitment & 8.4 & 2,115 & $0.0004^{*}$ \\
Litter Control & Pre & Abundance & 15.3 & 2,28 & $<0.0001^{*}$ \\
Litter Control & Pre & Richness & 17.8 & 2 & $0.0001^{*}$ \\
Litter Control & Pre & Arrival & 4.3 & 2,27 & $0.02^{*}$ \\
Litter Control & Bait & Richness & 2.7 & 2 & 0.25 \\
Litter Control & Bait & Arrival & 3.0 & 2,42 & $0.06^{*}$ \\
Litter Control & Bait & Recruitment & 12.0 & 2,55 & $<0.0001^{*}$ \\
Litter Removal & Pre & Abundance & 16.3 & 2,42 & $<0.0001^{*}$ \\
Litter Removal & Pre & Richness & 8.0 & 2 & $0.02^{*}$ \\
Litter Removal & Pre & Arrival & 1.7 & 2,33 & 0.19
\end{tabular}




\begin{tabular}{lllllr} 
Litter Removal & Bait & Richness & 3.1 & 2 & 0.21 \\
Litter Removal & Bait & Arrival & 2.9 & 2,42 & 0.07 \\
Litter Removal & Bait & Recruitment & 6.3 & 2,67 & $0.003^{*}$ \\
\hline
\end{tabular}

Table 9. All pairwise comparisons of significantly different global tests from the rope arrangement experiments. Values are provided for the tests of path density (Density), path connections (Connections) and differences in leaf litter (Litter Control, Litter Removal) under pre-bait and baited conditions. Values include the Z-statistic (Z) and the P-value (P) for each pairwise comparison between the various rope arrangements and the leaf litter. Significant differences marked with “*”.

\begin{tabular}{|c|c|c|c|c|c|}
\hline Experiment & Trial & Response & $\begin{array}{l}\text { Pairwise } \\
\text { Comparison }\end{array}$ & $Z$ & $\boldsymbol{P}$ \\
\hline Density & Pre & Abundance & Litter - Cross & 2.6 & $0.02^{*}$ \\
\hline Density & Pre & Abundance & Litter - Star & 4.8 & $0.001^{*}$ \\
\hline Density & Pre & Abundance & Cross - Star & 2.2 & 0.07 \\
\hline Density & Pre & Richness & Litter - Cross & 2.0 & 0.11 \\
\hline Density & Pre & Richness & Litter - Star & 4.0 & $0.0002^{*}$ \\
\hline Density & Pre & Richness & Cross - Star & 2.1 & 0.08 \\
\hline Density & Bait & Richness & Litter - Cross & 1.3 & 0.41 \\
\hline Density & Bait & Richness & Litter - Star & 3.0 & $0.009^{*}$ \\
\hline Density & Bait & Richness & Cross - Star & 1.8 & 0.19 \\
\hline Density & Bait & Arrival & Litter - Cross & 1.4 & 0.33 \\
\hline Density & Bait & Arrival & Litter - Star & 2.6 & $0.03^{*}$ \\
\hline Density & Bait & Arrival & Cross - Star & 1.2 & 0.46 \\
\hline Density & Bait & Recruitment & Litter - Cross & 1.5 & 0.31 \\
\hline Density & Bait & Recruitment & Litter - Star & 3.7 & $0.001^{*}$ \\
\hline Density & Bait & Recruitment & Cross - Star & 2.3 & 0.06 \\
\hline Connections & Pre & Abundance & Litter - Lines & 3.4 & $0.002^{*}$ \\
\hline Connections & Pre & Abundance & Litter - Pound & 4.9 & $<0.0001^{*}$ \\
\hline Connections & Pre & Abundance & Lines - Pound & 1.5 & 0.31 \\
\hline Connections & Pre & Richness & Litter - Lines & 2.6 & $0.02^{*}$ \\
\hline Connections & Pre & Richness & Litter - Pound & 3.9 & $0.0003^{*}$ \\
\hline Connections & Pre & Richness & Lines - Pound & 1.5 & 0.29 \\
\hline Connections & Bait & Recruitment & Litter - Lines & 2.4 & $0.04^{*}$ \\
\hline Connections & Bait & Recruitment & Litter - Pound & 4.1 & $0.0001^{*}$ \\
\hline Connections & Bait & Recruitment & Lines - Pound & 1.7 & 0.22 \\
\hline Litter Control & Pre & Abundance & Litter - Pound & $3 \cdot 3$ & $0.003^{*}$ \\
\hline Litter Control & Pre & Abundance & Litter - Star & $5 \cdot 5$ & $0.001 *$ \\
\hline
\end{tabular}




\begin{tabular}{lllllr} 
Litter Control & Pre & Abundance & Pound - Star & 2.2 & 0.07 \\
Litter Control & Pre & Richness & Litter - Pound & 3.0 & $0.008^{*}$ \\
Litter Control & Pre & Richness & Litter - Star & 3.7 & $0.0006^{*}$ \\
Litter Control & Pre & Richness & Pound - Star & 1.3 & 0.41 \\
Litter Control & Pre & Arrival & Litter - Pound & 2.8 & $0.01^{*}$ \\
Litter Control & Pre & Arrival & Litter - Star & 2.4 & $0.04^{*}$ \\
Litter Control & Pre & Arrival & Pound - Star & 0.6 & 0.82 \\
Litter Control & Bait & Recruitment & Litter - Pound & 4.8 & $0.001^{*}$ \\
Litter Control & Bait & Recruitment & Litter - Star & 3.3 & $0.003^{*}$ \\
Litter Control & Bait & Recruitment & Pound - Star & 1.6 & 0.23 \\
Litter Removal & Pre & Abundance & Litter - Pound & 3.1 & $0.008^{*}$ \\
Litter Removal & Pre & Abundance & Litter - Star & 5.7 & $0.001^{*}$ \\
Litter Removal & Pre & Abundance & Pound - Star & 2.3 & 0.06 \\
Litter Removal & Pre & Richness & Litter - Pound & 1.8 & 0.19 \\
Litter Removal & Pre & Richness & Litter - Star & 2.8 & $0.02^{*}$ \\
Litter Removal & Pre & Richness & Pound - Star & 1.2 & 0.48 \\
Litter Removal & Bait & Recruitment & Litter - Pound & 3.3 & $0.003^{*}$ \\
Litter Removal & Bait & Recruitment & Litter - Star & 2.9 & $0.01^{*}$ \\
Litter Removal & Bait & Recruitment & Pound - Star & 0.4 & 0.91 \\
\hline
\end{tabular}




\section{Figure Captions}

Figure 22. Examples of a typical exposed root site (A) and leaf litter site (B).

Figure 23. Schematic of the four artificial rope arrangements used to test the effects of the path density and the number of connections on ant pathway usage. Ropes are represented by blue lines. The red square on each design represents an example focal area for observation during trials.

Figure 24. Differences in mean $( \pm \mathrm{SE})$ abundance (A), species richness (B), arrival times (C), and recruitment times (D) on roots and nearby leaf litter sites during pre-bait and baited trials. Shared letters within a graph indicate means that do not significantly differ. Ant abundance was only measured during pre-bait trials. Ant species richness and arrival times were recorded for both pre-bait and baited trials. Ant recruitment was only recorded for baited trials.

Figure 25. Differences in mean $( \pm \mathrm{SE})$ abundance (A), species richness (B), arrival times (C), and recruitment times (D) on star and cross rope designs and in nearby leaf litter sites during pre-bait and baited trials. Shared letters within a graph indicate means that do not significantly differ. Abundance was only measured during pre-bait trials. Species richness and arrival times were recorded for both pre-bait and baited trials. Recruitment was only recorded for baited trials.

Figure 26. Differences in mean $( \pm \mathrm{SE})$ abundance $(\mathrm{A})$, species richness $(\mathrm{B})$, arrival times (C), and recruitment times (D) on pound and line rope arrangements and in nearby leaf litter sites during pre-bait and baited trials. Shared letters within a graph indicate means that do not significantly differ. Abundance was only measured during pre-bait trials. 
Species richness and arrival times were recorded for both pre-bait and baited trials. Recruitment was only recorded for baited trials.

Figure 27. Differences in mean $( \pm \mathrm{SE})$ abundance (A), species richness (B), arrival times (C), and recruitment times (D) on star and pound rope arrangements and in nearby leaf litter sites during pre-bait and baited trials. Trials were conducted in the litter control plots from a long-term leaf litter removal experiment (Sayer and Tanner 2010). Shared letters within a graph indicate means that do not significantly differ. Abundance was only measured during pre-bait trials. Species richness and arrival times were recorded for both pre-bait and baited trials. Recruitment was only recorded for baited trials.

Figure 28. Differences in mean $( \pm \mathrm{SE})$ abundance (A), species richness (B), arrival times (C), and recruitment times (D)on star and pound rope arrangements and in nearby leaf litter sites during pre-bait and baited trials. Trials were conducted in the litter removal plots from a long-term leaf litter removal experiment (Sayer and Tanner 2010). Shared letters within a graph indicate means that do not significantly differ. Abundance was only measured during pre-bait trials. Species richness and arrival times were recorded for both pre-bait and baited trials. Recruitment was only recorded for baited trials. 


\section{Figures}

Figure 23.

A.

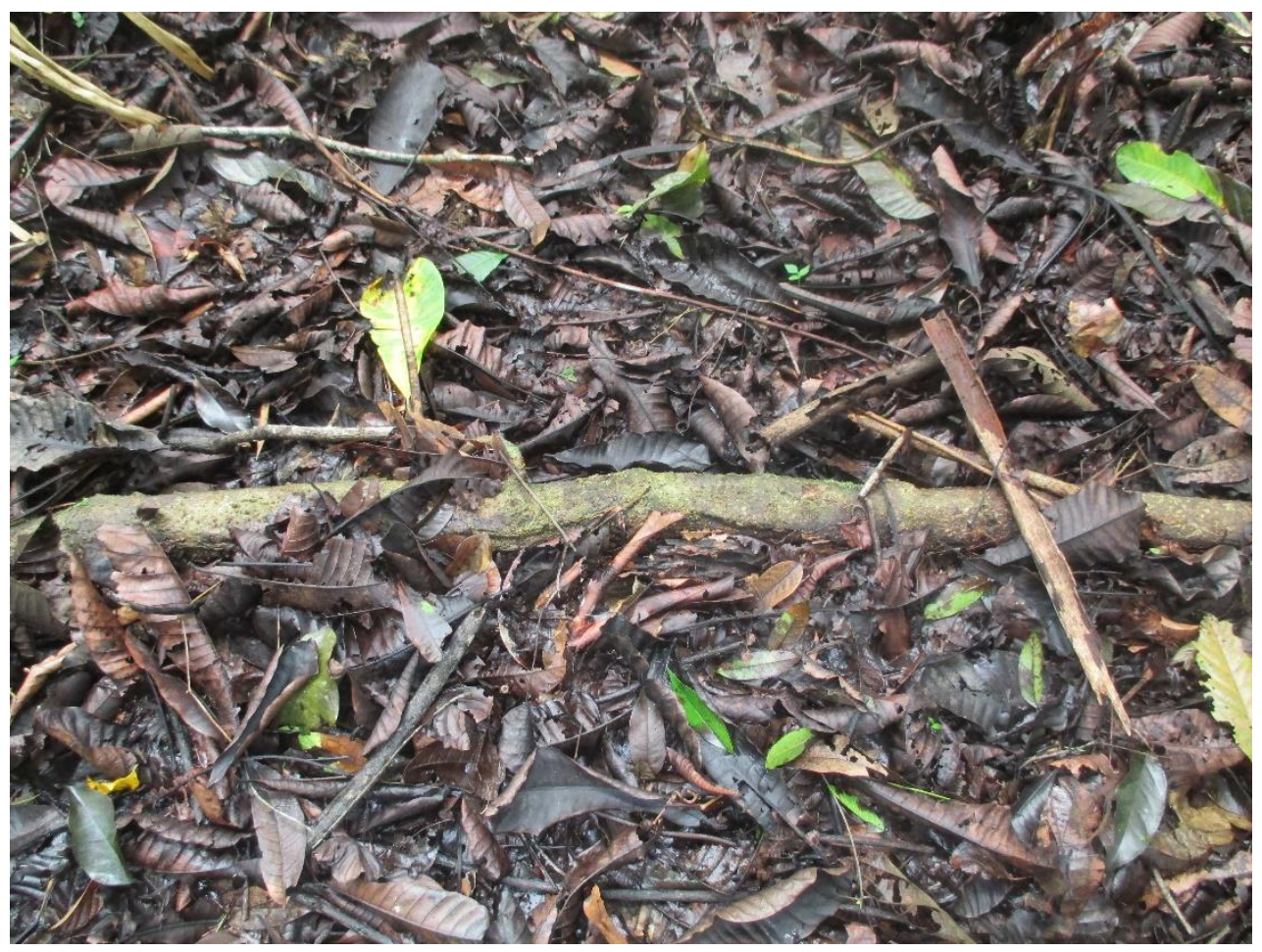

B.

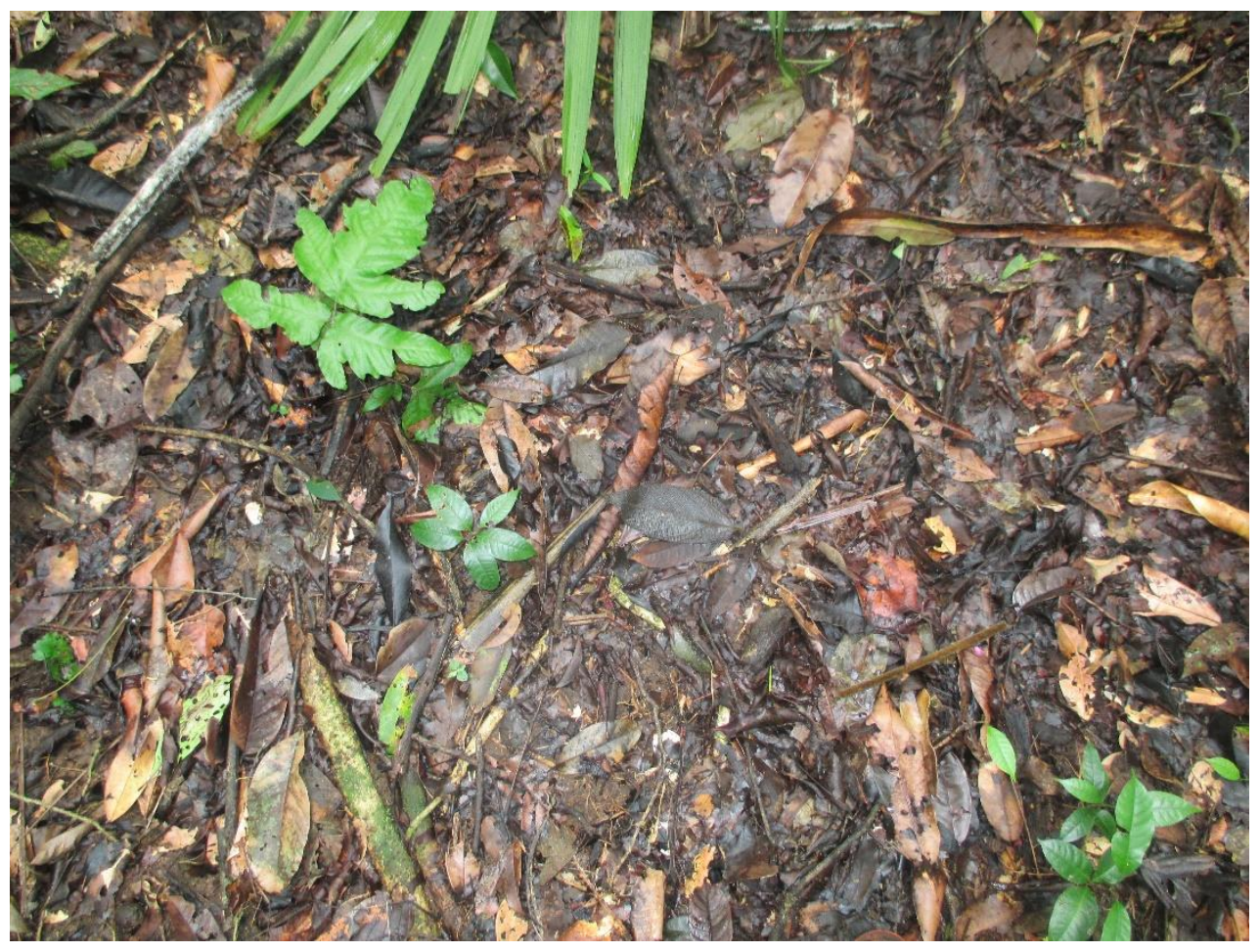


Figure 24 .

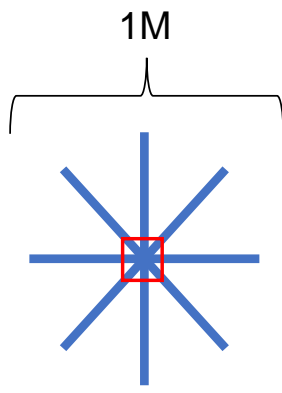

STAR

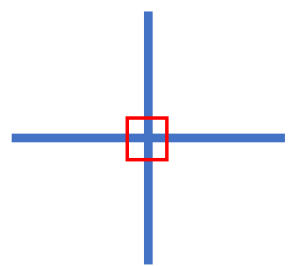

CROSS

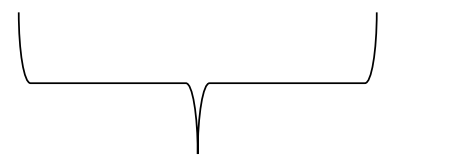

Total length

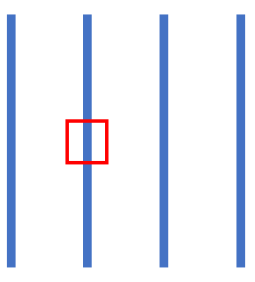

LINES

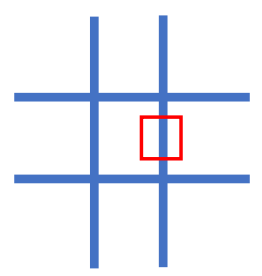

POUND

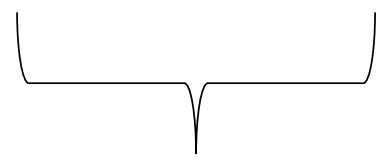

Connections 
Figure 25 .

A.

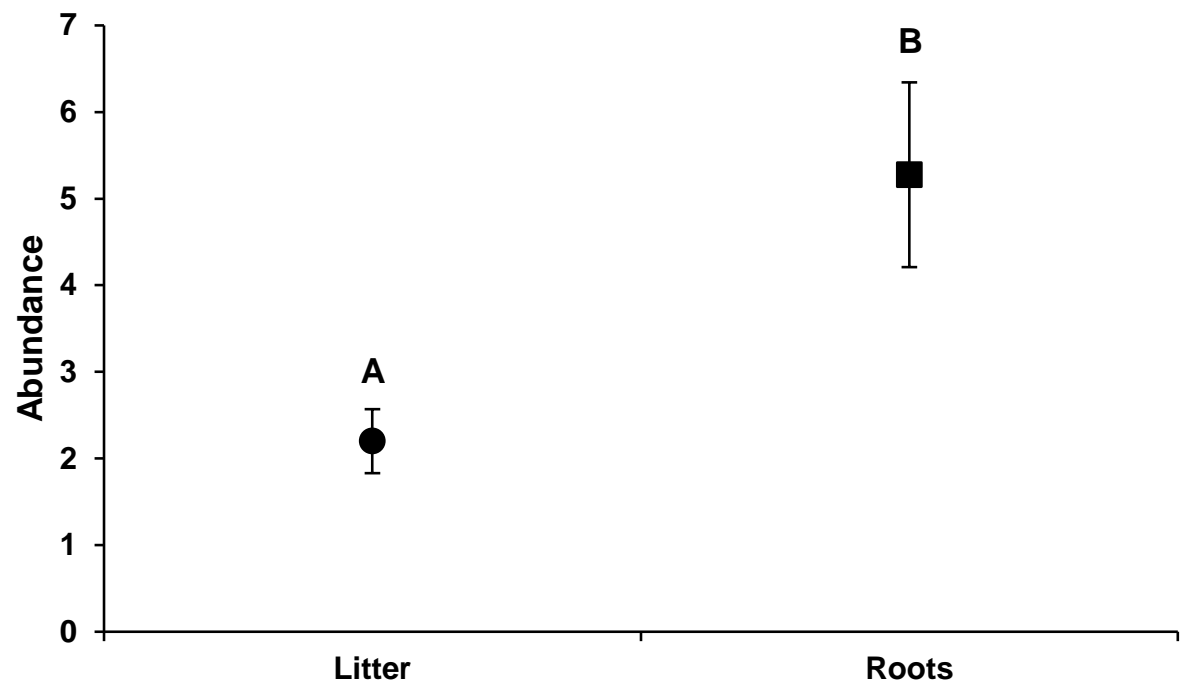

B.

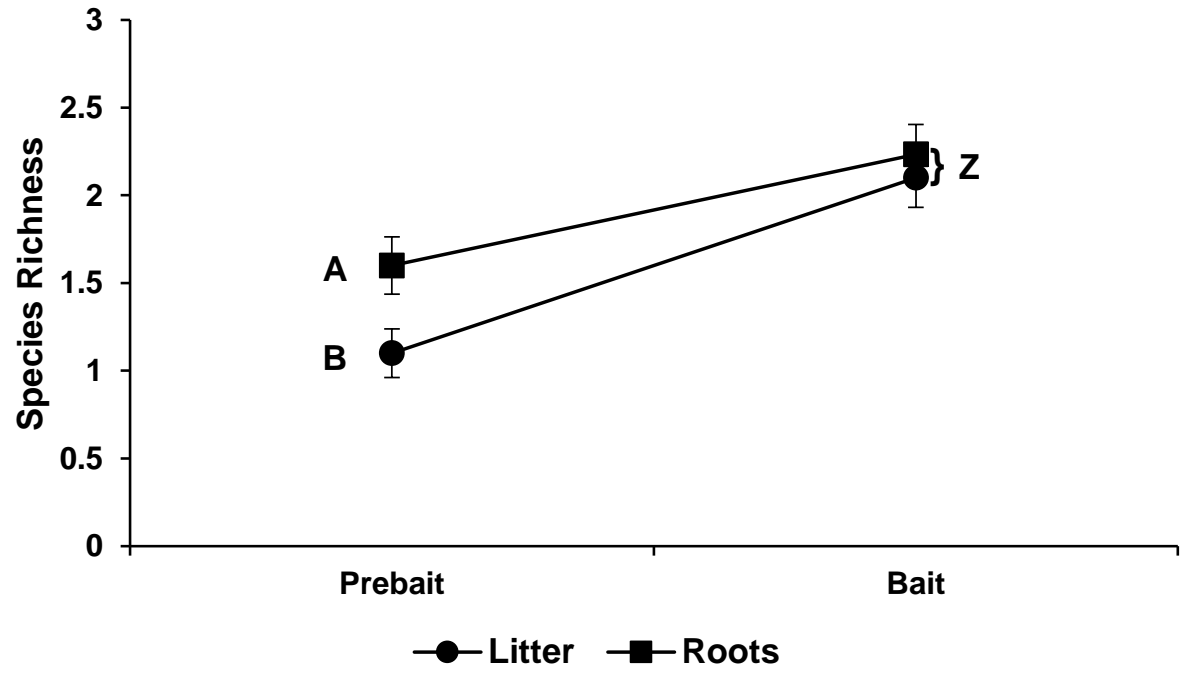


C.

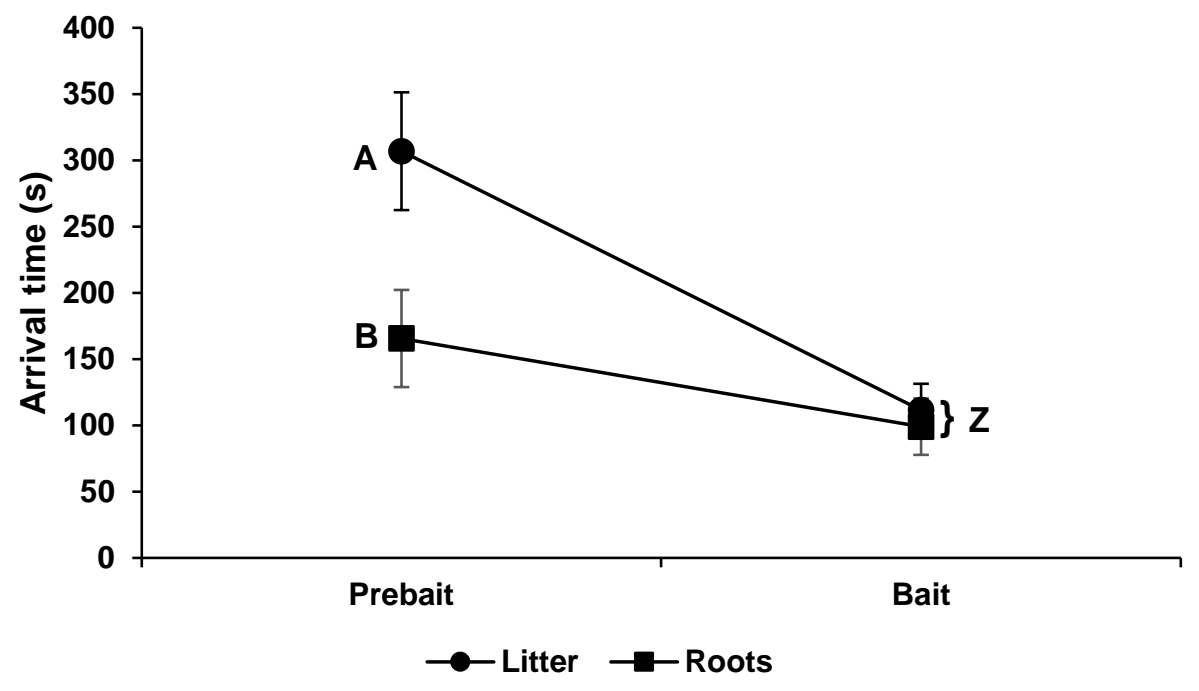

D.

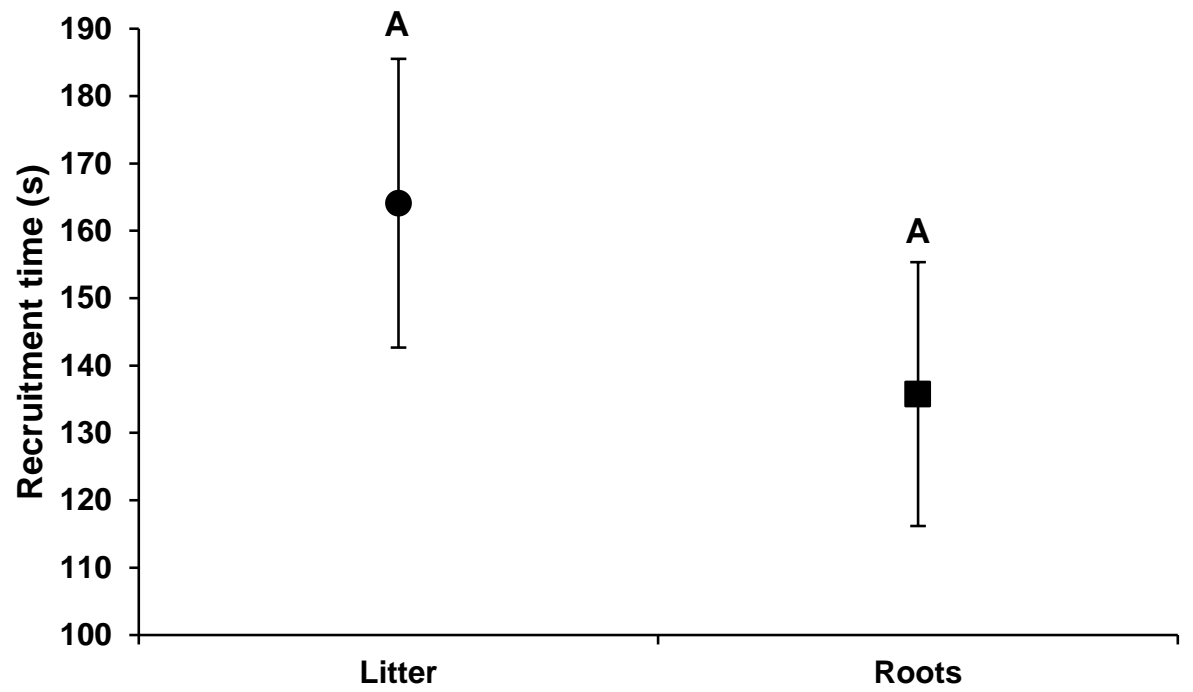


Figure 26.

A.

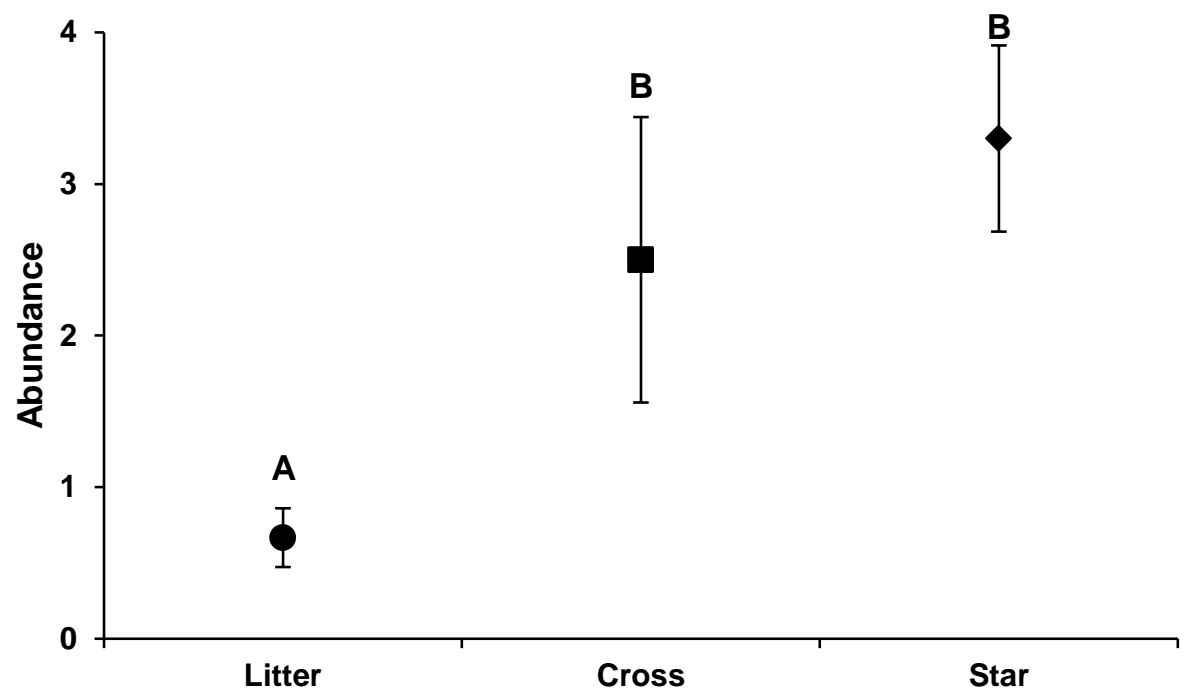

B.

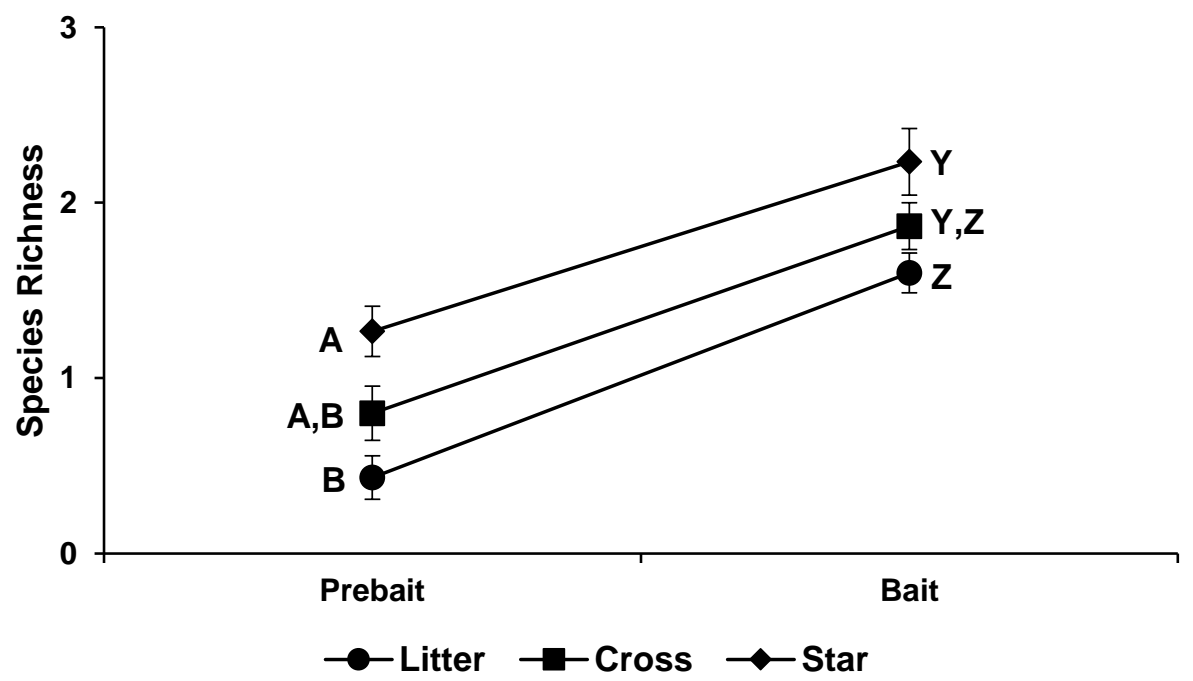


C.

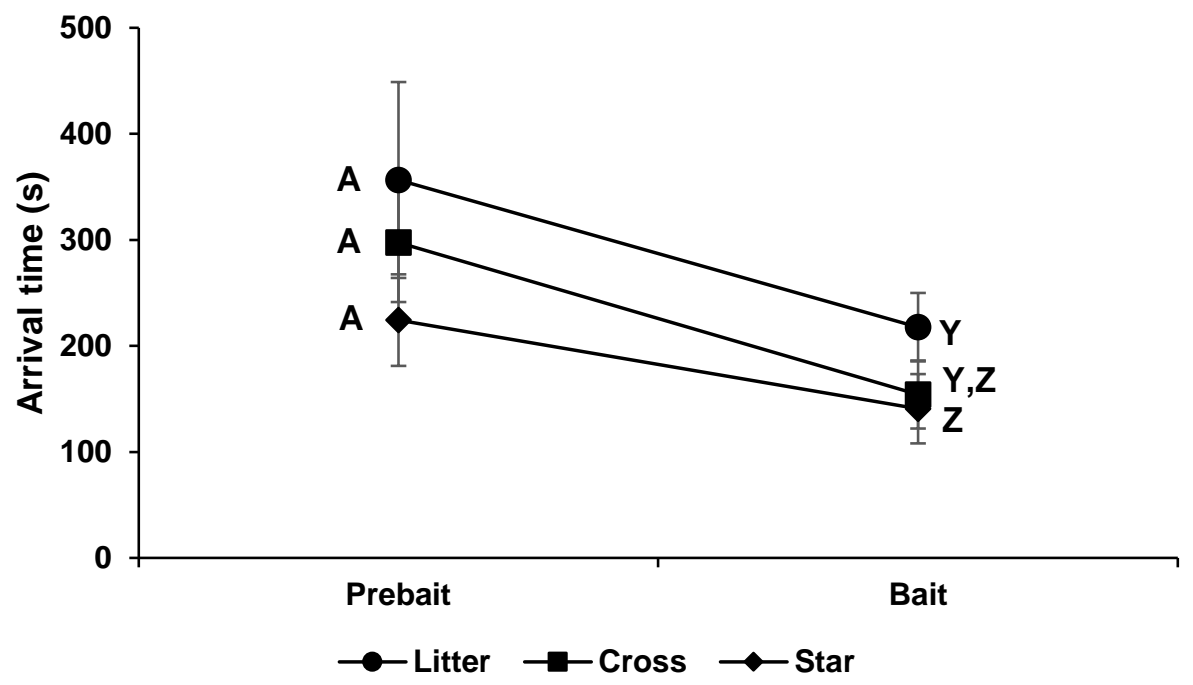

D.

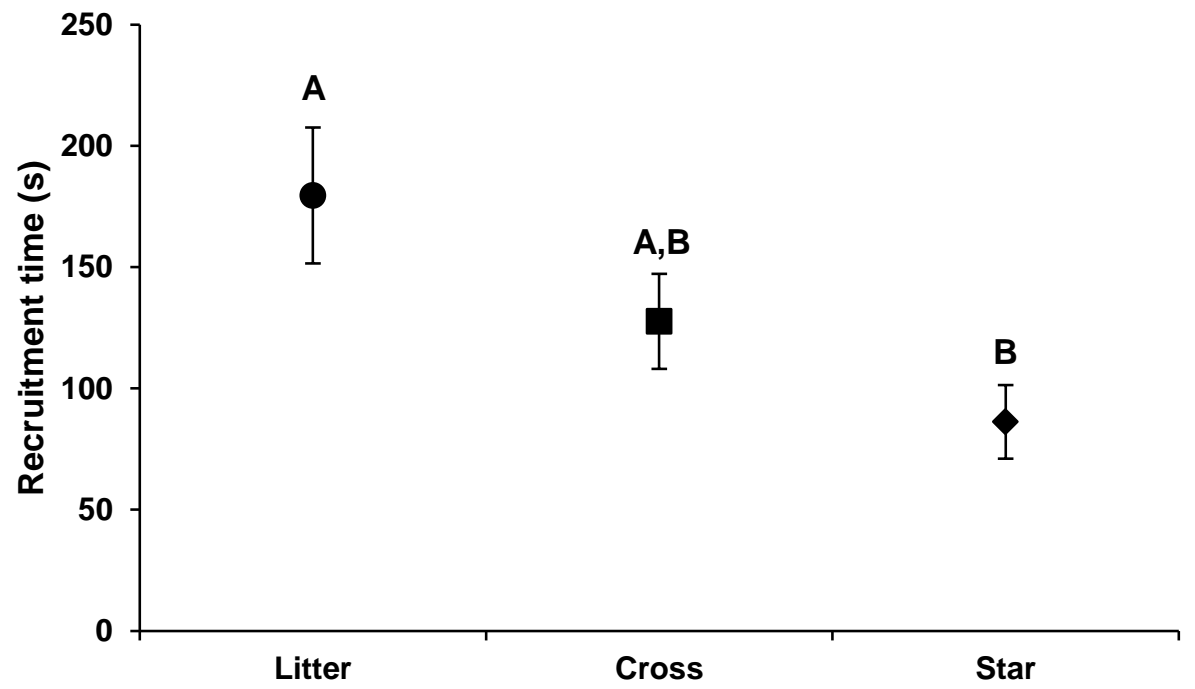


Figure 27.

A.

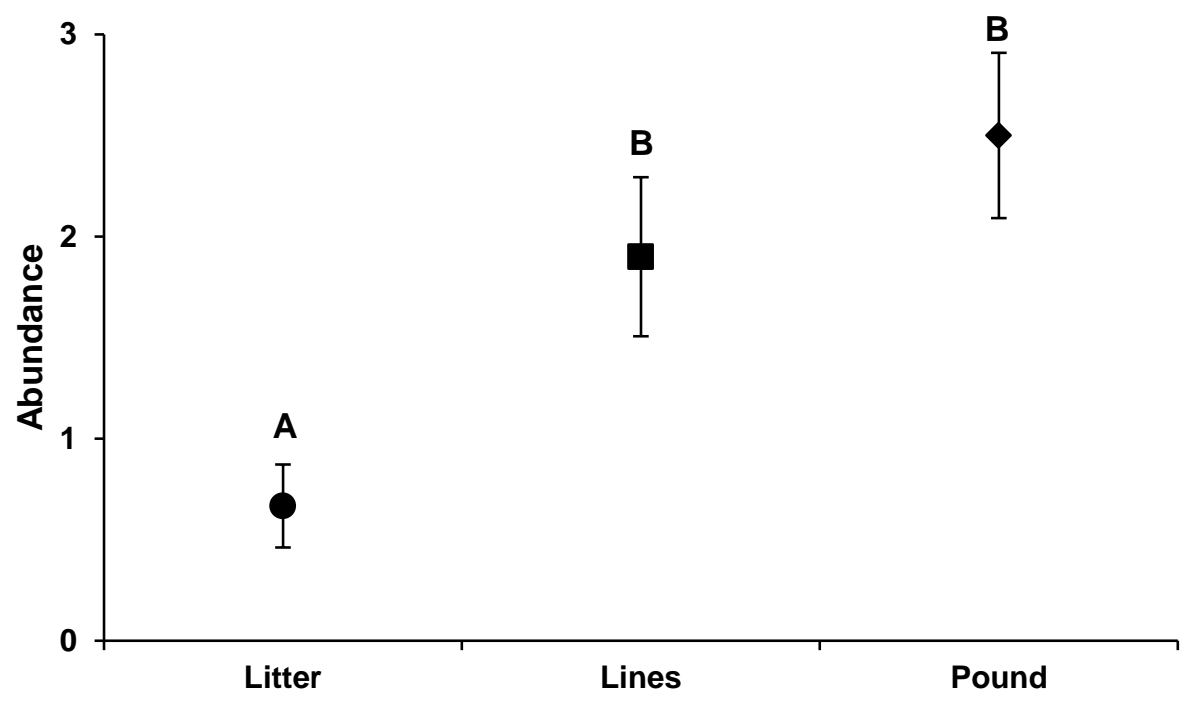

B.

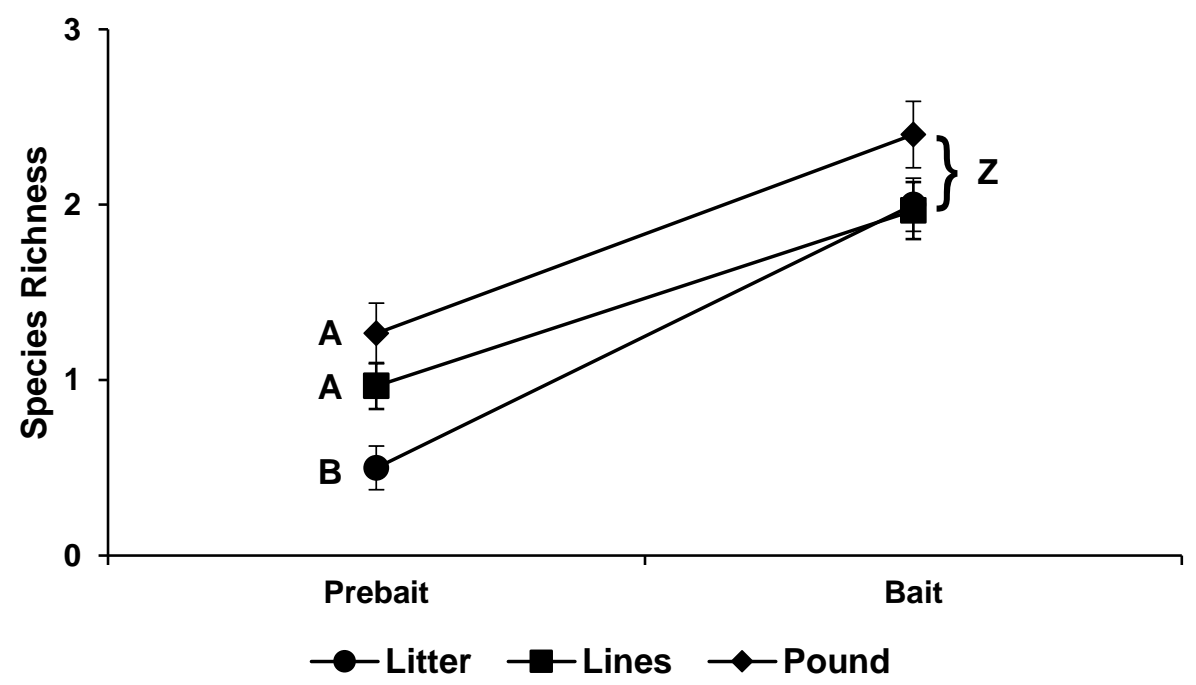


C.

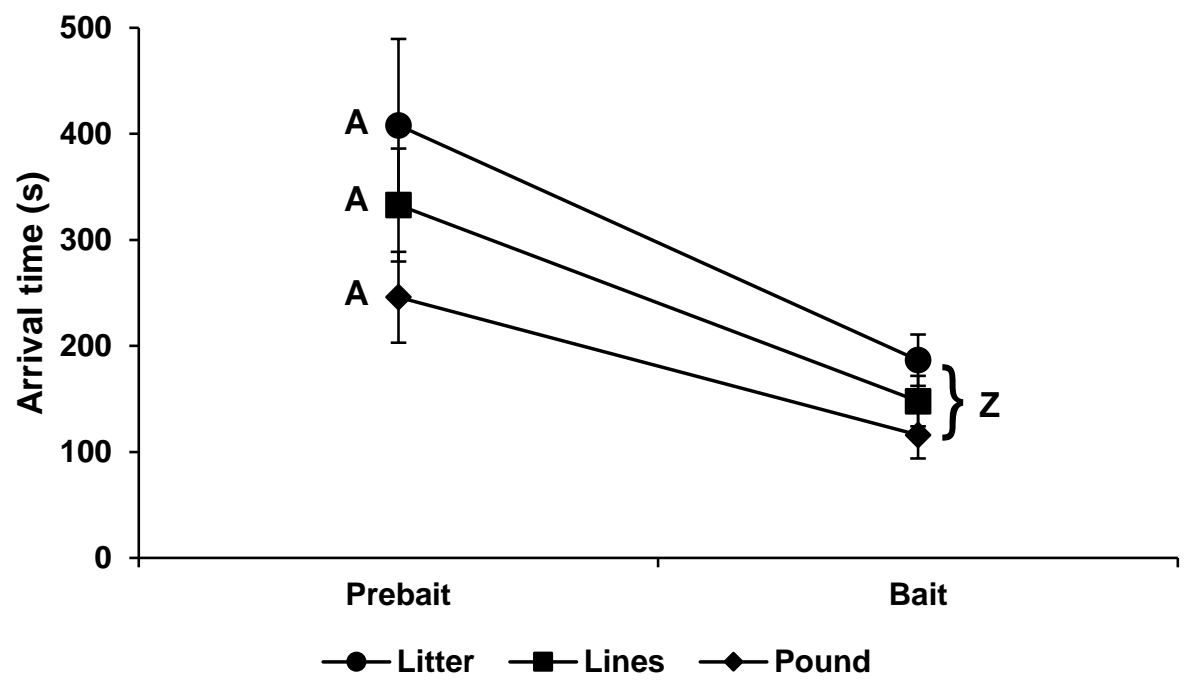

D.

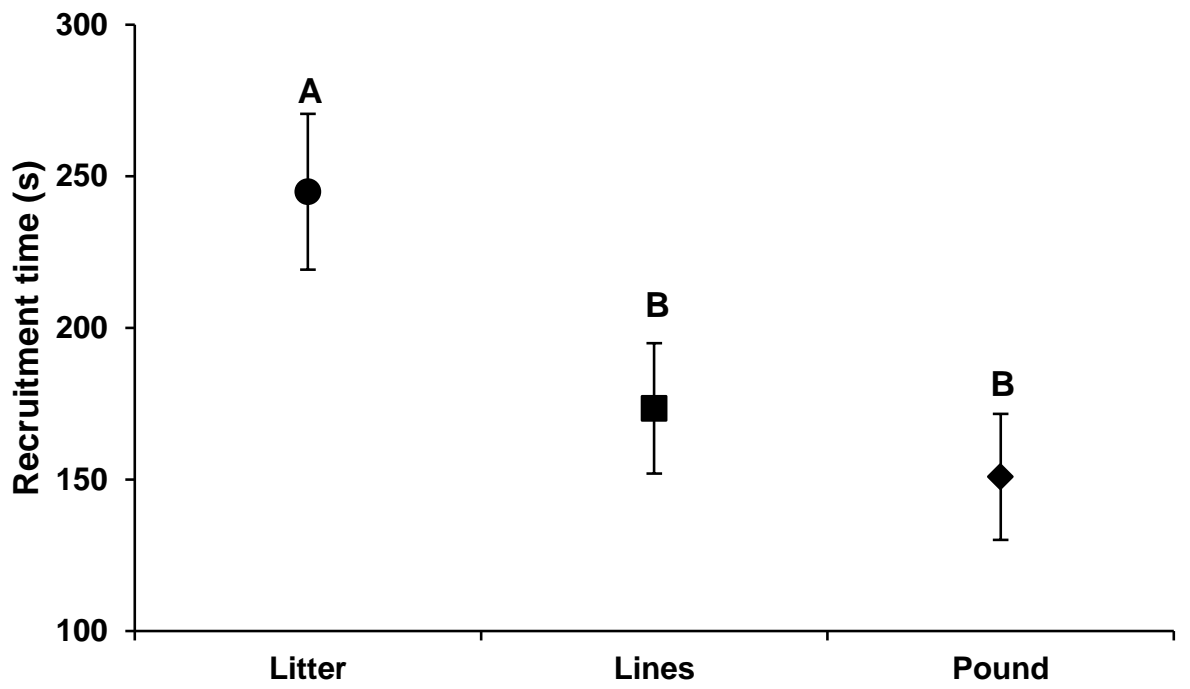


Figure 28.

A.

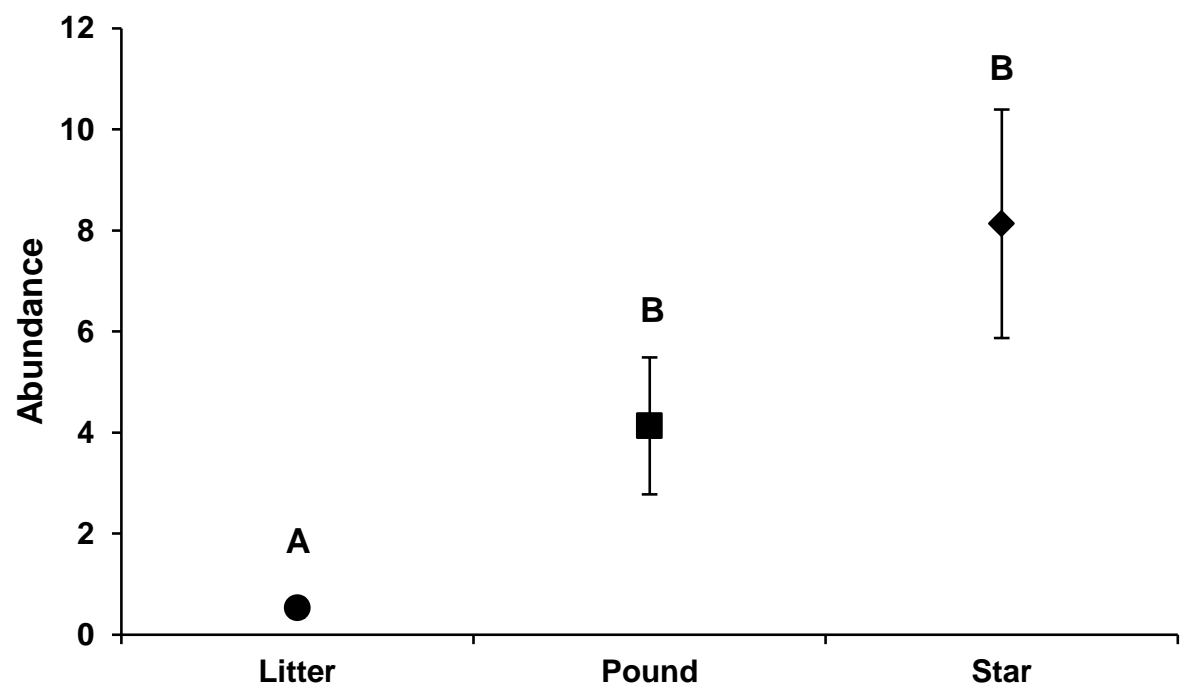

B.

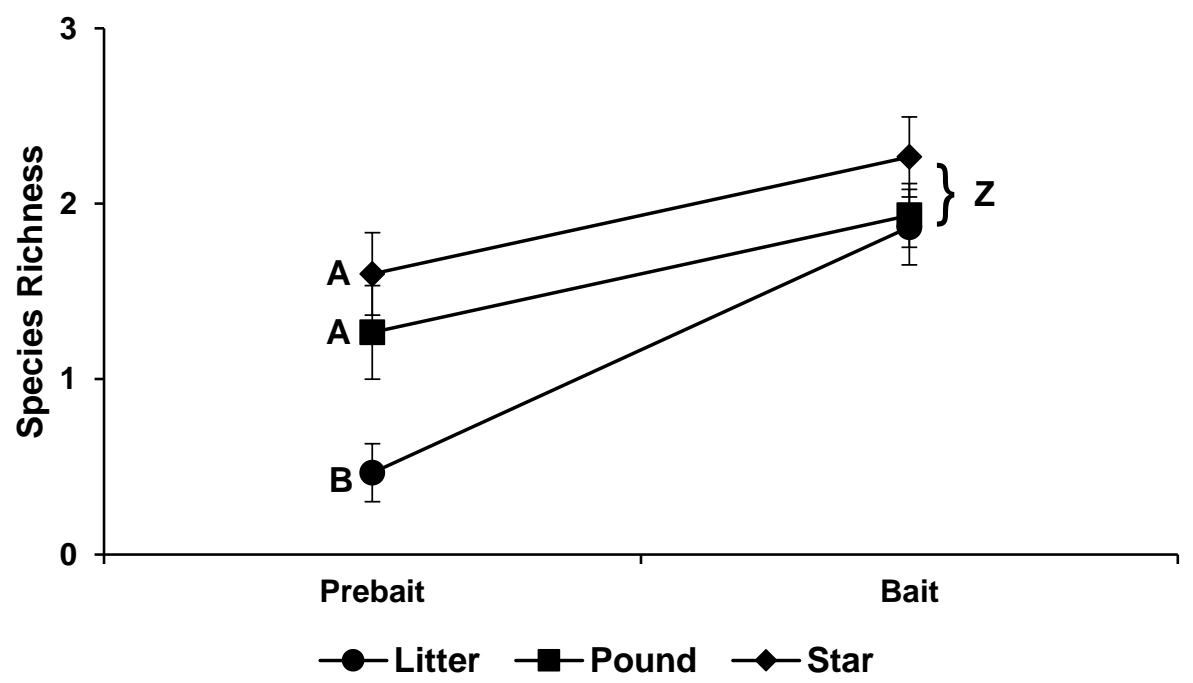


C.

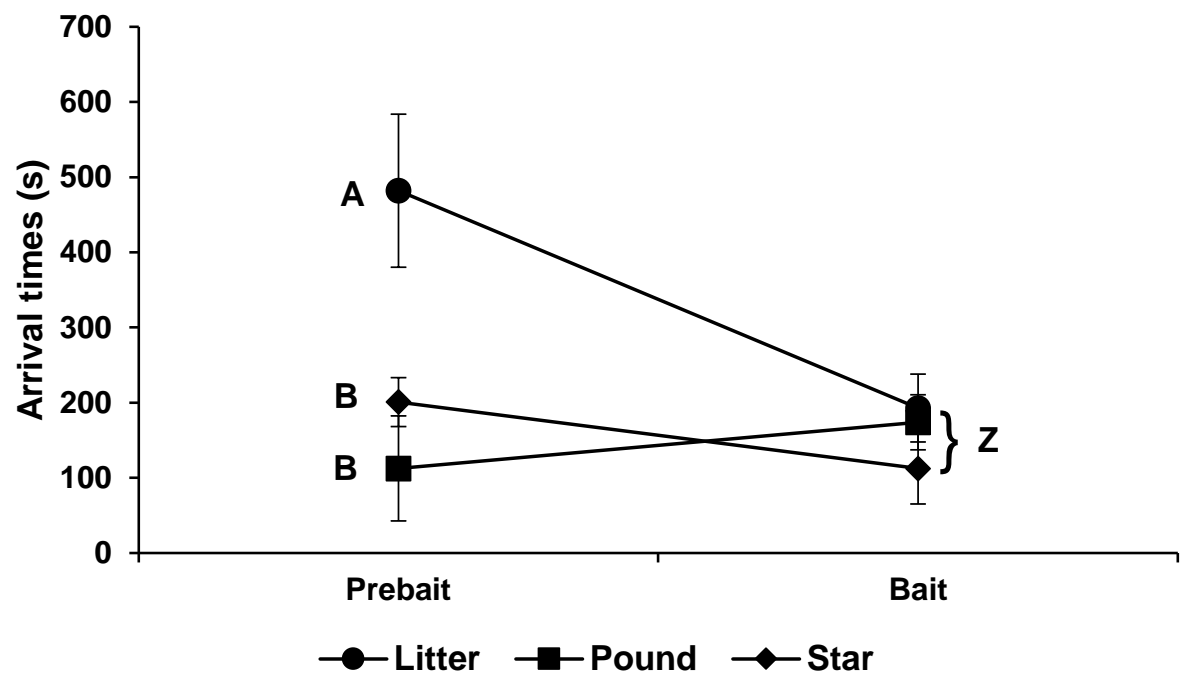

D.

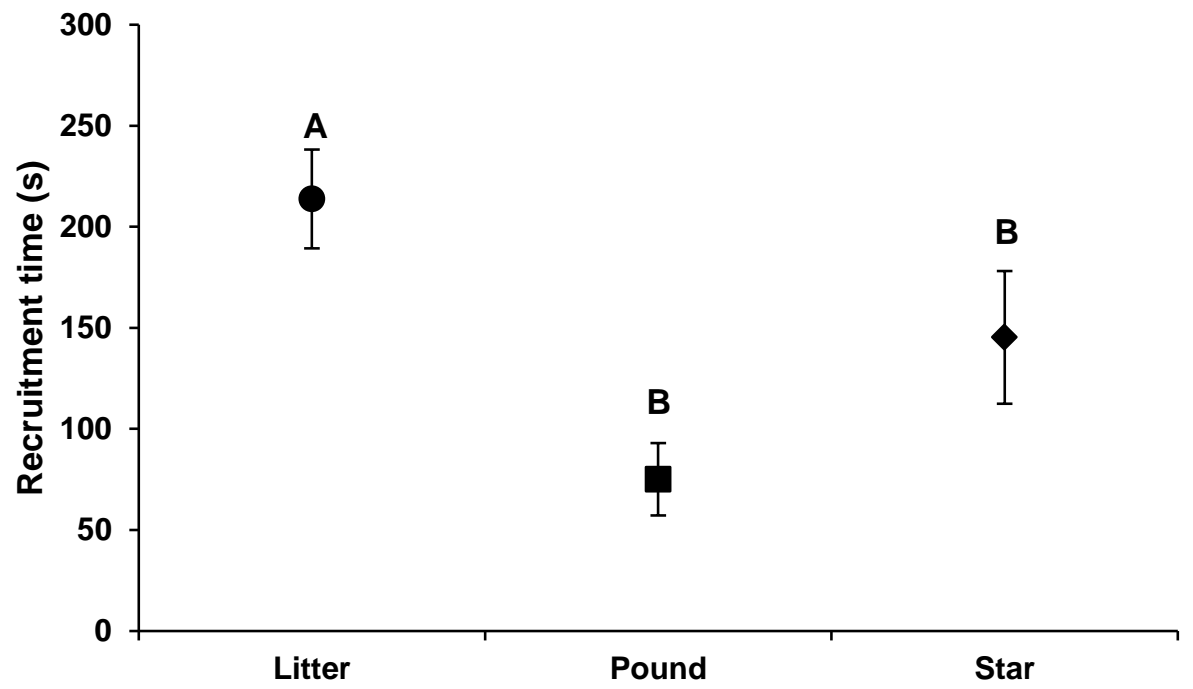


Figure 29.

A.

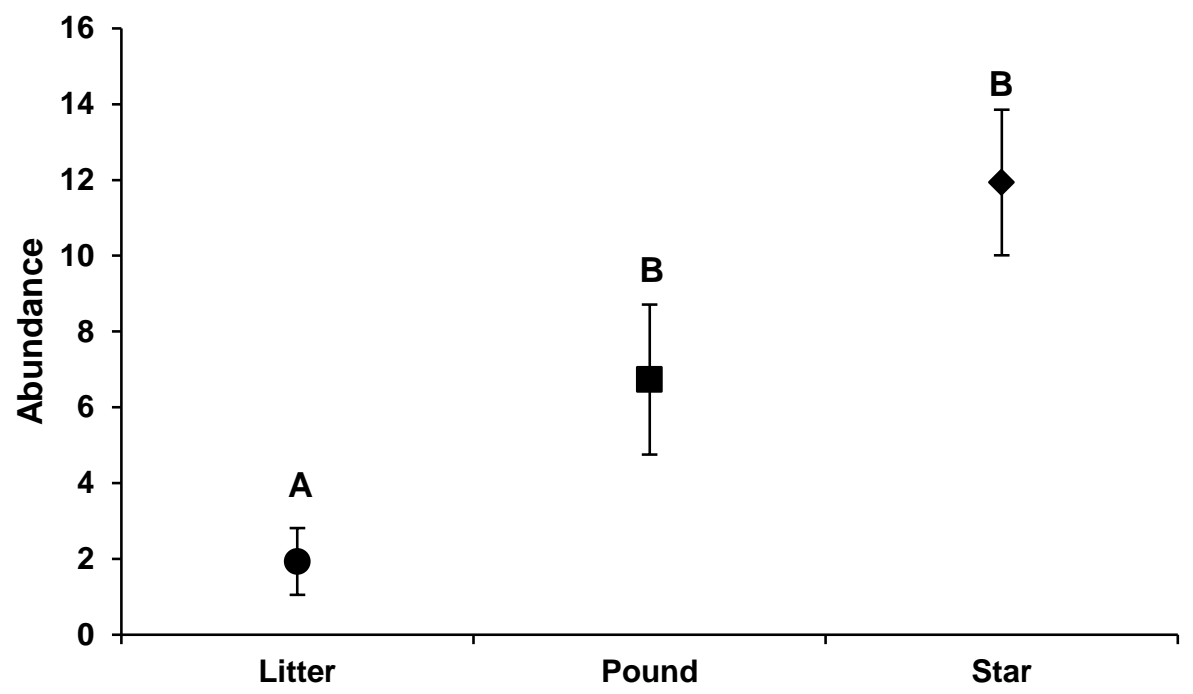

B.

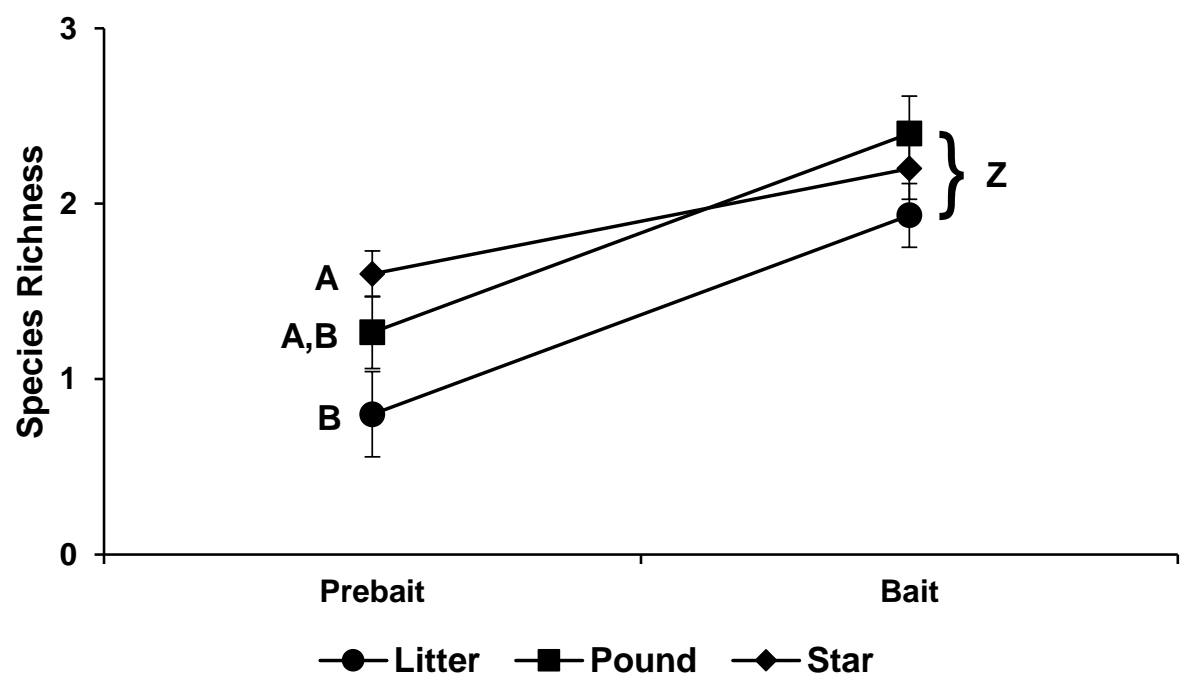


C.

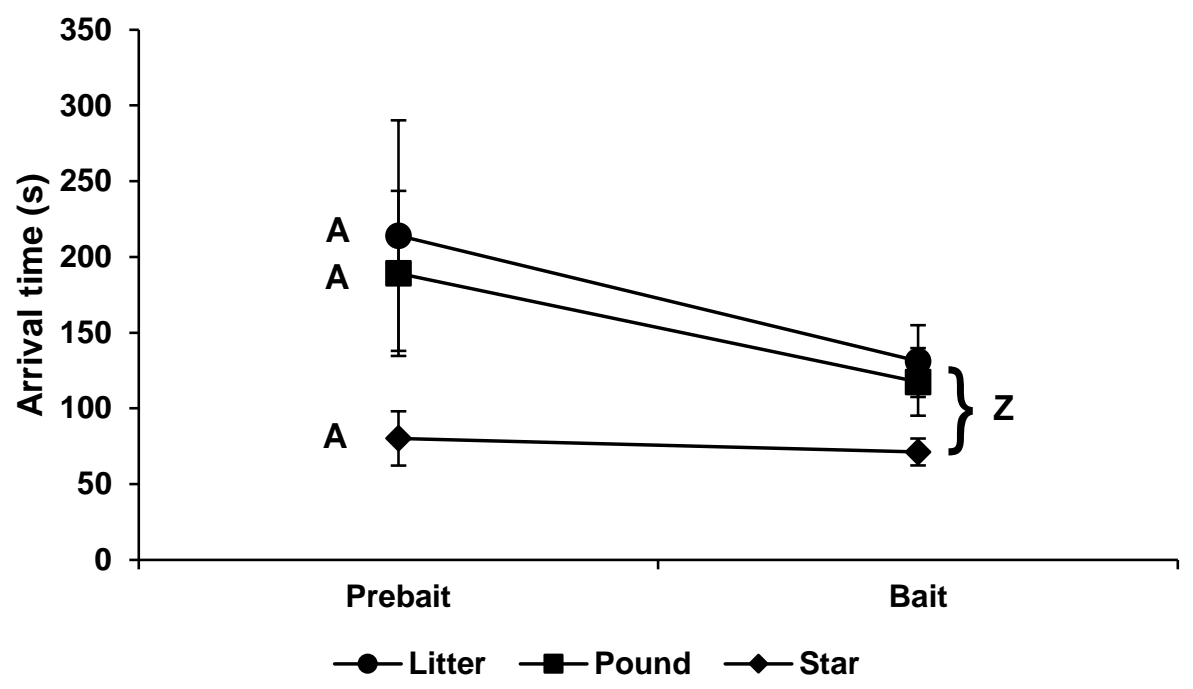

D.

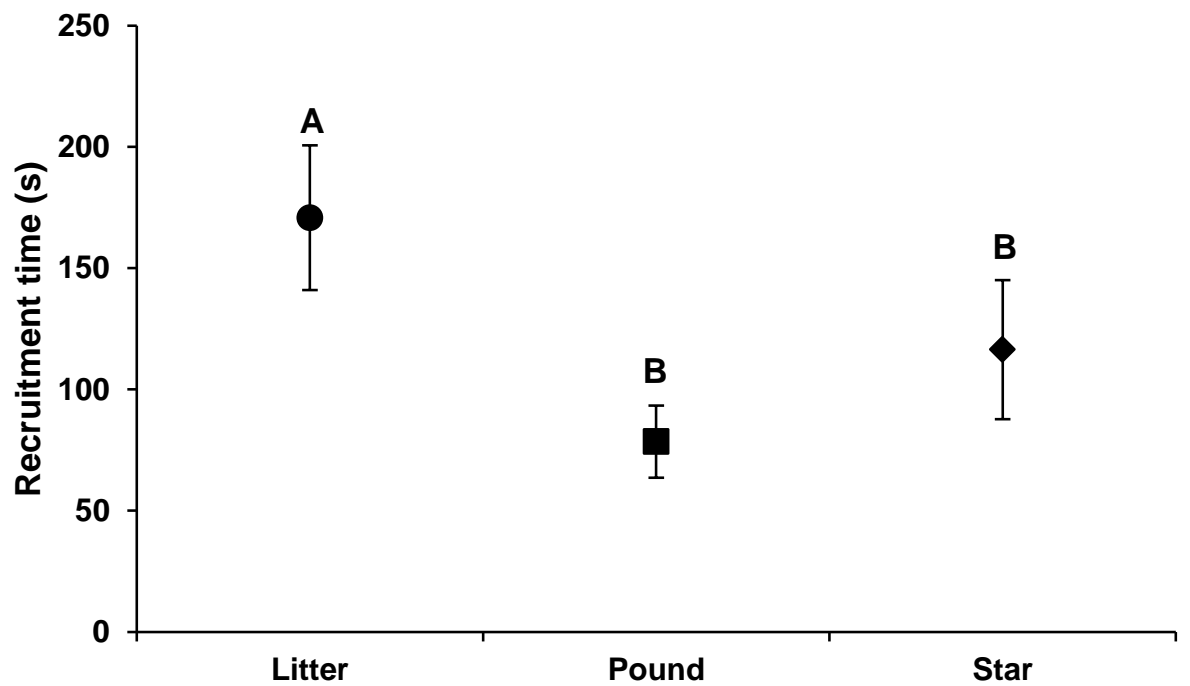




\section{CHAPTER V}

\section{SUMMARY AND FUTURE DIRECTIONS}

This dissertation investigated the role that physical connections play in shaping the diversity and behaviors of ants living in tropical forests. I determined that the structure of ant communities in individual tree crowns is affected by liana presence or absence. Ant species richness was, on average, higher in trees that had lianas. In trees without lianas, ant species richness fit a positive species-area relationship where larger trees tend to host more species of ants. Ant species composition also differed between trees with and without lianas. Specifically, ant species that are characterized by having wide-ranging, solitary foragers occurred more frequently in trees with lianas. Ant species that occupy disturbed and open habitats occurred 10 times more frequently in trees without lianas compared to trees with lianas. Removing lianas from a tree crown caused ant species richness to drop by 20\%. After three years, ant species richness also fit a species-area relationship very similar to that shown for naturally liana-free trees. The effects of liana removal could be mitigated by adding artificial connections among tree crowns using climbing ropes. Other resources provided by lianas, such as nest sites, did not appear to affect overall ant species richness or composition in a focal tree crown. These observations and experimental manipulations confirmed that connectivity among tree crowns provided by lianas is directly responsible for maintaining the difference in arboreal ant diversity detected in trees with and without lianas.

On the forest floor, epigeic ants occurred more frequently on cleared paths including exposed roots and ropes. The frequency with which ants used these paths was determined by the density of paths available within a given area. Ants also recruited to 
baits more quickly in areas that had a higher density of paths but only when four or more paths per $1 \mathrm{~m}^{2}$ were available. Changing the number of connections among paths or removing the surrounding leaf litter from the environment had no effect on whether ants used a pathway. Cleared paths are used more frequently by epigeic ants but it is unclear if path use is driven by foraging efficiency.

Collectively, the results of this dissertation highlight the importance of connective structures in the assembly and the maintenance of ant diversity in tropical forests. Furthermore, the results from this dissertation raise many additional questions and provide several avenues for informative future projects. First, do lianas function as important connective structures for ant communities at all stages of tropical forest succession? Arboreal ant communities develop ontologically in trees in temperate forests with younger trees in early secondary forests being primarily dominated by epigeic ant species (Tschinkel and Hess 1999). If the same pattern is true in tropical forests, it is likely that lianas will play a much more limited role in shaping arboreal ant species richness and composition as epigeic ants will readily cross the ground to move between tree crowns. Additionally, what role does connectivity play for arboreal ant communities in different tropical forests where vines are less present (Schnitzer and Bongers 2002)? The cost of defending territory decreases with decreases in the length of shared boundaries (Eason 1992, Adams 2001). Crown isolation could be the major driver behind the formation of territories ants aggressively defend in other tropical studies (Mayer 1976, Leston 1978, Sander et al. 2007). Lianas also decrease in abundance moving away from the tropics (Schnitzer and Bongers 2002). Ant communities in trees should be less strictly arboreal where readily available connections are not available to move through the canopy. Lianas and vines also are often pruned from urban environments like parks and greenspaces. Presumably, these urban environments should select for ant species that also can survive in both tree crowns and 
on the ground. Connective paths also are used by ants in the leaf litter but not necessarily to decrease foraging time. These paths should increase average ant running speed (Farji-Brener et al. 2007, Yanoviak et al. 2017) which could reduce predation and parasitoid pressure (Feener 2000, LeBrun 2005). Future studies should prioritize measure ant running speed and trajectory on and off cleared paths in the leaf litter. Ants living from the forest floor to the canopy rely on clear, connecting pathways to forage, explore, and move through their environments. As a result, connective structures like lianas and exposed roots have significant effects on ant communities and behaviors. Understanding how the physical elements of habitat regulate local communities is a fundamental to understanding patterns of diversity. 


\section{REFERENCES}

Adams, B. J., S. A. Schnitzer, and S. P. Yanoviak. 2017. Trees as islands: canopy ant species richness increases with the size of liana-free trees in a Neotropical forest. Ecography 40: 1067-1075

Adams, E. S. 1990. Boundary disputes in the territorial ant Azteca trigona: effects of asymmetries in colony size. Animal Behavior 39:321-328.

Adams, E. S. 2001. Approaches to the study of territory size and shape. Annual Review of Ecology and Systematics 32:277-303.

Adams, E. S. 2016. Territoriality in ants (Hymenoptera: Formicidae): a review. Myrmecological News 23:101-118.

Agrawal, A. A., D. D. Ackerly, F. Adler, A. E. Arnold, C. Cáceres, D. F. Doak, E. Post, P. J. Hudson, J. Maron, K. A. Mooney, M. Power, D. Schemske, J. Stachowicz, S. Strauss, M. G. Turner, and E. Werner. 2007. Filling key gaps in population and community ecology. Frontiers in Ecology and the Environment 5:145-152.

Anderson, M. J., R. Gorley, and K. Clarke. 2008. PERMANOVA+ for Primer. Plymouth, UK: Primer-E.

Anderson, M. J. 2006. Distance-based tests for homogeneity of multivariate dispersions. Biometrics 62:245-253.

Anderson, M. J., T. O. Crist, J. M. Chase, M. Vellend, B. D. Inouye, A. L. Freestone, N. J. Sanders, H. V. Cornell, L. S. Comita, and K. F. Davies. 2011. Navigating the multiple meanings of $\beta$ diversity: a roadmap for the practicing ecologist. Ecology Letters 14:19-28. 
Anderson, M. J., K. E. Ellingsen, and B. H. McArdle. 2006. Multivariate dispersion as a measure of beta diversity. Ecology Letters 9:683-693.

Ashford, O. S., W. A. Foster, B. L. Turner, E. Sayer, L. Sutcliffe, and E. V. Tanner. 2013. Litter manipulation and the soil arthropod community in a lowland tropical rainforest. Soil Biology and Biochemistry 62:5-12.

Basset, Y. 1992. Host specificity of arboreal and free-living insect herbivores in rain forests. Biological Journal of the Linnean Society 47:115-133.

Basset, Y., L. Cizek, P. Cuénoud, R. K. Didham, F. Guilhaumon, O. Missa, V. Novotny, F. Ødegaard, T. Roslin, J. Schmidl, A. K. Tishechkin, N. N. Winchester, D. W. Roubik, H.-P. Aberlenc, J. Bail, H. Barrios, J. R. Bridle, G. Castaño-Meneses, B. Corbara, G. Curletti, W. D. da Rocha, D. D. Bakker, J. H. C. Delabie, A. Dejean, L. L. Fagan, A. Floren, R. L. Kitching, E. Medianero, S. E. Miller, E. G. Oliveira, O. Orivel, M. Pollet, M. Rapp, S. P. Ribeiro, Y. Roisin, J. B. Schmidt, L. Sørensen, and M. Leponce. 2012. Arthropod diversity in a tropical forest. Science 338:14811484.

Basset, Y., G. A. Samuelson, A. Allison, and S. E. Miller. 1996. How many species of hostspecific insects feed on a species of tropical tree? Biological Journal of the Linnean Society 59:201-216.

Bates, D., M. Mächler, B. Bolker, and S. Walker. 2014. Fitting linear mixed-effects models using lme4. arXiv preprint arXiv:1406.5823.

Beckers, R., J.-L. Deneubourg, and S. Goss. 1992. Trails and U-turns in the selection of a path by the ant Lasius niger. Journal of Theoretical Biology 159:397-415.

Bernadou, A., X. Espadaler, V. Dos-Reis, and V. Fourcassié. 2011. Effect of substrate roughness on load selection in the seed-harvester ant Messor barbarus L. (Hymenoptera, Formicidae). Behavioral Ecology and Sociobiology 65:1763. 
Bloom, A. J., F. S. Chapin III, and H. A. Mooney. 1985. Resource limitation in plants-an economic analogy. Annual Review of Ecology and Systematics 16:363-392.

Blüthgen, N., and K. Fiedler. 2002. Interactions between weaver ants Oecophylla smaragdina, homopterans, trees and lianas in an Australian rain forest canopy. Journal of Animal Ecology 71:793-801.

Blüthgen, N., and N. E. Stork. 2007. Ant mosaics in a tropical rainforest in Australia and elsewhere: a critical review. Austral Ecology 32:93-104.

Blüthgen, N., N. E. Stork, and K. Fiedler. 2004. Bottom-up control and co-occurrence in complex communities: honeydew and nectar determine a rainforest ant mosaic. Oikos 106:344-358.

Blüthgen, N., M. Verhaagh, W. Goitía, K. Jaffé, W. Morawetz, and W. Barthlott. 2000. How plants shape the ant community in the Amazonian rainforest canopy: the key role of extrafloral nectaries and homopteran honeydew. Oecologia 125:229240.

Bovet, P., and S. Benhamou. 1991. Optimal sinuosity in central place foraging movements. Animal Behaviour 42:57-62.

Brown, J. H. 1971. Mammals on mountaintops: nonequilibrium insular biogeography. The American Naturalist 105:467-478.

Buhl, J., K. Hicks, E. R. Miller, S. Persey, O. Alinvi, and D. J. Sumpter. 2009. Shape and efficiency of wood ant foraging networks. Behavioral Ecology and Sociobiology 63:451-460.

Bultman, T. L., and G. W. Uetz. 1984. Effect of structure and nutritional quality of litter on abundances of litter-dwelling arthropods. American Midland Naturalist 111:165-172.

Burd, M. 1996. Foraging performance by Atta colombica, a leaf-cutting ant. The American Naturalist 148:597-612. 
Caley, M. J., and D. Schluter. 1997. The relationship between local and regional diversity. Ecology 78:70-80.

Camargo, R. X., and P. S. Oliveira. 2012. Natural history of the Neotropical arboreal ant, Odontomachus hastatus: nest sites, foraging schedule, and diet. Journal of Insect Science 12:48.

Camarota, F., S. Powell, A. S Melo, G. Priest, R. J Marquis, and H. L Vasconcelos. 2016. Co-occurrence patterns in a diverse arboreal ant community are explained more by competition than habitat requirements. Ecology and Evolution 6:8907-8918.

Campos, R. I., H. L. Vasconcelos, S. P. Ribeiro, F. S. Neves, and J. P. Soares. 2006. Relationship between tree size and insect assemblages associated with Anadenanthera macrocarpa. Ecography 29:442-450.

Carroll, C. R., and D. H. Janzen. 1973. Ecology of foraging by ants. Annual Review of Ecology and Systematics 4:231-257.

Charnov, E. L. 1976. Optimal foraging, the marginal value theorem. Theoretical population biology 9:129-136.

Christensen, R. H. B. 2010. ordinal-regression models for ordinal data. R package version 22.

Clarke, K. R., and R. N. Gorley. 2006. PRIMER V6: user manual-tutorial. Plymouth, UK: Primer-E.

Clay, N. A., M. Bauer, M. Solis, and S. P. Yanoviak. 2010. Arboreal substrates influence foraging in tropical ants. Ecological Entomology 35:417-423.

Colwell, R. K. 2009. EstimateS: statistical estimation of species richness and shared species from samples. Version 8.2. User's Guide and application published at: http://purl.oclc.org/estimates.

Condit, R. 1995. Research in large, long-term tropical forest plots. Trends in Ecology and Evolution 10:18-22. 
Cornell, H. V., and J. H. Lawton. 1992. Species interactions, local and regional processes, and limits to the richness of ecological communities: a theoretical perspective. Journal of Animal Ecology 61:1-12.

Couzin, I. D., and N. R. Franks. 2003. Self-organized lane formation and optimized traffic flow in army ants. Proceedings of the Royal Society of London B: Biological Sciences 270:139-146.

Cowen, R. K., K. M. Lwiza, S. Sponaugle, C. B. Paris, and D. B. Olson. 200o. Connectivity of marine populations: open or closed? Science 287:857-859.

Crist, T., and J. MacMahon. 1991. Individual foraging components of harvester ants: movement patterns and seed patch fidelity. Insectes Sociaux 38:379-396.

Cuissi, R. G., C. J. Lasmar, T. S. Moretti, F. A. Schmidt, W. D. Fernandes, A. B. Falleiros, J. H. Schoereder, and C. R. Ribas. 2015. Ant community in natural fragments of the Brazilian wetland: species-area relation and isolation. Journal of Insect Conservation 19:531-537.

Davidson, D. W. 1997. The role of resource imbalances in the evolutionary ecology of tropical arboreal ants. Biological Journal of the Linnean Society 61:153-181.

Davidson, D. W., and W. W. Epstein. 1989. Epiphytic associations with ants. Pages 200233 in U. Lüttge, editor. Vascular plants as epiphytes: evolution and ecophysiology. Springer-Verlag, Berlin.

Davidson, D. W., J. T. Longino, and R. R. Snelling. 1988. Pruning of host plant neighbors by ants: an experimental approach. Ecology 69:801-808.

Davidson, D. W., S. C. Cook, R. R. Snelling, and T. H. Chua. 2003. Explaining the abundance of ants in lowland tropical rainforest canopies. Science 300:969-972.

De Almeida, W. R., R. Wirth, and I. R. Leal. 2008. Edge-mediated reduction of phorid parasitism on leaf-cutting ants in a Brazilian Atlantic forest. Entomologia Experimentalis et Applicata 129:251-257. 
de Andrade, M. L., and C. Baroni Urbani. 1999. Diversity and adaptation in the ant genus Cephalotes, past and present. Stuttgarter Beiträge zur Naturkunde, Serie B (Geologie und Paläontologie). Stuttgart Museum of Natural History, Germany. de Cáceres, M. D., P. Legendre, and M. Moretti. 2010. Improving indicator species analysis by combining groups of sites. Oikos 119:1674-1684.

de Cáceres, M. D., and P. Legendre. 2009. Associations between species and groups of sites: indices and statistical inference. Ecology 90:3566-3574.

de Castro, E. A., and J. B. Kauffman. 1998. Ecosystem structure in the Brazilian Cerrado: a vegetation gradient of aboveground biomass, root mass and consumption by fire. Journal of Tropical Ecology 14:263-283.

Dejean, A., B. Corbara, and J. Orivel. 1999. The arboreal ant mosaic in two Atlantic rain forests. Selbyana 20:133-145.

Dejean, A., B. Corbara, J. Orivel, and M. Leponce. 2007. Rainforest canopy ants: the implications of territoriality and predatory behavior. Functional Ecosystems and Communities 1:105-120.

Dejean, A., D. McKey, M. Gibernau, and M. Belin. 2000. The arboreal ant mosaic in a Cameroonian rainforest (Hymenoptera: Formicidae). Sociobiology 35:403-423.

Denny, A. J., J. Wright, and B. Grief. 2001. Foraging efficiency in the wood ant, Formica rufa: is time of the essence in trail following? Animal Behaviour 62:139-146.

Dufrêne, M., and P. Legendre. 1997. Species assemblages and indicator species: the need for a flexible asymmetrical approach. Ecological Monographs 67:345-366.

Dussutour, A., J.-L. Deneubourg, and V. Fourcassié. 2005. Amplification of individual preferences in a social context: the case of wall-following in ants. Proceedings of the Royal Society of London B: Biological Sciences 272:705-714.

Dussutour, A., V. Fourcassie, D. Helbing, and J.-L. Deneubourg. 2004. Optimal traffic organization in ants under crowded conditions. Nature 428:70-73. 
Dussutour, A., S. C. Nicolis, J.-L. Deneubourg, and V. Fourcassié. 2006. Collective decisions in ants when foraging under crowded conditions. Behavioral Ecology and Sociobiology 61:17-30.

Eason, P. 1992. Optimization of territory shape in heterogeneous habitats: a field study of the red-capped cardinal (Paroaria gularis). Journal of Animal Ecology:411424.

Eason, P. K., G. A. Cobbs, and K. G. Trinca. 1999. The use of landmarks to define territorial boundaries. Animal Behaviour 58:85-91.

Ellison, A. M., N. J. Gotelli, R. R. Dunn, and N. J. Sanders. 2011. Counting ants (Hymenoptera: Formicidae): biodiversity sampling and statistical analysis for myrmecologists.

Emmons, L., and A. H. Gentry. 1983. Tropical forest structure and the distribution of gliding and prehensile-tailed vertebrates. American Naturalist 121:513-524.

Erwin, T. L. 1982. Tropical forests: their richness in Coleoptera and other arthropod species. The Coleopterists Bulletin 36:74-75.

Fahrig, L. 2003. Effects of habitat fragmentation on biodiversity. Annual Review of Ecology, Evolution, and Systematics 34:487-515.

Farji-Brener, A. G., G. Barrantes, and A. Ruggiero. 2004. Environmental rugosity, body size and access to food: a test of the size-grain hypothesis in tropical litter ants. Oikos 104:165-171.

Farji-Brener, A. G., and C. Sierra. 1998. The role of trunk trails in the scouting activity of the leaf-cutting ant Atta cephalotes. Ecoscience 5:271-274.

Farji-Brener, A. G., G. Barrantes, O. Laverde, K. Fierro-Calderón, F. Bascopé, and A. López. 2007. Fallen Branches as Part of Leaf-Cutting Ant Trails: Their Role in Resource Discovery and Leaf Transport Rates in Atta cephalotes. Biotropica 39:211-215. 
Feener, D. H. 2000. Is the assembly of ant communities mediated by parasitoids? Oikos 90:79-88.

Fewell, J. H. 1988. Energetic and time costs of foraging in harvester ants, Pogonomyrmex occidentalis. Behavioral Ecology and Sociobiology 22:401-408.

Floren, A., and K. E. Linsenmair. 2005. The importance of primary tropical rain forest for species diversity: an investigation using arboreal ants as an example. Ecosystems 8:559-567.

Frank, J. H., and L. P. Lounibos. 1987. Phytotelmata: swamps or islands? Florida Entomologist 70:14-20.

Frederickson, M. E. 2006. The reproductive phenology of an Amazonian ant species reflects the seasonal availability of its nest sites. Oecologia 149:418-427.

Fresneau, D. 1985. Individual foraging and path fidelity in a ponerine ant. Insectes Sociaux 32:109-116.

Garnier, S., A. Guérécheau, M. Combe, V. Fourcassié, and G. Theraulaz. 2009. Path selection and foraging efficiency in Argentine ant transport networks. Behavioral Ecology and Sociobiology 63:1167-1179.

Gause, G. F. 1934. Experimental analysis of Vito Volterra's mathematical theory of the struggle for existence. Science 79:16-17.

Gibb, H., and C. Parr. 2010. How does habitat complexity affect ant foraging success? A test using functional measures on three continents. Oecologia 164:1061-1073.

Godfray, H., O. Lewis, and J. Memmott. 1999. Studying insect diversity in the tropics. Philosophical Transactions of the Royal Society of London B: Biological Sciences 354:1811-1824.

Gonzalez, A., J. H. Lawton, F. S. Gilbert, T. M. Blackburn, and I. Evans-Freke. 1998. Metapopulation dynamics, abundance, and distribution in a microecosystem. Science 281:2045-2047. 
Gotelli, N. J. 2000. Null model analysis of species co-occurrence patterns. Ecology 81:2606-2621.

Gotelli, N. J., and W. Ulrich. 2012. Statistical challenges in null model analysis. Oikos 121:171-18o.

Gotelli, N.J. and A. M. Ellison. 2013. EcoSimR 1.oo. (<http://www.uvm.edu/ ngotelli/EcoSim/EcoSim.html >).

Guisan, A., and F. E. Harrell. 2000. Ordinal response regression models in ecology. Journal of Vegetation Science 11:617-626.

Hahn, D. A., and D. E. Wheeler. 2002. Seasonal Foraging Activity and Bait Preferences of Ants on Barro Colorado Island, Panama1. Biotropica 34:348-356.

Haines, B., and R. B. Foster. 1977. Energy flow through litter in a Panamanian forest. Journal of Ecology 65:147-155.

Hamilton III, W. J., and K. E. Watt. 1970. Refuging. Annual Review of Ecology and Systematics 1:263-286.

Hamilton, W. J., W. M. Gilbert, F. H. Heppner, and R. J. Planck. 1967. Starling Roost Dispersal and a Hypothetical Mechanism Regulating Rhthmical Animal Movement to and from Dispersal Centers. Ecology 48:825-833.

Hansen, R. A. 2000. Effects of habitat complexity and composition on a diverse litter microarthropod assemblage. Ecology 81:1120-1132.

Hanski, I. 1982. Dynamics of regional distribution: the core and satellite species hypothesis. Oikos 38:210-221.

Hanski, I., and M. Gilpin. 1991. Metapopulation dynamics: brief history and conceptual domain. Biological Journal of the Linnean Society 42:3-16.

Harkness, R., and N. Maroudas. 1985. Central place foraging by an ant (Cataglyphis bicolor Fab.): a model of searching. Animal Behaviour 33:916-928. 
Harris, L. D. 1984. The fragmented forest: island biogeography theory and the preservation of biotic diversity. University of Chicago press, Chicago, IL.

Henderson, G., R. O. Wagner, and R. L. Jeanne. 1989. Prairie ant colony longevity and mound growth. Psyche 96:257-268.

Hijii, N. 1986. Density, biomass, and guild structure of arboreal arthropods as related to their inhabited tree size in a Cryptomeria japonica plantation. Ecological Research 1:97-118.

Holder, K., and G. Polis. 1987. Optimal and central-place foraging theory applied to a desert harvester ant, Pogonomyrmex californicus. Oecologia 72:440-448.

Hölldobler, B., and C. J. Lumsden. 1980. Territorial strategies in ants. Science 210:732739.

Hölldobler, B., and E. O. Wilson. 1990. The ants. Harvard University Press.

Hortal, J., K. A. Triantis, S. Meiri, E. Thébault, and S. Sfenthourakis. 2009. Island species richness increases with habitat diversity. The American Naturalist 174:205-217.

Hosang, M., C. Schulze, T. Tscharntke, and D. Buchori. 2010. The potential of artificial nesting sites for increasing the population density of the black cacao ants. Indonesian Journal of Agriculture 3:45-40.

Howard, J. J. 2001. Costs of trail construction and maintenance in the leaf-cutting ant Atta columbica. Behavioral Ecology and Sociobiology 49:348-356.

Huffaker, C. B. 1958. Experimental studies on predation: dispersion factors and predator-prey oscillations. Hilgardia 27:343-383.

Huston, M. A. 1999. Local processes and regional patterns: appropriate scales for understanding variation in the diversity of plants and animals. Oikos 86:393-401. 
Ingram, K. K., A. Pilko, J. Heer, and D. M. Gordon. 2013. Colony life history and lifetime reproductive success of red harvester ant colonies. Journal of Animal Ecology 82:540-550.

Ingwell, L. L., S. Joseph Wright, K. K. Becklund, S. P. Hubbell, and S. A. Schnitzer. 2010. The impact of lianas on 10 years of tree growth and mortality on Barro Colorado Island, Panama. Journal of Ecology 98:879-887.

Janzen, D. H. 1966. Coevolution of mutualism between ants and acacias in Central America. Evolution 20:249-275.

Janzen, D. H. 1968. Host plants as islands in evolutionary and contemporary time. The American Naturalist 102:592-595.

Janzen, D. H. 1973. Host plants as islands. II. Competition in evolutionary and contemporary time. The American Naturalist 107:786-790.

Johnson, J. B., and K. S. Omland. 2004. Model selection in ecology and evolution. Trends in ecology \& evolution 19:101-108.

Kadmon, R., and O. Allouche. 2007. Integrating the effects of area, isolation, and habitat heterogeneity on species diversity: a unification of island biogeography and niche theory. The American Naturalist 170:443-454.

Kaspari, M. 1996. Litter ant patchiness at the $1-\mathrm{m}^{2}$ scale: disturbance dynamics in three Neotropical forests. Oecologia 107:265-273.

Kaspari, M., N. A. Clay, J. A. Lucas, S. Revzen, A. D. Kay, and S. P. Yanoviak. 2016. Thermal adaptation and phosphorus shape thermal performance in an assemblage of rainforest ants. Ecology 97:1038-1047.

Kaspari, M., and M. D. Weiser. 1999. The size-grain hypothesis and interspecific scaling in ants. Functional Ecology 13:530-538. 
Kaspari, M., and S. P. Yanoviak. 2008. Biogeography of litter depth in tropical forests: evaluating the phosphorus growth rate hypothesis. Functional Ecology 22:919923.

Kasuya, E. 1982. Central place water collection in a Japanese paper wasp, Polistes chinensis antennalis. Animal Behaviour 30:1010-1014.

Keddy, P. A. 1992. Assembly and response rules: two goals for predictive community ecology. Journal of Vegetation Science 3:157-164.

Klimes, P., C. Idigel, M. Rimandai, T. M. Fayle, M. Janda, G. D. Weiblen, and V. Novotny. 2012. Why are there more arboreal ant species in primary than in secondary tropical forests? Journal of Animal Ecology 81:1103-1112.

Kohn, D., and D. Walsh. 1994. Plant species richness--the effect of island size and habitat diversity. Journal of Ecology:367-377.

Kugler, C. 1984. Ecology of the ant Pogonomyrmex mayri: foraging and competition. Biotropica:227-234.

Lawton, J. 1983. Plant architecture and the diversity of phytophagous insects. Annual Review of Entomology 28:23-39.

LeBrun, E. G. 2005. Who is the top dog in ant communities? Resources, parasitoids, and multiple competitive hierarchies. Oecologia 142:643-652.

Leigh, E. G., A. S. Rand, and D. M. Windsor. 1996. The ecology of a tropical forest: Seasonal rhythms and long-term changes. Second Edition. Smithsonian Press, Washington DC.

Leston, D. 1978. A neotropical ant mosaic. Annals of the Entomological Society of America 71:649-653.

Levings, S. C., and D. M. Windsor. 1996. Seasonal and annual variation in litter arthropod populations. Pages $355-387$ in E. G. Leigh, Jr, A. S. Rand, and D. M. 
Windsor, editors. The ecology of a tropical forest. Smithsonian Press, Washington DC.

Levins, R., M. L. Pressick, and H. Heatwole. 1973. Coexistence Patterns in Insular Ants: In which it is shown that ants travel a lot from island to island, and what they do when they get there. American Scientist 61:463-472.

Longino, J. T. 2003. The Crematogaster (Hymenoptera, Formicidae, Myrmicinae) of Costa Rica. Zootaxa 151:1-150.

Longino, J. T. 2007. A taxonomic review of the genus Azteca (Hymenoptera: Formicidae) in Costa Rica and a global revision of the aurita group. Magnolia Press, Longwood, FL.

Longino, J. T. 2010. Ants of Costa Rica (http://academic.evergreen.edu/projects/ants/AntsOfCostaRica.html).

Longino, J. T., J. Coddington, and R. K. Colwell. 2002. The ant fauna of a tropical rain forest: estimating species richness three different ways. Ecology 83:689-702.

Losos, J. B., and R. E. Ricklefs. 2009. The theory of island biogeography revisited. Princeton University Press. Princeton, NJ.

MacArthur, R., and E. Wilson. 1967. The theory of biogeography. Princeton University Press, Princeton, NJ.

MacArthur, R. H., and J. W. MacArthur. 1961. On bird species diversity. Ecology 42:594598.

MacArthur, R. H., and E. R. Pianka. 1966. On optimal use of a patchy environment. The American Naturalist 100:603-609.

MacArthur, R. H., and E. O. Wilson. 1963. An equilibrium theory of insular zoogeography. Evolution:373-387.

Majer, J. 1972. The ant mosaic in Ghana cocoa farms. Bulletin of Entomological Research 62:151-16o. 
Majer, J. 1976. The maintenance of the ant mosaic in Ghana cocoa farms. Journal of Applied Ecology:123-144.

Majer, J., and J. Delabie. 1999. Impact of tree isolation on arboreal and ground ant communities in cleared pasture in the Atlantic rain forest region of Bahia, Brazil. Insectes Sociaux 46:281-290.

Majer, J. D., J. H. Delabie, and M. R. Smith. 1994. Arboreal ant community patterns in Brazilian cocoa farms. Biotropica 26:73-83.

Martínez-Izquierdo, L., M. M. García, J. S. Powers, and S. A. Schnitzer. 2016. Lianas suppress seedling growth and survival of 14 tree species in a Panamanian tropical forest. Ecology 97:215-224.

Metaxas, A., and R. E. Scheibling. 1993. Community structure and organization of tidepools. Marine ecology progress series. Oldendorf 98:187-198.

Moeed, A., and M. Meads. 1983. Invertebrate fauna of four tree species in Orongorongo Valley, New Zealand, as revealed by trunk traps. New Zealand journal of ecology 6:39-53.

Montgomery, G. G. 1985. Impact of vermilinguas (Cyclopes, Tamandua: Xenarthra = Edentata) on arboreal ant populations. Pages 351-363 in G. G. Montgomery, editor. The Evolution and Ecology of Armadillos, Sloths, and Vermilinguas. Smithsonian Press, Washington DC.

Moreau, C. S., C. D. Bell, R. Vila, S. B. Archibald, and N. E. Pierce. 2006. Phylogeny of the ants: diversification in the age of angiosperms. Science 312:101-104.

Myers, J. A., and K. E. Harms. 2009. Seed arrival, ecological filters, and plant species richness: a meta-analysis. Ecology Letters 12:1250-126o.

Nadkarni, N. M., G. G. Parker, H. B. Rinker, and D. M. Jarzen. 2004. The nature of forest canopies. Forest Canopies, Second Edition. Academic/Elsevier, San Diego, CA.

Ng, F. S. P. 1977. Shyness in trees. Nature Malaysiana 2:35-37. 
Nilsson, S. G., J. Bengtsson, and S. As. 1988. Habitat diversity or area per se? Species richness of woody plants, carabid beetles and land snails on islands. The Journal of Animal Ecology 57:685-704.

O'Brien, S. T., S. P. Hubbell, P. Spiro, R. Condit, and R. B. Foster. 1995. Diameter, height, crown, and age relationship in eight neotropical tree species. Ecology 76:1926-1939.

Ødegaard, F. 2000. The relative importance of trees versus lianas as hosts for phytophagous beetles (Coleoptera) in tropical forests. Journal of Biogeography 27:283-296.

Ozanne, C., D. Anhuf, S. Boulter, M. Keller, R. Kitching, C. Körner, F. Meinzer, A. Mitchell, T. Nakashizuka, and P. S. Dias. 2003. Biodiversity meets the atmosphere: a global view of forest canopies. Science 301:183-186.

Pacheco, J. A., W. P. Mackay, and J. Lattke. 2013. The systematics and biology of the New World thief ants of the genus Solenopsis (Hymenoptera: Formicidae). Edwin Mellen Press Lewiston, NY, USA.

Pérez-Salicrup, D. R., V. L. Sork, and F. E. Putz. 2001. Lianas and trees in a liana forest of Amazonian Bolivia. Biotropica 33:34-47.

Perry, D. R. 1978. A method of access into the crowns of emergent and canopy trees. Biotropica 10:155-157.

Philpott, S. M. 2010. A canopy dominant ant affects twig-nesting ant assembly in coffee agroecosystems. Oikos 119:1954-1960.

Philpott, S. M., and P. F. Foster. 2005. Nest-site limitation in coffee agroecosystems: artificial nests maintain diversity of arboreal ants. Ecological Applications 15:1478-1485. 
Poelman, E. H., J. J. van Loon, and M. Dicke. 2008. Consequences of variation in plant defense for biodiversity at higher trophic levels. Trends in plant science 13:534541.

Powell, S., A. N. Costa, C. T. Lopes, and H. L. Vasconcelos. 2011. Canopy connectivity and the availability of diverse nesting resources affect species coexistence in arboreal ants. Journal of Animal Ecology 80:352-36o.

Pratt, S. C., S. E. Brooks, and N. R. Franks. 2001. The use of edges in visual navigation by the ant Leptothorax albipennis. Ethology 107:1125-1136.

Preston, F. W. 1962. The canonical distribution of commonness and rarity: Part I. Ecology 43:185-215.

Putz, F. E. 1984a. How trees avoid and shed lianas. Biotropica 16:19-23.

Putz, F. E. 1984b. The natural history of lianas on Barro Colorado Island, Panama. Ecology 65:1713-1724.

Putz, F. E., G. G. Parker, and R. M. Archibald. 1984. Mechanical abrasion and intercrown spacing. American Midland Naturalist 112:24-28.

Pyke, G. H., H. R. Pulliam, and E. L. Charnov. 1977. Optimal foraging: a selective review of theory and tests. The Quarterly Review of Biology 52:137-154.

R Core Team. 2016. R: A language and environment for statistical computing. Vienna: R Foundation for Statistical Computing.

Rahel, F. J. 2007. Biogeographic barriers, connectivity and homogenization of freshwater faunas: it's a small world after all. Freshwater Biology 52:696-710.

Ratter, J. A., J. F. Ribeiro, and S. Bridgewater. 1997. The Brazilian cerrado vegetation and threats to its biodiversity. Annals of botany 80:223-230.

Reid, J. P., S. A. Schnitzer, and J. S. Powers. 2015. Short and long-term soil moisture effects of liana removal in a seasonally moist tropical forest. PLoS ONE 10:e0141891. 
Ribas, C. R., and J. H. Schoereder. 2002. Are all ant mosaics caused by competition? Oecologia 131:606-611.

Ribas, C. R., and J. H. Schoereder. 2004. Determining factors of arboreal ant mosaics in cerrado vegetation (Hymenoptera: Formicidae). Sociobiology 44:49-68.

Ribas, C. R., J. H. Schoereder, M. Pic, and S. M. Soares. 2003. Tree heterogeneity, resource availability, and larger scale processes regulating arboreal ant species richness. Austral Ecology 28:305-314.

Richardson, B. A., M. J. Richardson, G. González, A. B. Shiels, and D. S. Srivastava. 2010. A canopy trimming experiment in Puerto Rico: the response of litter invertebrate communities to canopy loss and debris deposition in a tropical forest subject to hurricanes. Ecosystems 13:286-301.

Ricklefs, R. E., and I. J. Lovette. 1999. The roles of island area per se and habitat diversity in the species-area relationships of four Lesser Antillean faunal groups. Journal of Animal Ecology 68:1142-116o.

Ricklefs, R. E., and D. Schluter. 1993. Species diversity: regional and historical influences. Pages 350-363 in R. E. Ricklefs and D. Schluter, editors. Species diversity in ecological communities. University of Chicago Press, Chicago, IL.

Rico-Gray, V., and P. S. Oliveira. 2007. The ecology and evolution of ant-plant interactions. University of Chicago Press, Chicago, IL.

Rosenzweig, M. L. 1995. Species diversity in space and time. Cambridge University Press, Cambridge, UK.

Sanders, N. J., G. M. Crutsinger, R. R. Dunn, J. D. Majer, and J. H. C. Delabie. 2007. An ant mosaic revisited: dominant ant species disassemble arboreal ant communities but co-occur randomly. Biotropica 39:422-427.

Sarty, M., K. L. Abbott, and P. J. Lester. 2006. Habitat complexity facilitates coexistence in a tropical ant community. Oecologia 149:465-473. 
Sayer, E. J., and E. V. J. Tanner. 2010. Experimental investigation of the importance of litterfall in lowland semi-evergreen tropical forest nutrient cycling. Journal of Ecology 98:1052-1062.

Schnitzer, S. A., and F. Bongers. 2002. The ecology of lianas and their role in forests. Trends in Ecology and Evolution 17:223-230.

Schnitzer, S. A., and F. Bongers. 2011. Increasing liana abundance and biomass in tropical forests: emerging patterns and putative mechanisms. Ecology Letters 14:397-406.

Schnitzer, S. A., S. A. Mangan, J. W. Dalling, C. Baldeck, S. P. Hubbell, A. Ledo, H. Muller-Landau, M. Tobin, S. Aguilar, D. Brassfield, A. Hernandez, S. Lao, R. Perez, O. Valdez, and S. R. Yorke. 2012. Liana abundance, diversity, and distribution on Barro Colorado Island, Panama. PLoS ONE 7:e52114.

Schulz, A., and T. Wagner. 2002. Influence of forest type and tree species on canopy ants (Hymenoptera: Formicidae) in Budongo Forest, Uganda. Oecologia 133:224-232.

Shepherd, J. D. 1982. Trunk trails and the searching strategy of a leaf-cutter ant, Atta colombica. Behavioral Ecology and Sociobiology 11:77-84.

Shulman, M. J. 1984. Resource limitation and recruitment patterns in a coral reef fish assemblage. Journal of Experimental Marine Biology and Ecology 74:85-109.

Simberloff, D. S., and E. O. Wilson. 1969. Experimental zoology of islands: the colonization of empty islands. Ecology 50:278-295.

Smith, C. L. 1978. Coral reef fish communities: a compromise view. Environmental Biology of Fishes 3:109-128.

Soltz, R. L. 1986. Foraging path selection in bumblebees: Hindsight or foresight? Behaviour 99:1-21.

Southwood, T. R. E., and C. E. J. Kennedy. 1983. Trees as islands. Oikos 41:359-371. 
Southwood, T. R. E., V. C. Moran, and C. E. J. Kennedy. 1982. The richness, abundance and biomass of the arthropod communities on trees. Journal of Animal Ecology 51:635-649.

Stickland, T., C. M. Tofts, and N. R. Franks. 1992. A path choice algorithm for ants. Naturwissenschaften 79:567-572.

Suriyampola, P. S., and P. K. Eason. 2014. A field study investigating effects of landmarks on territory size and shape. Biology Letters 10:20140009.

Sverdrup-Thygeson, A., and F. Midtgaard. 1998. Fungus-infected trees as islands in boreal forest: spatial distribution of the fungivorous beetle Bolitophagus reticulatus (Coleoptera, Tenebrionidae). Ecoscience 5:486-493.

Tan, Z.-J., X.-W. Zou, S.-Y. Huang, W. Zhang, and Z.-Z. Jin. 2002. Random walk with memory enhancement and decay. Physical Review E 65:041101.

Tanaka, H. O., S. Yamane, and T. Itioka. 2010. Within-tree distribution of nest sites and foraging areas of ants on canopy trees in a tropical rainforest in Borneo. Population Ecology 52:147-157.

Tewksbury, J. J., D. J. Levey, N. M. Haddad, S. Sargent, J. L. Orrock, A. Weldon, B. J. Danielson, J. Brinkerhoff, E. I. Damschen, and P. Townsend. 2002. Corridors affect plants, animals, and their interactions in fragmented landscapes. Proceedings of the National Academy of Sciences 99:12923-12926.

Tews, J., U. Brose, V. Grimm, K. Tielbörger, M. C. Wichmann, M. Schwager, and F. Jeltsch. 2004. Animal species diversity driven by habitat heterogeneity/diversity: the importance of keystone structures. Journal of Biogeography 31:79-92.

Tilman, D. 1982. Resource competition and community structure. Princeton university press, Princeton, NJ. 
Tilman, D., and S. Pacala. 1993. The maintenance of species richness in plant communities. Pages 13-25 in R. E. Ricklefs and D. Schluter, editors. Species diversity in ecological communities. University of Chicago Press, Chicago, IL.

Tockner, K., F. Schiemer, C. Baumgartner, G. Kum, E. Weigand, I. Zweimüller, J. Ward, and J. Layzer. 1999. The Danube restoration project: species diversity patterns across connectivity gradients in the floodplain system. Regulated Rivers: Research \& Management 15:245-258.

Tschinkel, W. R. 2002. The natural history of the arboreal ant, Crematogaster ashmeadi. Journal of Insect Science 2:12.

Tschinkel, W. R., and C. A. Hess. 1999. Arboreal ant community of a pine forest in northern Florida. Annals of the Entomological Society of America 92:63-70.

van der Heijden, G. M., and O. L. Phillips. 2008. What controls liana success in Neotropical forests? Global Ecology and Biogeography 17:372-383.

Ward, P. S. 1989. Systematic studies on Pseudomyrmecine ants: revision of the Pseudomyrmex oculatus and P. subtilissimus species groups, with taxonomic comments on other species. Quaestiones entomologicae 25:393-468.

Ward, P. S. 1993. Systematic studies on Pseudomyrmex acacia-ants (Hymenoptera: Formicidae: Pseudomyrmecinae). Journal of Hymenoptera Research 2:117-168.

Ward, P. S. 1999. Systematics, biogeography and host plant associations of the Pseudomyrmex viduus group (Hymenoptera: Formicidae), Triplaris- and Tachigali-inhabiting ants. Zoological Journal of the Linnean Society 126:451540.

Wardle, D. A. 2002. Communities and ecosystems: linking the aboveground and belowground components. Princeton University Press, Princeton, NJ. 
Wardle, D. A., G. W. Yeates, G. M. Barker, P. J. Bellingham, K. I. Bonner, and W. M. Williamson. 2003. Island biology and ecosystem functioning in epiphytic soil communities. Science 301:1717-1720.

Wehner, R., and M. V. Srinivasan. 1981. Searching behaviour of desert ants, genus Cataglyphis (Formicidae, Hymenoptera). Journal of comparative physiology 142:315-338.

Weiser, M. D., and M. Kaspari. 2006. Ecological morphospace of New World ants. Ecological Entomology 31:131-142.

Werner, E. E., and D. J. Hall. 1974. Optimal foraging and the size selection of prey by the bluegill sunfish (Lepomis macrochirus). Ecology 55:1042-1052.

Wilson, E. O. 1987. The arboreal ant fauna of Peruvian Amazon forests: a first assessment. Biotropica 19:245-251.

Wright, S. J., and F. H. Cornejo. 1990. Seasonal drought and leaf fall in a tropical forest. Ecology 71:1165-1175.

Wu, J., J. Huang, X. Han, Z. Xie, and X. Gao. 2003. Three-Gorges dam--experiment in habitat fragmentation? Science 300:1239-1240.

Yanoviak, S. P. 2015. Effects of lianas on canopy arthropod community structure. Pages 345-361 in S. A. Schnitzer, F. Bongers, R. Burnham, and F. E. Putz, editors. The ecology of lianas. Wiley-Blackwell, Chichester, UK.

Yanoviak, S. P., S. M. Berghoff, K. E. Linsenmair, and G. Zotz. 2011. Effects of an epiphytic orchid on arboreal ant community structure in Panama. Biotropica 43:731-737.

Yanoviak, S. P., B. L. Fisher, and A. Alonso. 2007. Arboreal ant diversity (Hymenoptera: Formicidae) in a central African forest. African Journal of Ecology 46:6o-66.

Yanoviak, S. P., and M. Kaspari. 2000. Community structure and the habitat templet: ants in the tropical forest canopy and litter. Oikos 89:259-266. 
Yanoviak, S. P., and S. A. Schnitzer. 2013. Functional roles of lianas for forest canopy animals. Pages 209-214 in M. Lowman, S. Devy, and T. Ganesh, editors. Treetops at risk: challenges of global forest canopies. Springer, New York, NY.

Yanoviak, S. P., C. Silveri, C. A. Hamm, and M. Solis. 2012. Stem characteristics and ant body size in a Costa Rican rain forest. Journal of Tropical Ecology 28:199-204.

Yanoviak, S. P., C. Silveri, A. Y. Stark, J. T. Van Stan, and D. F. Levia. 2017. Surface roughness affects the running speed of tropical canopy ants. Biotropica 49:92100. 


\title{
CURRICULUM VITAE
}

\author{
Benjamin "Max" Adams \\ University of Louisville, Department of Biology - Louisville, KY 40293 \\ Email: benjamin.adams@louisville.edu Phone: 337.739.9389
}

\section{Education}

2018 Ph.D. Biology, University of Louisville (UofL), Advisor: Dr. Stephen Yanoviak Dissertation: The effects of habitat and connectivity on tropical ant ecology and behavior

2012 M.S. Entomology, Louisiana State University (LSU), Advisor: Dr. Linda Hooper-Bùi

Thesis: Oil-mediated mortality and induced behavioral modifications in coastal insects

2010 B.S. Biology (Concentration in Secondary Education), LSU, Honors College

\section{Publications}

*Denotes undergraduate author

Adams B, Schnitzer S, Yanoviak S. 2017. Trees as islands: canopy ant species richness increases with the size of liana-free trees in a Neotropical forest. Ecography 40: 10671075. doi: 10.1111/ecog.02608

Adams B, Chen X, Hooper-Bùi. 2017. A comparison of two insect collection techniques in oiled and non-oiled Spartina alternaflora salt marshes in Louisiana. Florida Entomologist 100: 366-371

Chen X, Adams B, Layne M, Swarzenski C, Norris D*, Hooper-Bùi L. 2017. Effects of isolation on ant assemblages depend on microhabitat. Ecosphere 12: e02049. doi: 10.1002/ecs2.2049

Stark A, Adams B, Fredley J*, Yanoviak S. 2017. Out on a limb: thermal microenvironments in the tropical forest canopy. Journal of Thermal Biology 69: 32-38

Spicer M, Stark A, Adams B, Kneale R*, Yanoviak S. 2017. Thermal constraints on foraging of tropical canopy ants. Oecologia 183: 1007-1017. doi: 10.1007/s00442-017$3825-4$ 
Chen X, Adams B, Sabo A*, Crupi T*, Hooper-Bùi L. 2016. Ant assemblages and cooccurrence patterns in Cypress-Tupelo swamp. Wetlands 36: 849-861. doi:

10.1007/s13157-016-0795-y

Chen X, Adams B, Bergeron C*, Sabo A*, Hooper-Bùi L. 2015. Ant community structure and response to disturbances on coastal dunes of Gulf of Mexico. Journal of Insect Conservation 19: 1-13. doi: 10.1007/s10841-014-9722-9

Adams B, Parker J, VanWeelden M. (Eds.) Abraham, C, Overall L. 2013. ESA student debates 2011: identify, clarify and speak out about the land-grant mission, organic agriculture, and host plant resistance programs. American Entomologist 59: 214-228

Carlton C, Adams B. 2013. The search for an alternative commercial cricket for the U.S. industry. Louisiana Agriculture 56: 26

Chen X, MacGown J, Adams B, Parys K, Strecker R, Hooper-Bùi L. 2012. First record of Pyramica epinotalis (Hymenoptera: Formicidae) for the United States. Psyche 2012: doi:10.1155/2012/850893

Adams B, Hooper-Bùi L, Strecker R, O’Brien D*. 2011. Raft formation by the red imported fire ant, Solenopsis invicta. Journal of Insect Science 11: doi:

10.1673/031.011.17101

Adams B* Chen X, Hooper-Bùi L. 2010. Odontomachus clarus (Roger) (Hymenoptera: Formicidae) reported in Kisatchie National Forest, Louisiana. Midsouth Entomologist 3: 104-105

\section{Publications in Preparation}

*Denotes undergraduate author

Adams B, Gora E, van Breugel M, Hall J, Schnitzer S, Yanoviak S. Ant communities across a tropical forest successional gradient: Do lianas matter?

Adams B, Schnitzer S, Yanoviak S. Lianas shape arboreal ant communities by physically connecting isolated tree crowns.

Adams B, Prince D, Short $\mathrm{H}^{*}$, Lash C, Yanoviak S. Tree size and species identity shape arboreal ant species richness and composition along an urban gradient in Kentucky.

Adams B, Yanoviak S. Substrate use by leaf litter ants in a Neotropical forest.

Chen X, Presley S, Sikes B, Adams B, Renken K, Hooper-Bùi L. Changes in ant distribution and assembly processes in northern Gulf of Mexico coastal dunes.

\section{Professional Presentations}

*Denotes undergraduate author

\section{Invited Presentations}

2018 Adams B, The effects of habitat and connectivity on tropical ant ecology. Natural History Museum of Los Angeles County

2016 Adams B, Yanoviak S. Tree crowns functional as islands for arboreal ant communities. $7^{\text {th }}$ International Canopy Conference 
2016 Adams B, Gora E, Yanoviak S. Real-time monitoring of lightning strikes in a tropical forest. $7^{\text {th }}$ International Canopy Conference

2015 Adams B. Ants above us: canopy communities in Kentucky and Panama. Kentucky Society of Natural History

2010 Adams B*, Strecker R, O’Brien D*, Hooper-Bùi L. Rafting behavior of red imported fire ants. Proceedings of the 2010 NCUE 1: 23-25

\section{Conference Presentations}

I typically attend at least one professional meeting a year such as the Entomological Society of America's annual meeting. Below is a list of relevant talks covering my recent research areas. A complete list of presentations is available upon request.

2017 Adams B, Gora E, van Breugel M, Hall J, Schnitzer S, Yanoviak S. Ant communities across a tropical forest successional gradient: Do lianas matter? Proceedings of the Entomological Society of America

2016 Adams B, Yanoviak S. Connectivity and nest site availability influence arboreal ant communities. XXV International Congress of Entomology

2015 Adams B, Yanoviak S. Biodiversity of ants in the canopy: the role of area and structure. Smithsonian Tropical Research Institute, Bambi series

2014 Adams B, Yanoviak S. Canopy connectivity enhances arboreal ant communities. Proceedings of the Entomological Society of America

2012 Adams B, Chen X, Hooper-Bùi L. Oil pollution mediated mortality and behavior modifications in coastal insects. Proceedings of the Entomological Society of America

2011 Adams B, Hooper-Bùi L, Strecker R, O’Brien D*. The raft behavior of the red imported fire ant. 2011 Imported Fire Ant Conference Proceedings

\section{Awards and Funding}

2017 UofL Biology Student Publication Award

2016 "Faculty Favorite" Teaching Award Nominee

2015 Clay Memorial Scholarship $\$ 1,000$

2015 UofL Biology Student Outreach Award \$150

2014 Beechmont Garden Club Award \$1,000

2014 Carl C. Cornett Entomology Endowment \$2,500

2014 Gulf of Mexico Research Initiative Scholar $\$ 100$

2013 Sponsored Research Tuition Award $\quad \$ 11,658$

2012 L.D. Newsom Award for Outstanding Achievement \$1,000

2012 LSU Graduate Presentation Award $\quad \$ 100$ 
\begin{tabular}{lll}
2011 & NSF-GRFP Honorable Mention & \\
2010 & National Conference on Urban Entomology B.S. Scholarship & $\$ 1,500$ \\
2009 & LSU College of Agriculture Grant & $\$ 3,000$ \\
2009 & Sigma Xi Undergraduate Grant-in-Aid & $\$ 250$ \\
2009 & NSF Stem-TP Scholarship for Education Students & $\$ 500$ \\
2008 & NSF Stem-TP Scholarship for Education Students & $\$ 500$ \\
2006 & TOPS Honors Scholarship & $\$ 34,516$ \\
2006 & Chancellor's Student Aid Scholarship & $\$ 6,200$ \\
2006 & LSU Alumni Association Top 10o Scholarship & $\$ 8,000$ \\
\hline Teaching Experience & \\
\hline
\end{tabular}

\section{Teaching Assistantships}

Spring 2017 Tropical Biology Field Course (BIOL 571), UofL

Fall 2014/15 Principles of Biology Lab (BIOL 244), UofL

Fall 2013 Entomology (BIOL 382/692), UofL

\section{Guest Lectures}

Summer 2017 Canopy Ecology, Organization for Tropical Studies (OTS)

Summer 2016 Insect Ecology, OTS

Fall 2014 Invertebrate Zoology (BIOL 390), UofL

Fall 2013/17 Entomology (BIOL 382/692), UofL

Fall 2012 Aquatic Entomology (ENTM 7007), LSU

\section{Pedagogy Courses}

Fall 2009 Science Pedagogy (4 credit hrs +50 hrs teaching), LSU

Spring 2009 Content Area Readings in Biology (4 credit hrs + 50 hrs teaching), LSU

Fall 2008 Student Development and Diversity (4 credit hrs +25 hrs teaching), LSU

Spring 2008 Education, Schools, and Society ( 3 credit hrs +5 hrs observations), LSU

\section{Undergraduate Mentorship}

Heather Short - Arboreal ant communities in Kentucky - UofL

Ongoing

Amanda Winters - Arboreal ant diversity in Neotropical rain forests - UofL

2014 
Marilyn Feil - Epigeic ant diversity in Neotropical rain forests - UofL

Mark Accardo - Survivorship of Crematogaster pilosa during flooding - LSU 2012

Amber Papillion - Venom dilution in Solenopsis invicta due to flooding - LSU 2011

Daniel O’Brien - Rafting behavior of Solenopsis invicta - LSU 2011

Service

\section{Manuscript Reviews}

Biotropica, Entomologia Experimentalis et Applicata, Insectes Sociaux, Journal of Applied Ecology, Journal of Insect Science, Myrmecological News, Restoration Ecology

\section{Conference Organization}

2014 Judge, Undergraduate Research - Ecology Posters, The Kentucky Academy of Science Annual Meeting

2013 Session Moderator, Undergraduate Research - Ecology Presentations, The Kentucky Academy of Science Annual Meeting

2012 Judge, Undergraduate Research - Entomology Research, Collegiate $4 \mathrm{H}$ in Louisiana

\section{Professional Service}

2017 Reviewer for the BCI Scholarship for Panamanian students (in Spanish)

2017 Reviewer for the Alan Smith Award for Panamanian students (in Spanish)

2017 BCI Resident Representative for the Beijing Genomics Institute

2017 President of the Biology Graduate Student Association (BGSA) at UofL

2017 BGSA Representative on Cancer Biology Hiring Committee

2016 Grant Committee member for BGSA Research and Travel grants

2015-16 BGSA Representative for Undergraduate Curriculum Committee

2015 Liaison for US Congressional Delegation on Barro Colorado Island

2014 Grant Committee member for BGSA Research and Travel grants

2014 BGSA Outreach and Community Service coordinator

2012 Liaison to Copesan Technical Committee at LSU

2010-12 Secretary of the LSU Entomology Club

\section{Community Service/Outreach}

2018 Entomologist for the UofL "Day of Science" for $6^{\text {th }}$ grade students

2017 Entomology Advocate at the Smithsonian's ACCelerate Festival 


\section{Outreach Presentations}

2017 Research in the canopy. Panama Canal Authority in BCI, Panama

2017 Ants in the canopy. UCSB Smithsonian Scholars in BCI, Panama

2017 Exploring the tropical canopy. Cape Henry School in BCI, Panama

2016 Insects are all around us! St. Matthews Elementary in Louisville, KY

2014 Insects are all around us! St. Matthews Elementary in Louisville, KY

2014 Ants in the tropical rain forest canopy. South East Middle in Austin, TX

2013 How to identify an insect. Olmsted Academy North in Louisville, KY

2012 Is that an insect? Woodlawn Middle School in Baton Rouge, LA

2012 Is that an insect? Southside Development Center in Baton Rouge, LA

\section{Media Attention}

2017 "Mysteries of the Rain Forest” - Smithsonian Channel (video)

2017 “Questions lead us to discoveries. What's your question?” - STRI (video)

2017 "Rainforest Trees Are Like Islands" - The Atlantic

2017 "Every Tree, an Island" - Natural History

2017 "Recap of ACCelerate festival with Max Adams” - UofL Today (radio)

2016 "Ant bridges connect tropical tree crowns" - Smithsonian Insider

2016 "Secrets of the Rainforest: Journey to the Canopy" - Smithsonian Earth (video)

2016 “Ants See Trees as Islands Connected by Lianas" - STRI News (Front cover)

2016 “Tree crowns act as islands for arboreal ant communities" - ICAN “What's Up" 
2015 "University Students Take Research Plunge in Panama: REU" - Tropicos 2015 "Coiba BioBlitz" - Tropicos (Front cover plus video) 